\title{
SURVIVORS OF PSYCHOPATHS:
}

\section{AN INVESTIGATION OF VICTIMIZATION EXPERIENCES, COPING, AND SOCIAL SUPPORT}

\author{
A thesis submitted to \\ the Faculty of Graduate Studies and Research \\ in Partial Fulfillment of the requirements for the degree \\ Master of Arts
}

by

Melissa J. L. Pagliaro

Department of Psychology

Carleton University

May 2009

(C)2009 Melissa J. L. Pagliaro 


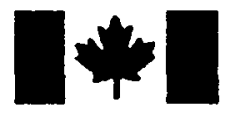

\author{
Library and Archives \\ Canada \\ Published Heritage \\ Branch \\ 395 Wellington Street \\ Ottawa ON K1A ON4 \\ Canada
}

Bibliotheqque et

Archives Canada

Direction du

Patrimoine de l'édition

395 , rue Wellington

Ottawa ON K1A ON4

Canada
Your file Votre reférence
ISBN: 978-0-494-58435-4
Our file Notre reference
ISBN: $978-0-494-58435-4$
NOTICE:

The author has granted a nonexclusive license allowing Library and Archives Canada to reproduce, publish, archive, preserve, conserve, communicate to the public by telecommunication or on the Internet, loan, distribute and sell theses worldwide, for commercial or noncommercial purposes, in microform, paper, electronic and/or any other formats.

The author retains copyright ownership and moral rights in this thesis. Neither the thesis nor substantial extracts from it may be printed or otherwise reproduced without the author's permission.
AVIS:

L'auteur a accordé une licence non exclusive permettant à la Bibliothèque et Archives Canada de reproduire, publier, archiver, sauvegarder, conserver, transmettre au public par télécommunication ou par l'Internet, prêter, distribuer et vendre des thèses partout dans le monde, à des fins commerciales ou autres, sur support microforme, papier, électronique et/ou autres formats.

L'auteur conserve la propriété du droit d'auteur et des droits moraux qui protège cette thèse. $\mathrm{Ni}$ la thèse ni des extraits substantiels de celle-ci ne doivent être imprimés ou autrement reproduits sans son autorisation.
In compliance with the Canadian Privacy Act some supporting forms may have been removed from this thesis.

While these forms may be included in the document page count, their removal does not represent any loss of content from the thesis.
Conformément à la loi canadienne sur la protection de la vie privée, quelques formulaires secondaires ont été enlevés de cette thèse.

Bien que ces formulaires aient inclus dans la pagination, il n'y aura aucun contenu manquant.

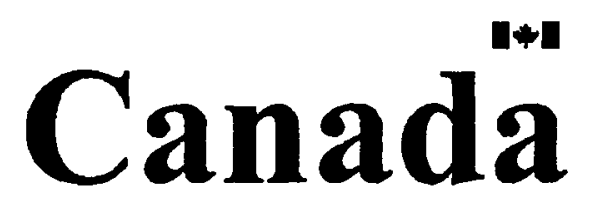




\begin{abstract}
Psychopathy research neglects victimcentric studies. Hypotheses on psychological consequences, deception, distress predictors, psychopathy severity, coping, and social support were tested. Adult survivors of psychopaths $(N=490-707)$ recruited from support groups and professional referrals completed web-based questionnaires. Survivors experienced physiological, psychological, and interpersonal consequences, but victim status affected distress similarly. Delayed-path psychopaths were closely and frequently involved with victims, but were similar to shortcut-path psychopaths in psychopathic traits. Distress predictors included closer relationships, frequent exposures, increased physical injury severity, and physically violent crimes. Problem- and avoidance-focused coping and psychopathy severity were associated with increases in distress and decreases in social support. Emotion-focused coping and social support were negatively related to distress. Survivors who used emotion-focused coping techniques had more social support. Knowledge of the victimization experiences of survivors and psychopathic deception could encourage ideas for predictive, preventative, and treatment measures.
\end{abstract}




\section{Acknowledgements}

First and foremost, my Masters Thesis is dedicated to the hundreds of survivors of psychopaths from all over the world whose courage enabled them to describe their experiences to an unfamiliar yet sympathetic researcher. Like many of you have expressed, it is my hope that this research will benefit others. May this work fulfill its ultimate goals of public awareness of victimization by psychopaths within the community and forensic or criminal institutions, to allow for the healing and recovery of past and present survivors. I would like to extend my thanks to the online maintainers of support groups devoted to survivors of psychopaths and psychopathy researchers who promoted my study.

Several academic faculty and administrative professionals were instrumental in the production of this Masters Thesis. To my advisor, Dr. Adelle Forth, one of the leading experts in the field of psychopathy research, thank you for your guidance and support from the brainstorming stage to the final document itself. To Dr. Shelley Brown and Dr. Connie Kristiansen, your advice during my Thesis Proposal "Meeting” were noted, implemented, and well appreciated. Judith Godin, thank you very much for being my content and analysis tutor for Structural Equation Modeling so I could present certain results in a more comprehensive manner. Thanks to Etelle Bourassa and Natalie Pressburger for your friendly smiles and helpfulness with respect to various administrative aspects throughout my career as a graduate student. My appreciation also goes out to Dr. Diana Majury of the Department of Law at Carleton University, my external defense committee member, for her questions and comments during the final presentation of my study. 
Thanks to all my friends and family for being there and understanding the crazy fluctuations of downtime and busyness that come with being a graduate student. Heartfelt thanks particularly go to Miss Fox, my twin in almost everything, who recently graduated with a Masters degree in Forensic Psychology at Carleton University. You truly empathized with my joys and sorrows, in my personal, social, and academic life, during our online conversations and our regular restaurant outings. To both my significant others, Christopher Kafka and Karla Nissle, thank you for being there for me with your practical, emotional, and informational support. For Rockefeller, my service dog with perhaps more crystallized education than most canines on the face of this Earth, thank you for being by my side and alerting me to important sounds as I continuously revised this document. To the three felines that currently rule my household, thank you all for being mischievous, as you reduced my stress levels through making me laugh while I was writing my Thesis. Finally, because I could never conclude any of my publications without some kind of dedication to Her - capitalized on purpose, I devote this work to my beloved Demeter, a feline whose spirit is like the wind, who is always watching over me, and guiding me through hard times.

This research was supported by a Canada Graduate Scholarship - Master's (\#0066-20060920) from the Social Sciences and Humanities Research Council of Canada. 


\section{Table of Contents}

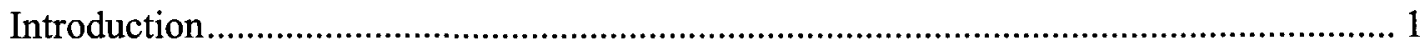

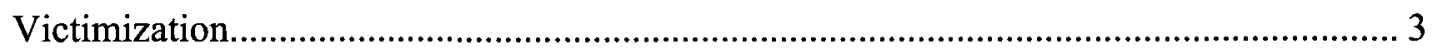

Psychological Consequences .......................................................................... 7

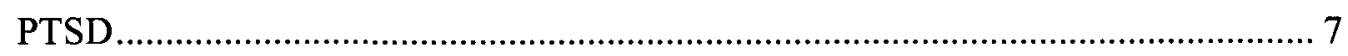

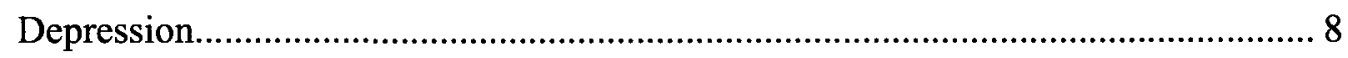

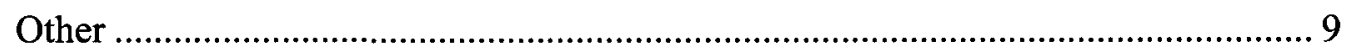

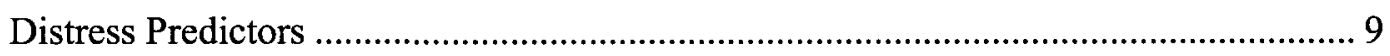

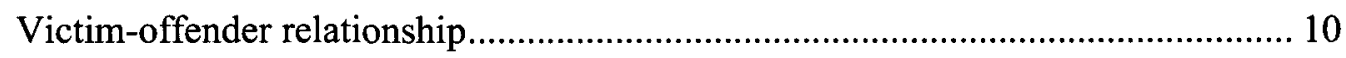

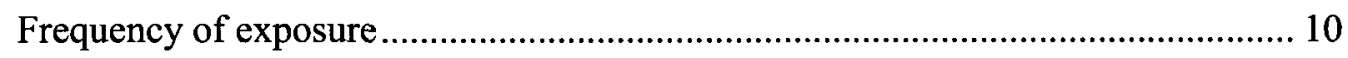

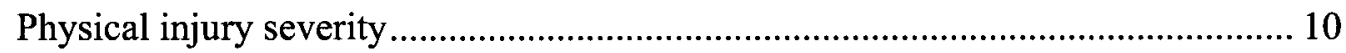

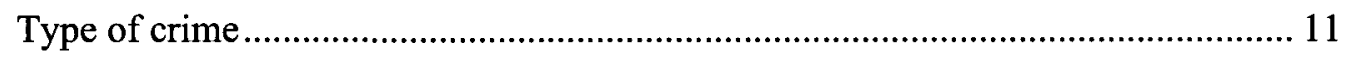

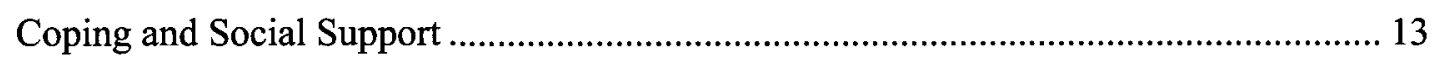

Coping and Social Support in Crime Victimization ............................................ 18

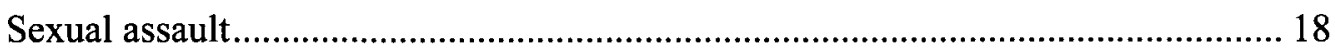

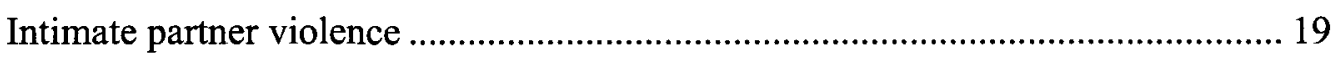

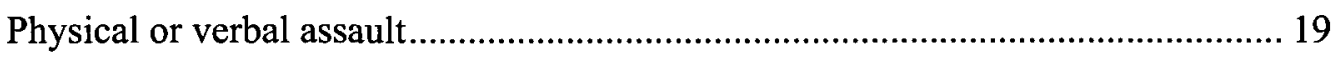

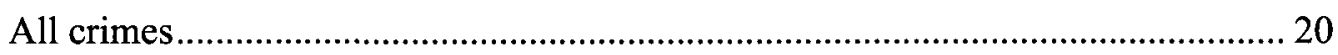

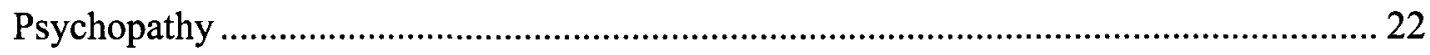

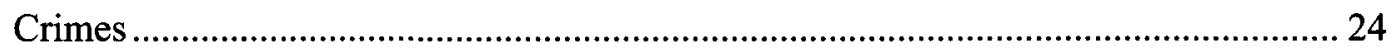

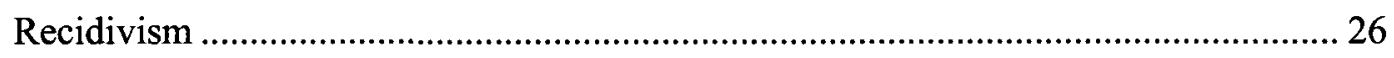

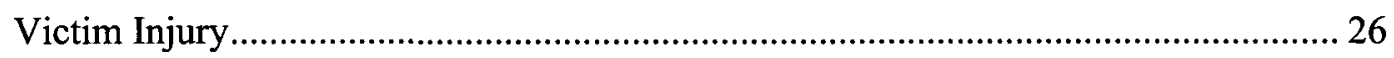

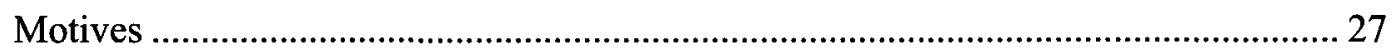




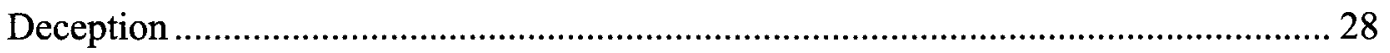

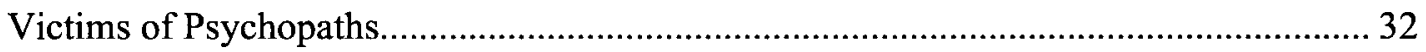

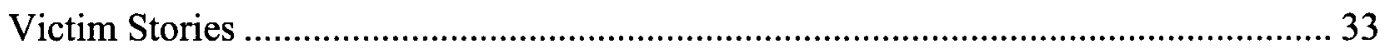

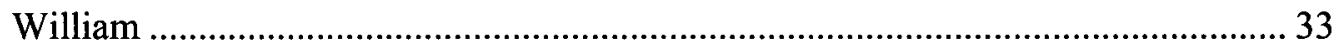

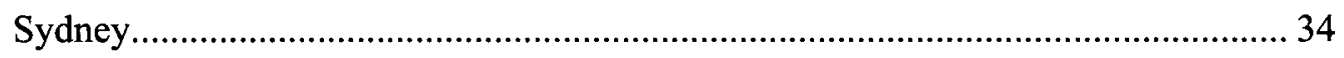

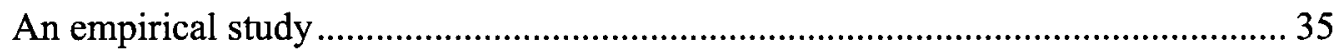

Psychological Consequences ……………………………………............................. 39

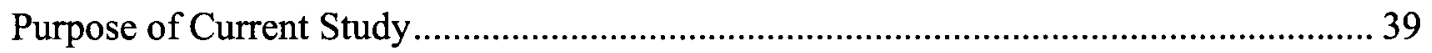

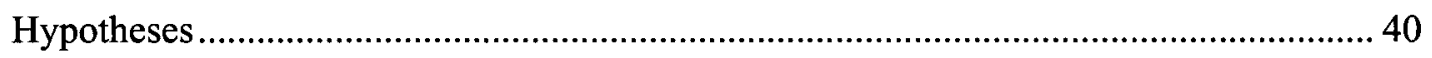

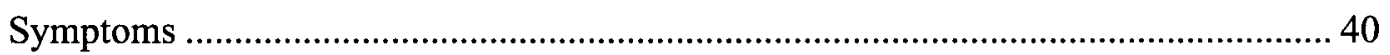

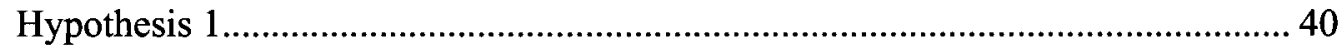

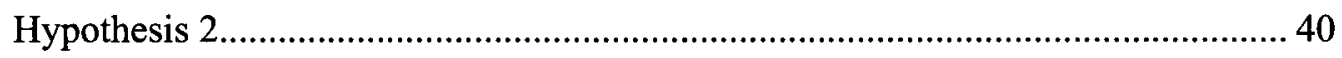

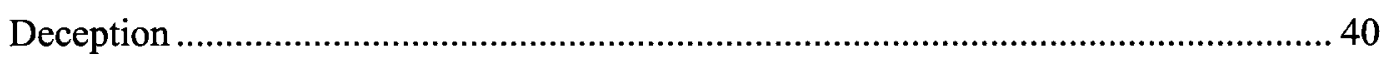

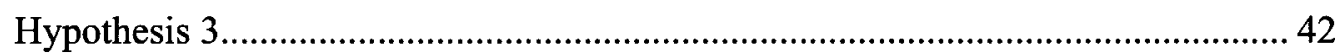

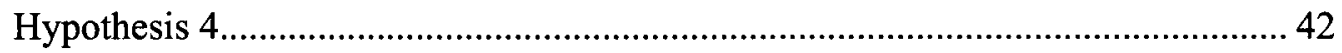

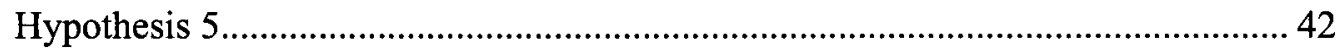

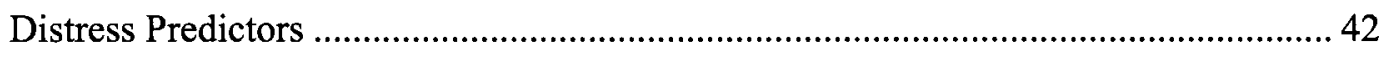

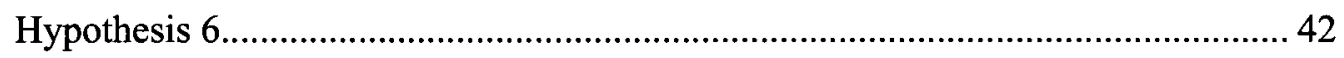

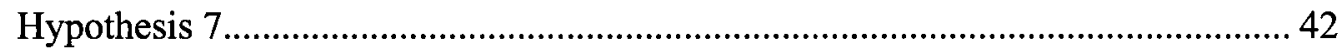

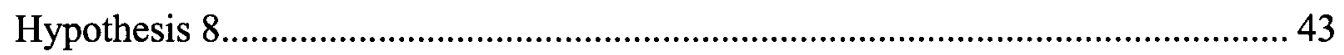

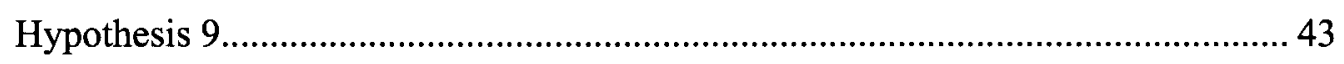

Relationships Between Psychopathy Severity, Coping, Social Support, and Distress. 43

Method 45 


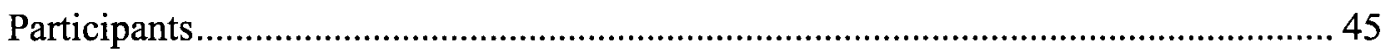

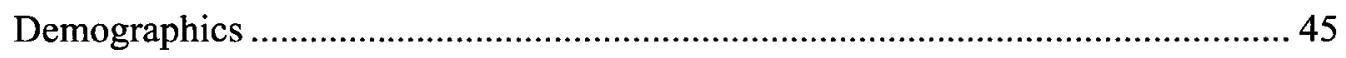

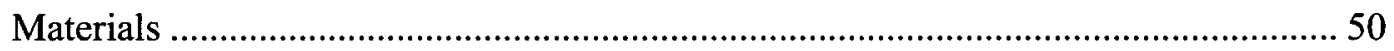

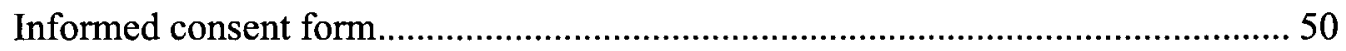

Self-Report Psychopathy Scale-III........................................................................ 50

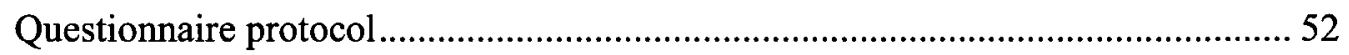

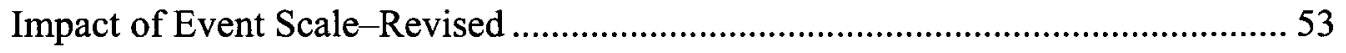

Beck Depression Inventory-II .......................................................................... 54

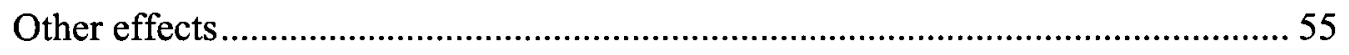

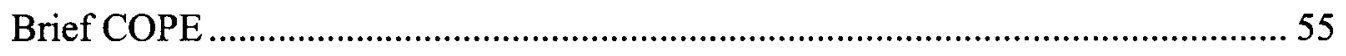

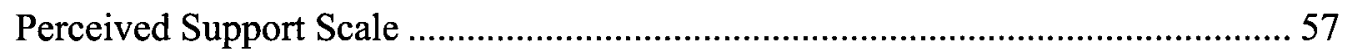

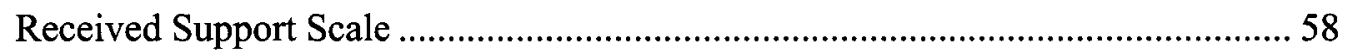

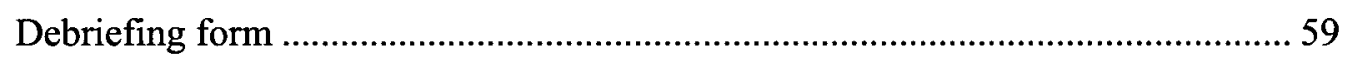

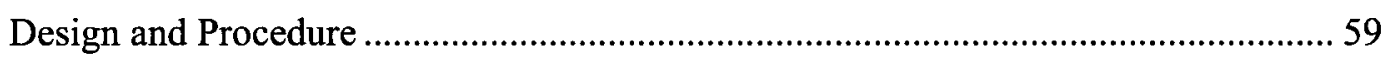

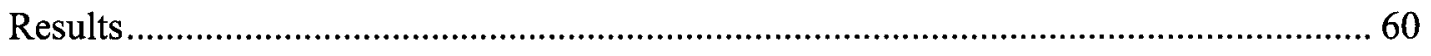

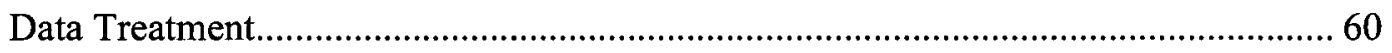

Survivors' Ratings of Psychopathy ............................................................................ 62

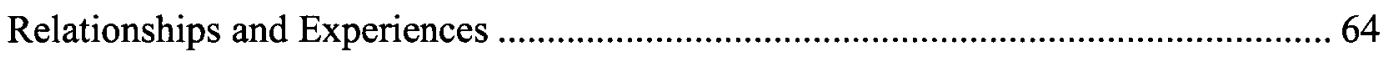

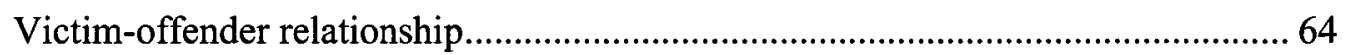

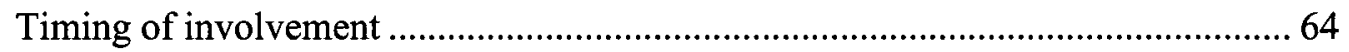

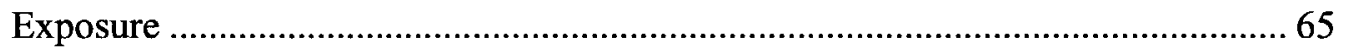

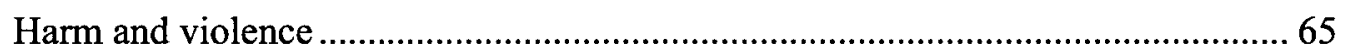

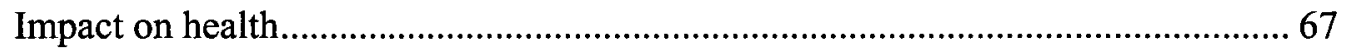




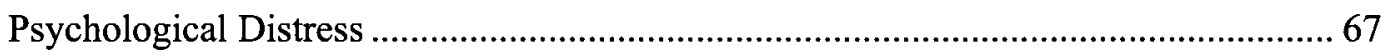

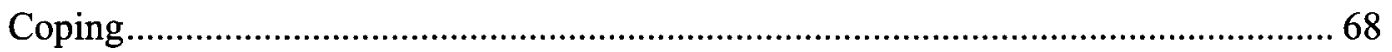

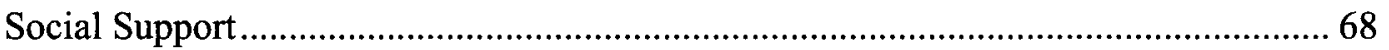

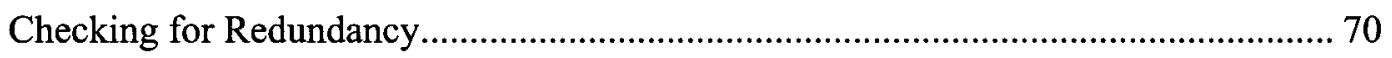

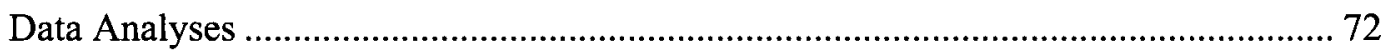

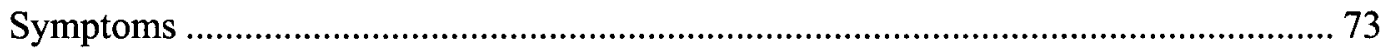

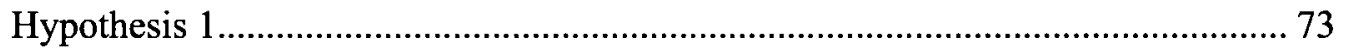

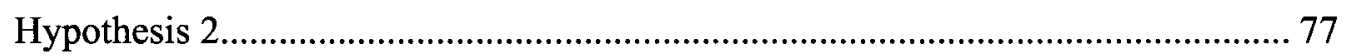

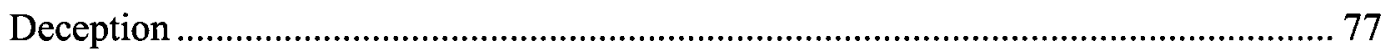

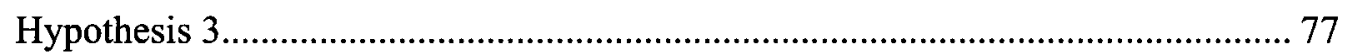

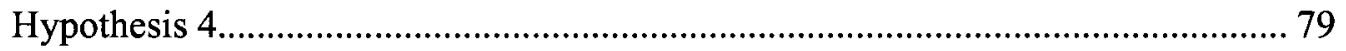

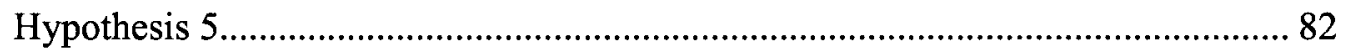

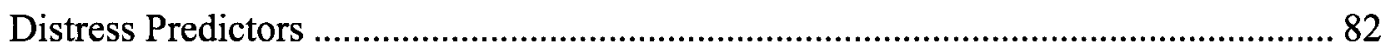

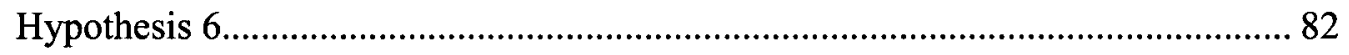

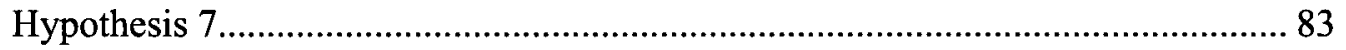

Hypothesis 8

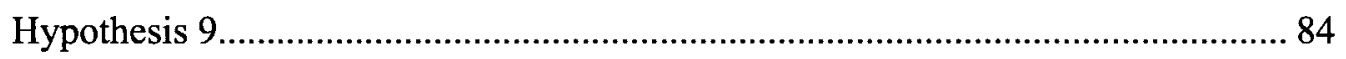

Relationships Between Psychopathy Severity, Coping, Social Support, and Distress..85

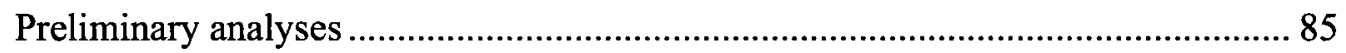

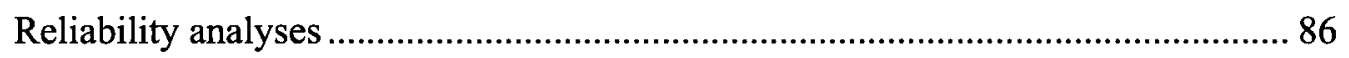

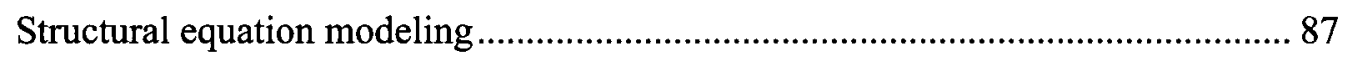

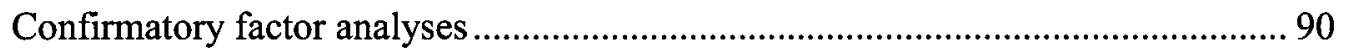

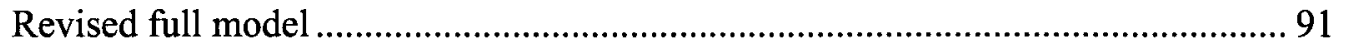


Structural equation modeling and correlations ............................................. 91

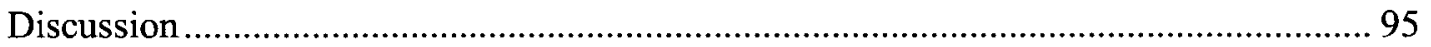

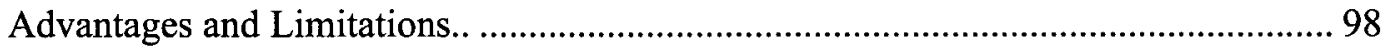

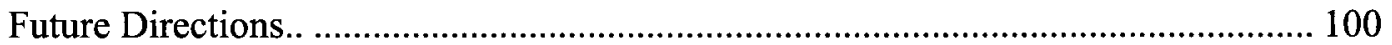

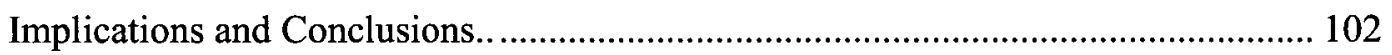

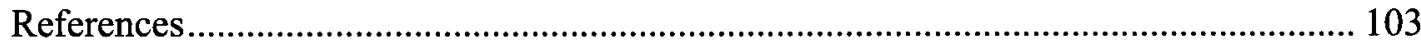

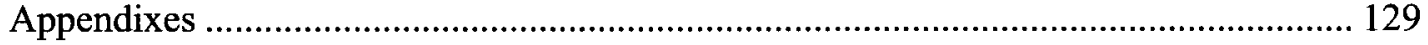




\section{List of Tables}

Table 1. Abridged Reproduction of the Stages of Crime-based Victimization Model

Developed by Casarez-Levison (1992) ................................................ 6

Table 2. Common Characteristics of Male Psychopaths in Heterosexual

Relationships Extracted from Participants' Interview Responses in the

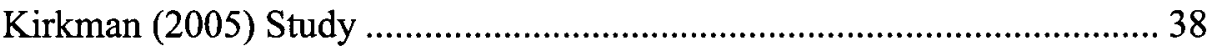

Table 3. Ethnicity or Race of Survivors and Psychopaths .................................. 45

Table 4. Location, Employment, and Education Status of Survivors...............47

Table 5. Referral Sources and Corresponding Website Addresses for Recruited

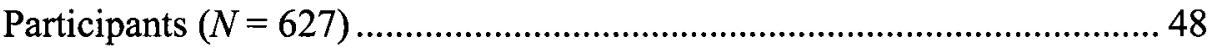

Table 6. Participants' Motives for Participation and Descriptive Examples ............. 49

Table 7. Examples of Items for Each Coping Strategy on the Brief COPE and

Corresponding Subscales ............................................................ 56

Table 8. Descriptive Statistics of Survivors' Ratings of Psychopathic Factors by

Gender

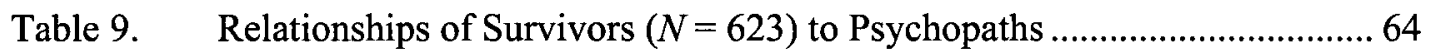

Table 10. Duration of Survivors' Past and Current Involvement with Psychopaths ... 65

Table 11. Time Lapsed Since Past-Involved Survivors' Last Contact with Psychopaths

$(N=440)$

Table 12. Type of Physical and Non-physical but Harmful Acts Experienced by

Survivors of Psychopaths $(N=643)$

Table 13. Impact of Victimization on Physical and Mental Health of Survivors of

Psychopaths 
Table 14. Survivors of Psychopaths' Ratings of PTSD and Depression on the Impact of Event Scale - Revised (IES-R) and Beck Depression Inventory-II (BDI-

II). 67

Table 15. Survivors of Psychopaths' Ratings of Coping Strategies on the Brief COPE $(N=505)$

Table 16. Survivors of Psychopaths' Ratings of Perceived and Received Social Support. 70

Table 17. Correlations Between Potentially Overlapping Constructs to Check for Redundancy. 71

Table 18. Consequences of Victimization By Psychopaths Organized with the McCann et al. (1998) Model of Psychological Adaptation ... 76

Table 19. A $2 \times 2$ Contingency Table of the Association between Closeness of Relationship and Deception Pathways.

Table 20. A $2 \times 4$ Contingency Table of the Association between Frequency of Exposure and Deception Pathways. 79

Table 21. Responses of Psychopaths to Survivors' Exposure of their Deception ....... 81

Table 22. Summary Statistics of Psychopathic Factors for Shortcut and Delayed-Path

Psychopaths. 82

Table 23. Summary Statistics for Frequency of Exposure and Psychological Distress

Table 24. Cronbach's Alpha Coefficients $(\alpha)$ for the Measured Variables 87

Table 25. Fit of the Measurement and Full Models. 92 


\section{List of Figures}

Figure 1. Hypothesized Shortcut and Delayed Deception Pathways Representing Interactions Between Psychopaths (P) and Victims (V)

Figure 2. Hypothesized Structural Model of the Relationships Between Psychopathy, Problem-, Emotion-, and Avoidance-Focused Coping, Social Support, and Distress, for Survivors of Psychopaths.

Figure 3. Measurement Model of Psychopathy (IPM = Interpersonal Manipulation, $\mathrm{CA}=$ Callous Affect, ELS $=$ Erratic Lifestyle, $\mathrm{CT}=$ Criminal Tendencies $)$, Social Support (PS = Perceived Support, RS = Received Support), Distress $(\mathrm{PTSD}=$ posttraumatic stress disorder, DEP $=$ depression $)$, Coping (Problem-Focused: AC $=$ Active Coping, $\mathrm{P}=$ Planning, $\mathrm{STS}=$ Seeking Tangible Support; Emotion-Focused: SES = Seeking Emotional Support, PR $=$ Positive Reframing, $\mathrm{A}=$ Acceptance, $\mathrm{TTR}=$ Turning to Religion, $\mathrm{SU}=$ Substance Use, SB = Self-Blame, $\mathrm{V}=$ Venting, $\mathrm{H}=$ Humour; AvoidanceFocused: $\mathrm{D}=$ Denial, $\mathrm{SD}=$ Self-Distraction, $\mathrm{BD}=$ Behavioural Disengagement).

Figure 4. Full Model of Psychopathy (IPM = Interpersonal Manipulation, $\mathrm{CA}=$ Callous Affect, ELS = Erratic Lifestyle, $\mathrm{CT}=$ Criminal Tendencies), Social Support $(\mathrm{PS}=$ Perceived Support, RS $=$ Received Support), Distress (PTSD = posttraumatic stress disorder, DEP = depression), Coping (Problem-: AC = Active Coping, $\mathrm{P}=$ Planning; Emotion-: $\mathrm{PR}=$ Positive Reframing, $\mathrm{A}=$ Acceptance, $\mathrm{TTR}=$ Turning to Religion, $\mathrm{V}=$ Venting, $\mathrm{H}=$ Humour; 
Avoidance: $\mathrm{D}=$ Denial, $\mathrm{SD}=$ Self-Distraction, $\mathrm{BD}=$ Behavioural

Disengagement).

Figure 5. Relationships between Coping Strategies (Problem-, Emotion-, and Avoidance-Focused) and Psychopathy on Distress and Social Support for

Survivors of Psychopaths........................................94 


\section{List of Appendices}

Appendix A. Informed Consent Form.................................... 129

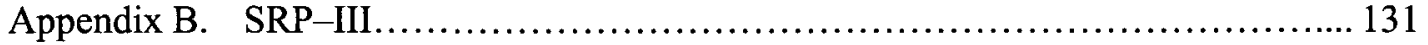

Appendix C. Interview Protocol........................................ 133

Appendix D. Impact of Event Scale-Revised (IES-R)....................... 139

Appendix E. Beck Depression Inventory-II (BDI-II) $\ldots \ldots \ldots \ldots \ldots \ldots \ldots \ldots \ldots \ldots \ldots \ldots$

Appendix F. Open-Ended Questions: Mental and Physical Health.................. 143

Appendix G. Brief COPE.................................................... 144

Appendix H. Perceived Support.......................................... 145

Appendix I. Received Support........................................... 146

Appendix J. Debriefing................................................ 147

Appendix K. E-mail Correspondence Template for Permission to Promote the Current

Study ....................................................... 149

Appendix L. E-mails to Psychopathy Researchers Template $\ldots \ldots \ldots \ldots \ldots \ldots \ldots \ldots \ldots \ldots \ldots$

Appendix M. LoveFraud's Promotion of the Current Study...................... 151

Appendix N. Psychopath-Research's Promotion of the Current Study.................152

Appendix O. Aftermath: Surviving Psychopathy's Promotion of the Current

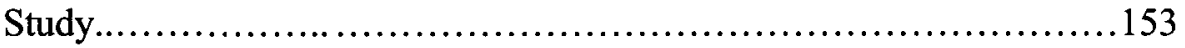

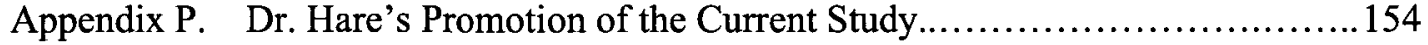

Appendix Q. E-mail of Summary of Results............................... 155 
Survivors of Psychopaths: An Investigation of Victimization Experiences, Coping Strategies, and Social Support

Psychopathy is a personality construct characterized by a constellation of interpersonal traits, affective features, social deviance, and antisocial lifestyles (Hare, 1999a). Interpersonal relations are marked by glibness, superficiality, grandiosity, egocentricity, pathological lies, deceitfulness, and manipulation. Psychopaths are deficient in conscience-relevant emotions, such as guilt, remorse, and empathy. Verbal and nonverbal behaviour signifying their emotions are shallow acts of mimicry. Their impulsivity and constant need for stimulation encourages participation in risky activities such as high stakes gambling. Refusals to accept responsibility, behavioural problems in adolescence, and antisocial acts in adulthood are all common amongst psychopaths.

Given that many psychopaths engage in behaviour which attracts the attention of the criminal justice system, they are especially common within prison populations at a base rate of approximately $15-25 \%$ (Hare, 1996). Nevertheless, various estimates and studies suggest that psychopaths also exist in noncriminal and noninstitutionalized populations. Hare (1999a) states that:

However, many psychopaths never go to prison or any other facility. They appear to function reasonably well - as lawyers, doctors, psychiatrists, academics, mercenaries, police officers, cult leaders, military personnel, businesspeople, writers, artists, entertainers, and so forth - without breaking the law, or at least without being caught and convicted (p. 113).

Hare (1999a) provides a conservative estimate of 2 million male and female psychopaths in North America alone. More global estimates indicate that psychopaths comprise $1 \%$ (Babiak \& Hare, 2006; Hare, 1996) to $4 \%$ (Stout, 2005) of the world's population. 
Research supports the notion that noncriminal or noninstitutionalized psychopaths exist (i.e., Monahan et al., 2001). Although baserates are relatively low, studies have found that there are psychopaths in the general community, educational institutions, and corporations. Psychopaths constitute a small proportion of participants recruited from community samples of adult males (Belmore \& Quinsey, 1994; DeMatteo, Heilbrun, \& Marczyk, 2006) and women (for reviews, see Nicholls, Ogloff, Brink, \& Spidel, 2005; Vitale \& Newman, 2001). Psychopathic traits have also been found in elementary, secondary, and postsecondary students (Andershed, Hodgins, \& Tengström, 2007, Forth, Brown, Hart, \& Hare, 1996; Frick, Bodin, \& Barry, 2000; Levenson, Kiehl, \& Fitzpatrick, 1995; Lilienfeld \& Andrews, 1996; Ross \& Rausch, 2001; Salekin, Trobst, \& Kriukova, 2001; Skilling, Quinsey, \& Craig, 2001). Workplace psychopaths have been the focus of recent investigations (Babiak, 1995, 1996, 2000; Babiak \& Hare, 2006; Boddy, 2006). According to Clarke (2007), approximately $10 \%$ of people in business management positions display psychopathic traits and behaviour.

Psychopathy has dire implications for society, especially as the "psychological damage done by individuals with this disorder is far out of proportion to their numbers" (Babiak \& Hare, 2006, p. 18). Despite such consequences, the voices of survivors of psychopaths have largely been neglected in current theoretical and empirical psychopathy research. The extant literature primarily consists of case studies (Kreuter, 2003, 2004, 2006; Meloy, 1997), brief anecdotes (Babiak \& Hare, 2006; Hare, 1999a; Stout, 2005), or vague descriptions in conference proceedings (Clarke, 2007). The current investigation of victimization experiences, coping strategies, and social support systems of survivors of psychopaths is important due to such paucity. Understanding victimization, coping, and 
social support can improve the knowledge and quality of medical, psychological, and legal services. Mental health and criminal justice professionals can benefit from this research through effective prioritization of therapy targets and better-informed judicial decisions for survivors of psychopaths. An awareness of interactions between survivors and psychopaths can be raised in the general public as a preventative measure. Moreover, this study could be a springboard for more victimcentric studies in psychopathy research.

\section{Victimization}

General victimization surpasses the occurrence of traumatic events, such as crimes, natural disasters, human-induced catastrophes, and the deaths of loved ones. Victimization captures the influence of threatening situations on victims' lives, coping, struggles, and reconciliation with their identities as trauma survivors. Dictionary definitions for victim refer to vulnerability through fraud, physical or psychological harm, injury, or death. The Concise Oxford English Dictionary (2006) defines victim as "a person harmed, injured, or killed as a result of crime, accident, etc.; a person who has been tricked; a person who has come to feel helpless and passive in the face of misfortune" (Definition 1.). Similarly, Merriam-Webster (2005) describes victim as "one that is acted on and usually adversely affected by a force or agent; injured, destroyed, or sacrificed; subjected to oppression, hardship, or mistreatment; tricked or duped" (Definitions 2, 2a(1), 2a(2), 2b). Fields (1977) focuses more on mental ramifications, as a victim is a person who deals with psychological consequences because his or her life, bodily integrity, security or self-image has been threatened. Alternately, survivor conveys empowerment, as it embodies positive qualities such as coping, determination, resistance, decision-making, strength, and agency (Barry, 1979; Dunn, 2005; McLeer, 1998). 
Crime victims experience direct or indirect suffering due to victimization by specific harmful or illegal acts (Barkas, 1978). Casarez-Levison (1992) developed a comprehensive model of crime-based victimization based on an empirical, descriptive, time-series correlational investigation. Victims of assault, which varied in type and severity, participated in structured interviews, and filled out standardized measures once a month until four months passed. Participation occurred at any point between days and seven months after victimization. Inquiries revolved around immediate, short- and medium-term coping strategies following a crime, and thoughts and feelings surrounding victimization. Casarez-Levison's final model, which incorporated universal human reactions to victimization based on the research literature, is summarized in Table 2 . The previctimization/organization stage focuses on the person as a whole before the traumatic event, and takes into account the would-be victim's personality, psychological defenses, appraisal (i.e., coping mechanisms, perceptions, problem-solving capabilities), history (i.e., predisposition to illness, substance use or abuse, intimacy capability, general health and well-being, coping strategies from previous victimization), goals, sexual differences and preferences, and proneness to violence. During victimization/disorganization, the focus is on the victim's immediate alarm response and adaptation, including psychological and physiological responses and seeking assistance or lack thereof, from medical, mental health, criminal justice, financial, and social support resources. Universal reactions include denial, displacement, numbness, shock, disorientation, grief, intrusive thoughts, and feelings of vulnerability. Individual physiological and psychological reactions are based on previctimization influences. The transition/protection stage involves either reintegration or exhaustion. Symptoms from the previous stage continue, 
and new methods of coping may surface. Additionally, victims engage in bargaining, a defense mechanism in which people appeal to a higher authority with promises in exchange for a desired outcome. For example, victims may make a request of their deities to make them forget about the traumatic event in exchange for their regular devotion. Victims may start to recover, depending on intervention and support. Finally, victims will enter the reorganization/resolution stage, which typically lasts between 6-12 months, but can be more than six years in cases where victimization is severe. Victims reconstruct their views of themselves, initiate stable functioning patterns, and begin to accept their status as survivors. Similar to previous stages, recovery also depends on support.

Other trauma models focus on response patterns. For example, after looking at research on disaster-, war-, and crime-based victimization, McCann, Sakheim, and Abrahamson (1988) established a "model of psychological adaptation" and categorized reactions to trauma as cognitive, biological, behavioural, emotional, or interpersonal. Cognitive response patterns consist of perceptual disturbances such as hallucinations, flashbacks, and dissociation. Physiological hyperarousal, such as increased blood pressure, heart rate, and respiration, and somatic disturbances, including muscle tension, gastrointestinal problems, ulcers, and headaches, are examples of biological consequences. Behavioural responses include aggression, suicide attempts, substance abuse, and avoidance of social situations. Emotional reactions include fear, anxiety, depression, anger, guilt, shame, and decreased self-esteem. Interpersonal issues include sexuality and relationship problems, and revictimization. The Casarez-Levison (1992) and psychological adaptation models emphasize that victimization is a process which involves major physical and mental health consequences. 
0
0
0
0
0
0
0
0
0
0
0
0
0
0
0
0
0
0

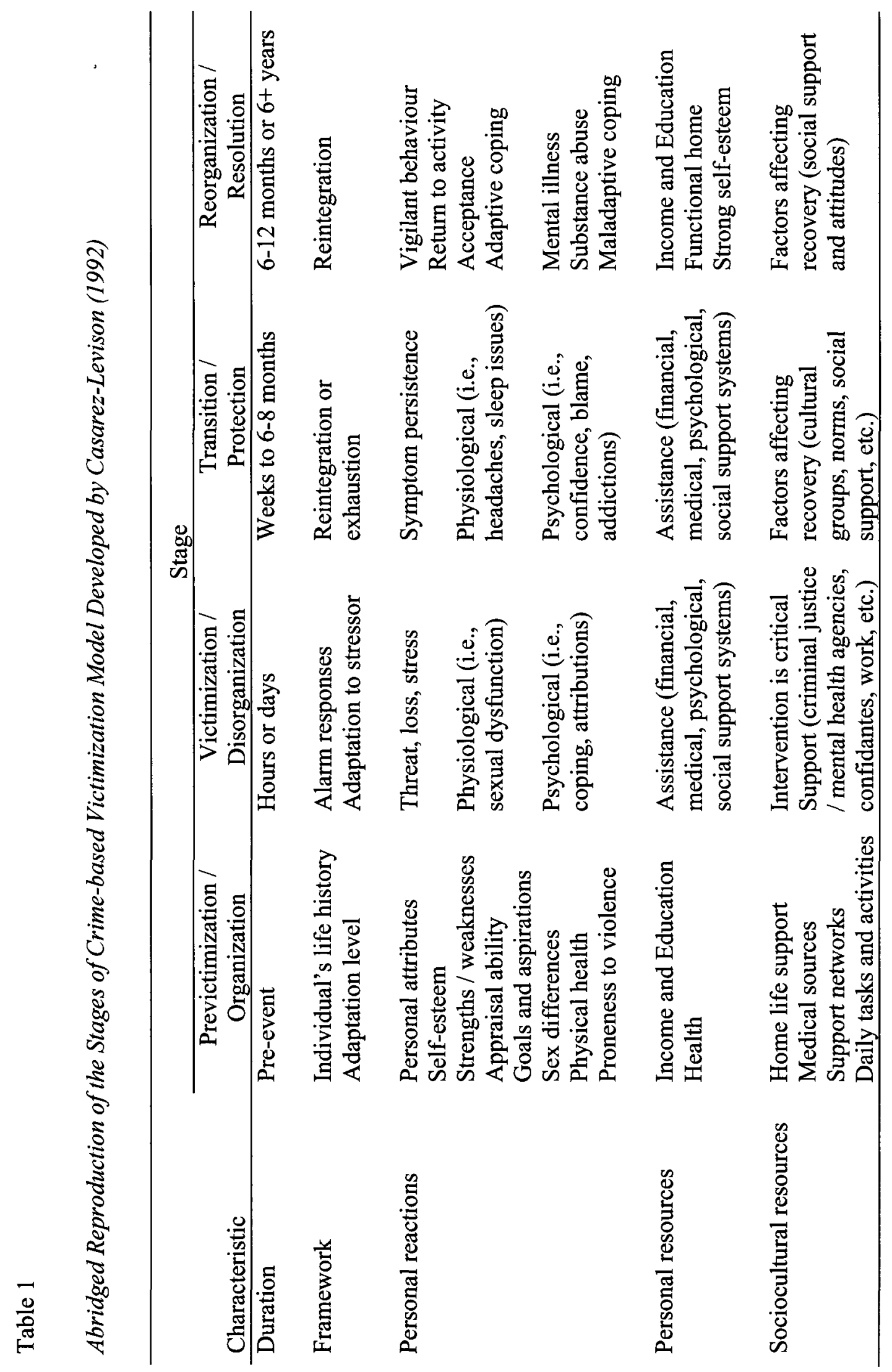


Note: Adapted from "An Empirical Investigation of the Coping Strategies Used by Victims of Crime: Victimization Redefined," (pp. 52-53) by R. Casarez-Levison, 1992. In E. Viano (Ed.), Critical Issues in Victimology: International Perspectives. New York: Springer Publishing Company.

\section{Psychological Consequences}

Without a doubt, violent or nonviolent criminal victimization "is among one of the most stressful and potentially traumatizing human experiences"' (Green \& Pomeroy, 2007a, p. 63), thus psychological distress is a central and dominant response of crime victims (Cook, Smith, \& Harrell, 1987). Not surprisingly, the rich victimology literature reports that adverse physical and mental symptoms commonly emerge as consequences of crime victimization, particularly posttraumatic stress disorder (PTSD) and depression. Posttraumatic stress disorder. The criteria for PTSD, an anxiety disorder, in the current Diagnostic and Statistical Manual of Mental Disorders (DSM-IV; American Psychiatric Association, 1994), includes intrusion (i.e., flashbacks, nightmares), behavioural and/or cognitive avoidance of trauma-related stimuli (increased substance use, denial of occurrence), and hyperarousal (i.e., hypervigilance, concentration difficulties, insomnia) that exist for more than one month, and which are caused by trauma. Lifetime PTSD diagnoses are common for sexual abuse (68.8\%), physical assault $(58.3 \%)$, robbery $(27.3 \%)$, and burglary $(16.7 \%)$ victims involved with criminal justice

agencies (Freedy, Resnick, Kilpatrick, Dansky, \& Tidwell, 1994). Kilpatrick and Acierno (2003) report that crime victims are more likely to have current and lifetime PTSD symptoms or diagnoses $(9.7 \%$ and $25.8 \%)$ than nonvictims $(3.4 \%$ and $9.4 \%)$. 
Posttraumatic stress disorder is prevalent for sexual abuse (for reviews, see Ellis, 1983; Hanson, 1990; Steketee \& Foa, 1987), intimate partner violence (Golding, 1999; Jones, Hughes, and Unterstaller, 2001), and nondomestic physical or verbal assault (Blaauw, Winkel, Arensman, Sheridan, \& Freeve, 2002; Driscoll, Worthington, \& Hurrell, 1995; Elklit, 2002; Elklit \& Brink, 2004; Johansen, Wahl, Eilertsen, Hanestad, \& Weisaeth, 2006; Pathé \& Mullen, 1997, Purcell, Pathé, \& Mullen, 2005; Riggs, Rothbaum, \& Foa, 1995) victims. There is a general consensus that a significant majority of sexual abuse victims exhibit PTSD symptoms postassault and that signs generally decrease after 3-4 months, though some may experience PTSD for years. A substantial proportion of domestic or intimate partner violence victims (31-84\%) also show symptoms of PTSD. Prevalence figures for survivors of nonsexual and nondomestic assault range from $13-65 \%$. Driscoll et al. found that assaulted workers were $82 \%$ more likely to show symptoms than employees who never experienced abuse. Pathé and Mullen found that $37 \%$ of stalking victims $(N=100)$ met PTSD criteria, while over $80 \%$ reported anxiety and arousal symptoms.

Depression. According to the DSM-IV (American Psychiatric Association, 1994), major depression is characterized by persistent negative feelings about oneself such as worthlessness and hopelessness, weight issues, disrupted sleep, restlessness, anhedonia, psychosomatic complaints, cognitive problems, suicidal ideation and/or attempts.

Depression has been consistently found to be a consequence of sexual victimization, (Ellis, 1983; Hanson, 1990; Resick, 1993), and although most symptoms decrease over time, some persist (Ellis, Atkeson, \& Calhoun, 1981). In one study, $43 \%$ of rape victims experienced a major depressive episode within a month after the assault (Frank \& 
Stewart, 1984). Domestic violence victimization reviews (Golding, 1999; Jones et al., 2001) pinpoint depression as a common consequence. For instance, Golding's metaanalysis of 18 studies revealed that on average, $47.6 \%$ of intimate partner violence survivors experience depression, and $17.9 \%$ engage in suicidal ideations or attempts. Forty-four percent of the Johansen et al. (2006) sample of physical assault victims was diagnosed with depression. Workplace threats and/or violence (Driscoll et al., 1995; Wieclaw et al., 2006) and stalking (Blaauw et al., 2002; Purcell et al., 2005) victims are also more likely to suffer from suicidal ideation and depression than nonvictims. Survivors of workplace assault were $55 \%$ more likely to report depressive symptoms than their nonassaulted co-workers (Driscoll et al., 1995). Furthermore, $1.5 \%$ and $2.7 \%$ of a sample of short- and long-term criminal harassment survivors $(N=432)$ were diagnosed with severe depression (Purcell et al., 2005).

Other symptoms. Sexual dysfunction (Becker, Skinner, Abel, \& Treacy, 1982;

LeTourneau, Resnick, Kilpatrick, Saunders, \& Best, 1996; Orlando \& Koss, 1983), substance abuse (Kilpatrick, Acierno, Resnick, Saunders, \& Best, 1997; Resnick, Kilpatrick, Dansky, Saunders, \& Best, 1993), anger or hostility (Green and Pomeroy, 2007a; Kilpatrick et al., 1985; Norris \& Kaniasty, 1994) and fear (Denkers \& Winkel, 1998; Norris \& Kaniasty, 1994) have also been reported.

\section{Distress Predictors}

It is also important to note the complex nature behind the psychological consequences of victimization. Certain characteristics, such as offender-victim relationship, physical injury severity, and type of crime, may increase or decrease the potential for symptoms of anxiety, depression, and other mental health effects. 
Victim-offender relationship. Intimate partnerships and/or close relationships of victims with perpetrators tends to increase the likelihood of PTSD and depression symptoms compared to acquaintance or stranger encounters, particularly in sexual assault cases (Gutner, Rizvi, Monson, \& Resick, 2006; Stermac, Del Bove, \& Addison, 2001; Temple, Weston, Rodriguez, \& Marshall, 2007). Again, little is known about the effect of victim-offender relationship on distress in physical assault cases, however Lawyer, Ruggiero, Resnick, Kilpatrick, and Saunders (2006) found that adolescent victims of interpersonal violence $(N=4,023)$ by known assailants are at increased risk for PTSD and major depression. Possible explanations for the increase in psychological distress for victims of sexual and/or physical assault in intimate or other close relationships to offenders are more emotional and financial investment (Culbertson \& Dehle, 2001; Lawyer et al., 2006) and the greater potential for repeated versus isolated incidents due to easy access (Temple et al., 2007).

Physical injury severity. Severity of victims' physical injury is also related to psychological distress. A small to moderate positive correlation exists between severity of criminal victimization and psychological distress (Kilpatrick et al., 1985; Norris \& Kaniasty, 1994; Resnick et al., 1993; Weaver \& Clum, 1995). Severity of interpersonal violence is positively related to psychological distress $(r=.18)$ according to Weaver and Clum's meta-analysis. Similarly, Johansen et al. (2006) reports that there is a significant positive correlation between perceived severity of nondomestic physical assault and $\operatorname{PTSD}(r=.22)$. Potential reasons for the association between severity of victim injury and psychological distress are somatic reminders and the likelihood of stronger links to chronic versus isolated incidents, which is also associated with distress symptoms. 
Type of crime. Studies have compared the effect of fraud, sexual versus nonsexual and/or violent versus nonviolent crimes on psychological distress. The information on psychological consequences of fraud victims is scarce and typically descriptive, but Titus, Heinzelman, and Boyle (1995) reports that $14 \%$ of a sample of personal fraud survivors $(N=720)$ suffered from health or emotional problems, which were not specifically identified by the authors. Weaver and Clum (1995) revealed a small but significant averaged effect size $(r=.24)$ for interpersonal violence and its impact on psychological distress. Although sexual assaults $(r=.21)$ have a stronger relationship to distress symptoms than nonsexual crimes $(r=.16)$, this difference was not significant. Effect sizes for specific types of interpersonal violence are as follows: rape $(r=.21)$, multiple stressors $(r=.19)$, and physical assault $(r=.08)$.

Several studies (Boudreaux, Kilpatrick, Resnick, Best, \& Saunders, 1998; Green \& Pomeroy, 2007a; Kilpatrick et al., 1985; Norris \& Kaniasty, 1994; Sorenson \& Golding, 1990; Wirtz \& Harrell, 1987a) have compared various crimes and their influences on mood and anxiety disorders. Kilpatrick et al. examined the effect of criminal victimization on nervous breakdown, suicidal ideation, and suicide rates for adult female victims and nonvictims $(N=2,004)$ from South Carolina who answered a telephone survey on demographics, incident characteristics, event disclosure, and mental health. Survivors of sexual assault scored higher than other victims and nonvictims on all three variables. These results foreshadowed Sorenson and Golding's study, which explored depression and suicidality in crime victims $(n=2,279)$ and nonvictims $(n=421)$ from Los Angeles. Victims of any crime were more depressed and suicidal than nonvictims. Boudreaux et al. explored mental health consequences of criminal 
victimization with a subset of the Kilpatrick et al. (1985) sample. Victims were more likely than nonvictims to receive a diagnosis of major depression, agoraphobia, obsessive-compulsive disorder, social and simple phobia.

Wirtz and Harrell (1987a) also conducted a study comparing psychological distress symptoms of victims $(N=273)$ of physical assault (rape, domestic abuse, nondomestic assault) and nonassaultive (robbery, burglary) crimes. Both types of victims experienced similar levels of fear, anxiety, and stress, although physical assault survivors had more symptoms. Similarly, Norris and Kaniasty (1994) used random digit dialing procedures to interview victims of violent $(n=105)$ and property $(n=227)$ crime as well as nonvictims $(n=190)$ from Kentucky. Diverse symptomatology was found amongst all victims, including depression, somatization, hostility, anxiety, and fear. Violent crime victims experienced more symptoms than property crime survivors and nonvictims. Property crime victims tended to have more symptoms than nonvictims.

More recently, Green and Pomeroy (2007a) examined the effect of violent and property crimes on victims' mental health. Violent crimes included homicide, assault, assault (aggravated, sexual, or intoxication), elder or family abuse, and manslaughter with or without intoxication. Nonviolent crimes comprised of theft, robbery, burglary, and domestic disturbance. One hundred and seventy five survivors of crime (violent $n=$ 86; nonviolent $n=89$ ) completed scales measuring PTSD, depression, anxiety, and anger. Significant differences between violent and nonviolent crime victims were found for all measures of psychological distress. Victims of violent crime experienced more posttraumatic stress, depression, anxiety and anger than those who were victimized by nonviolent crime. Thirty-one percent of the variance in psychological distress symptoms 
was explained by type of crime. Overall, victims of assault crimes exhibit more symptoms than survivors of nonassault crimes, who tend to be more distressed than nonvictims, nonetheless, survivors of any crime experience psychological consequences.

Researchers theorize that victims experience PTSD, depression, and other mental symptoms or disorders because their assumptions and expectations about themselves and the world are challenged (Frieze, Hymer, \& Greenberg, 1987; Janoff-Bulman \& Frieze, 1983). More specifically, assumptions of personal invulnerability, a meaningful world, and view of self as positive are shattered. People perceive themselves as invulnerable to harm, therefore victimization results in feelings of vulnerability and helplessness. In a world expected to be comprehensible and orderly, victims question what brought about their victimization. For example, people expect cautious behaviour, such as tightening security or vigilance of surroundings, to be able to prevent the occurrence of crime, so criminal victimization is discordant with victims' conception of a world which makes sense. Finally, positive assumptions about oneself such as self-worth are threatened by victimization and its ability to trigger negative self-perceptions.

\section{Coping and Social Support}

Stressful circumstances such as crime victimization can cause disequilibrium in psychological functioning and daily routines, and therefore influences victims' coping mechanisms and social support systems. As defined by Lazarus and Folkman (1984), coping consists of "constantly changing cognitive and behavioral efforts to manage specific external and/or internal demands that are appraised as taxing or exceeding the resources of the person" (p. 141). People use problem-, emotion-, and/or avoidancefocused coping in an attempt to master, tolerate, minimize or reduce the impact of 
stressful or traumatic events. Problem-focused coping, such as implementing a regular sleep schedule to deal with fatigue, is goal-oriented and includes behavioural and/or cognitive efforts to resolve problems caused by stressful situations (Lazarus \& Folkman, 1984). Emotion-focused coping consist of regulating feelings surrounding the stressful event (Lazarus \& Folkman, 1984), such as anger and sadness about victimization. Avoidance encompasses behavioural and cognitive efforts which distract or divert attention away from stress (Cosway, Endler, Sadler, \& Deary, 2000; Endler \& Parker, 1990), such as denial of the stressor's occurrence.

Coping can be either effective or ineffective. Problem-oriented strategies are adaptive because they provide a sense of control, which subsequently leads to positive outcomes such as improved physical and mental health (Billings \& Moos, 1981; Folkman, 1997; Lazarus \& Folkman, 1984). On the other hand, emotion- and avoidancefocused strategies are generally maladaptive and lead to greater distress symptomatology, because no action is undertaken to change or control the stressor (Endler \& Parker, 1990). However, some researchers (Roth \& Cohen, 1986) suggest that labeling specific strategies as adaptive or maladaptive is too simplistic, as approach and avoidance coping techniques have their own advantages and disadvantages. For example, approach strategies allow for the resolution of trauma, but increases distress and worry, whereas avoidance techniques reduce stress, but results in emotional numbness and flashbacks. Furthermore, temporal location and perceived controllability of the stressor affect effectiveness (Folkman, Lazarus, Dunkel-Schetter, DeLongis, \& Gruen, 1986; Mullen \& Suls, 1982). Avoidance is more effective when the outcome is immediate or short-term, whereas approach techniques are better for long-term or chronic stressors. Additionally, 
if the stressful situation is perceived as controllable, problem-focused solutions would be more appropriate, whereas emotion- and avoidance-focused strategies work best for events considered uncontrollable.

Social support has been extensively researched as part or independent of coping. Hobfoll and Stokes (1988) define social support as "social interactions or relationships that provide individuals with actual assistance or with a feeling of attachment to a person or group that is perceived as caring or loving" (p. 499). Social support can be either perceived or received. Perceived social support is the belief that significant people in one's life, such as family and friends, will be available for support, whereas received social support involves actual assistance, including advice and reassurance (Norris \& Kaniasty, 1996). Both types of support can be of an emotional, tangible, or informational nature (House, 1981). Emotional support manifests as love, caring, esteem, and sympathy. Tangible assistance involves actions and materials provided by others to enable functioning during distress, such as accompanying crime survivors to hospitals. Informational aid includes offering advice, feedback, opinions or facts relevant to current difficulties in an attempt to make life easier for people in need (House, 1981). Greater support from others is essential because it accommodates basic human needs such as longlasting relationships, expression of feelings, belonging, and self-worth (Caplan, 1974; Hobfall, Freedy, Lane, \& Geller, 1990).

According to Thoits (1986), social support would be better conceptualized as coping assistance for better integration within a general theory of stress reduction or buffering. Social support and coping serve similar functions. For example, problemoriented coping and tangible support are focused on changing or managing stressful 
circumstances. The goal of emotion-focused coping and emotional support is to alleviate negative feelings accompanying exposure to stress. Furthermore, social support and coping as a whole assist in changing situations, meanings of events, and/or emotional reactions, particularly to control feelings of anxiety or depression associated with the demands of stressful circumstances. Lazarus and Folkman (1984) consider social support as a factor which precedes and influences coping.

Similar to coping, social support could have a positive or negative impact on psychosocial adaptation to stressful events. Initially, social support was seen as a factor that promotes resistance to adverse psychological consequences, and this has been well documented (Barrera, 1986; Cohen \& McKay, 1984; Cohen \& Wills, 1985; Holohan \& Moos, 1981). Additionally, the ability of strong social support to reduce stress and weak social support's tendency to increase psychological symptoms is known as the Stress Buffer Model (Cassel, 1976; Cobb, 1976; Wilcox, 1981). Furthermore, this model suggests that social support acts as a moderator between stress and mental health. In other words, quality of the social support affects the direction and strength of the relationship between the stressor and distress.

However, further research reveals that the relationship between social support and psychological effects for traumatic events is more complicated. There are differences in terms of perceived and received social support's impact on mental health. Wethington and Kessler (1986) reviewed the literature on social support and the Stress Buffer Model, and found that perceived support is a consistent significant predictor of adjustment to stressful situations, whereas the effect of received support is weak. More specifically, an increase in perceived support is associated with a decrease in psychological distress. To 
further confirm the results of the review, Wethington and Kessler explored perceived and received support for the most recent stressful events recalled by a large sample $(N=$ 1,269) of adults from a national survey. Perceived support was negatively related to stress $(r=-.30)$, after controlling for received support. Actual assistance showed nonsignificant positive relationships to psychological distress.

The Support Deterioration Model (Norris \& Kaniasty, 1996) is an attempt to explain received support's limited ability to alleviate psychological maladjustment. In this model, social support is conceptualized as a dynamic and stressor-dependent variable which mediates the relationship between the stressor and psychological adjustment (Lepore, Evans, \& Schneider, 1991). More specifically, changes in social support characteristics such as optimal matching of needs (Cutrona \& Russell, 1987), quality of delivery (Dakof \& Taylor, 1990; Holohan \& Moos, 1981; Norris \& Kaniasty, 1996) and temporal location (Lepore et al., 1991; Norris \& Kaniasty, 1996) cause the relationship between the stressor and distress. Lepore et al. suggest that social support is initially a moderator between a stressor and distress which then transitions to a mediator.

Overall, coping and social support plays an important role in attenuating distress caused by stressful situations (Billings \& Moos, 1981). Billings and Moos found that coping and social support demonstrated moderate negative associations with anxiety, depression, and psychosomatic symptoms for adult survivors of various traumatic events $(N=297)$. Additionally, Billings and Moos indicated that "approximately one-half of the criterion [psychological distress] variance 'explained' by coping and by social resources was shared... e.g., people who use avoidance coping responses have fewer social resources and these two factors combine to detrimentally influence their functioning" (p. 
154). Furthermore, coping and social support have a cumulative effect on psychological distress, especially with respect to traumatic events, such as crime.

\section{Coping and Social Support in Crime Victimization}

Studies of coping and social support of crime victims place emphasis on their relationships to psychological distress. Coping and social support may buffer against negative consequences of victimization by crime. Coping well with victimization promotes growth. Knowledge of coping techniques can assist counsellors in understanding victims' cognitive and/or behavioural repertoire, and optimally match therapeutic techniques or design alternative strategies for better recovery. Social support improves one's quality of life because it allows for the maintenance and enhancement of self-esteem (Cobb, 1976; Cohen \& Wills, 1985), which is essential for victims and survivors of crime. Furthermore, social support has a positive impact on help-seeking behaviour (Ellis, 1983; Ellis et al., 1981; Kaniasty \& Norris, 1992; Kimerling \& Calhoun, 1994). Positive coping and social support is crucial for victims of any crime, but tends to be especially important for survivors of sexual and violent crimes (Kaniasty $\&$ Norris, 1992). Overall, successful coping and utilization of social support networks facilitates crime victim recovery.

Sexual assault. According to a review by Ullman (1999), the adaptiveness of coping strategies used by rape victims changes over time and social support has a negative association with psychological distress. Avoidant coping strategies such as substance abuse and social withdrawal tend to be more effective in the immediate aftermath, but distress symptomatology increases significantly if avoidance continues in the 6 to 12 months after victimization. On the other hand, approach coping techniques 
such as taking self-defense lessons are either unrelated or mildly positively associated with distress symptomatology. Survivors of sexual assault who are able to confide in at least one or two friends or relatives perceived themselves as more healthy and were less likely to experience somatic manifestations of stress than crime survivors without support systems (Kimerling \& Calhoun, 1994).

Intimate partner violence. Findings on the effectiveness of coping and social support on psychological health for intimate partner violence victims are similar to survivors of sexual assault. Mitchell and Hodson (1983) found that violence frequency and severity, lack of social support, and use of more avoidant coping styles were associated with more severe depressive symptoms in battered women $(N=60)$ residing at a shelter. Similar results on PTSD and depression held true for research with African American women who have been abused (Kocot \& Goodman, 2003; Thompson, Kingree, Rashid, Puett, Jacobs, \& Matthews, 2000). Straight, Harper, and Arias (2003) researched the effects of psychological abuse and coping on health behaviours and status in college women $(N=151)$. Less active coping strategies were associated with binge drinking, negative health perceptions, and physical limitations as level of psychological abuse increased. High avoidant coping techniques were indirectly related to substance abuse, and directly associated with smoking, binge drinking, and physical limitations.

Physical or verbal assault. Little is known about the coping strategies and social support systems of survivors of nondomestic physical or verbal assault. Elklit (2002) found that there was a negative correlation between avoidant coping strategies and PTSD in robbery and assault victims, but pointed out that this may have been due to frantic efforts to adapt in the immediate aftermath of the crime. Decreases in social support 
results in an increase in PTSD symptomatology in physical assault survivors (Elklit \& Brink, 2004). Multiple stressors or severity of assault were associated with an increase in depression and PTSD respectively (Elklit, 2002; Elklit \& Brink, 2004). Social support plays a strong role in buffering the effects of workplace violence and aggression, but virtually no studies have examined the influence of coping strategies. In a study of health care workers $(N=225)$ who experienced physical, psychological, or vicarious violence in the workplace, Schat and Kelloway (2003) found that tangible support was positively related to emotional well-being, somatic health, and job-related affect. There was a positive association between informational support and emotional well-being. Research on coping and/or social support of stalking survivors is even more limited. In a descriptive study of stalking victims $(N=55)$, Nicastro, Cousins, and Spitzberg (2000) reported that the most common coping technique was phone hang-ups. However, their descriptive profiles suggest that legal, problem-focused actions such as calling the police (96\%), filing police reports (94\%) and pressing charges (69\%) were especially frequent.

All crimes. Many studies have compared coping and/or social support of different types of crime victims. Green, Streeter, and Pomeroy (2005) investigated factors which influence well-being after crime victimization, including psychological consequences, coping, and social support. Adult victims of violent (i.e., assault, elder abuse, manslaughter, aggravated robbery, family violence) and nonviolent (i.e., theft, robbery, burglary, domestic disturbance) crimes $(N=175)$, crimes which occurred within 4 to 6 weeks of the study participated in a semi-structured interview and rated their anxiety and depression using standardized measurements. Green et al. found that psychological distress had moderate relationships with problem- $(r=-.59)$ and emotion- $(r=.55)$ 
focused coping strategies. Greater levels of anxiety and depression were associated with a reduction in problem-focused strategies, and an increase in emotion-focused techniques. Social support is moderately correlated with problem-focused coping techniques $(r=$ $.40)$. Victims who had larger social support networks were more likely to utilize problemfocused strategies than emotion-oriented techniques. Although nonsignificant, social support was found to have a negative relationship with psychological distress $(r=-.04)$ and emotion-focused coping ( $r=-.14)$. Green and Pomeroy (2007b) further explored the effect of perceived and received social support on psychological distress. Nonsignificant negative relationships were found between perceived support and anger $(r=-.29)$, and received support and anxiety $(r=-.13)$. Additionally, a strong inverse relationship between perceived support and psychological distress was found.

These studies reflect the common findings of the effect of coping and social support on psychological distress in crime victims. Problem-focused coping is associated with a decrease in distress and an increase in social support. Emotion- and avoidanceoriented coping techniques is associated with distress and a decrease in social support (Gutner et al., 2006; Scarpa, Haden, \& Hurley, 2006; Valentiner, Foa, Riggs, \& Gershuny, 1996; Wirtz \& Harrell, 1987b). Distress has a negative association with social support. However, research on perceived and received social support tends to be mixed. Whereas perceived social support has a negative correlation with distress, received assistance appears to have limited influence (Kaniasty \& Norris, 1992; Scarpa et al., 2006), and these contradictions may be explained by temporal location, such as social support in the immediate aftermath versus six months after the crime, and isolated versus chronic victimization (Denkers, 1999; Yap \& Devilly, 2004). Overall, coping and social 
support are strongly related to distress. As a whole, individual differences, coping strategies, social support, and well-being accounts for $70 \%$ of the variance in crime victims' emotional stress (Green \& Diaz, 2007).

\section{Psychopathy}

Many psychopathic traits are conducive to physical, sexual, emotional, spiritual, and/or financial harm to others. Hence, victims of psychopaths are affected by acts of a harmful and/or criminal nature, regardless of legal sanctions imposed. Hare (1999b) elaborates on the notion that the defining characteristics of psychopathy make it reasonable to assume that psychopaths pose a high risk for aggressive behaviour and violence (Hart \& Hare, 1997) by stating that:

Even a cursory inspection of the features that define the disorder - callousness, impulsivity, egocentricity, grandiosity, irresponsibility, lack of empathy, guilt, or remorse, and so forth - indicates that psychopaths should be much more likely than other members of the general public to bend and break the rules and laws of society (p. 185).

In fact, psychopaths are "responsible for a markedly disproportionate amount of serious crime and social distress" (Hare, 1999b, p. 186). There is a strong positive relationship between psychopathy and crime, particularly violent behaviour (for reviews, see Hare, 1999b; Hemphill, Hare, \& Wong, 1998). Institutionalized or not, psychopaths are more likely to be socially disruptive, aggressive, and violent than nonpsychopaths.

Pioneer studies assessed psychopathy using clinical criteria proposed by Cleckley (1976), many of which were borrowed for standardized and self-report measures. According to Cleckley, psychopathic traits include superficial charm, absence of mental illness, failure to learn by experience, egocentricity, affective deficiencies, antisocial behaviour, and interpersonal unresponsiveness. An empirical evaluation of Cleckley 
criteria laid the foundation for the gold standard in psychopathy assessment, the Hare Psychopathy Checklist-Revised (PCL-R; Hare, 2003). The PCL-R is a 20 -item standardized psychopathy measure that assesses correctional or forensic inmates using semistructured interviews and collateral sources, such as police reports and family members. The diagnostic cutoff is 30 out of a possible total of 40 , but approximately 25 is acceptable for research purposes. People from the general community or civil psychiatric populations are assessed with the Hare Psychopathy Checklist: Screening Version (PCL: SV; Hart, Cox, \& Hare, 1995). Self-report inventories such as the SelfReport Psychopathy scale-III (SRP-III; Paulhus, Hemphill, \& Hare, in press), and the Psychopathic Personality Inventory (PPI; Lilienfeld \& Andrews, 1996) ask respondents to rate themselves on statements reflecting psychopathic thoughts and behaviours.

Most assessments of psychopathy divide psychopathic traits into two factors, each with two facets: Factor 1 (Interpersonal / Affective) and Factor 2 (Social Deviance / Antisocial Lifestyles). Each facet includes specific descriptors which are analyzed, as follows: Interpersonal (glibness, superficial charm, grandioseness, egocentricity, deceitfulness and manipulative), Affective (callousness, lack of remorse / guilt / shame / empathy, and shallow emotions), Social Deviance (impulsivity, poor behaviour controls, excitement-seeking, refusal to admit responsibility, and early behaviour problems), and Antisocial Lifestyles (antisocial acts and criminal versatility). All types of measures have been used in studies of psychopaths' crimes, recidivism rates, victim injury, motives, and deceptive behaviour in institutionalized populations and the general public. 


\section{Crimes}

Numerous studies have compared the general, violent, and sexual crimes of psychopathic versus nonpsychopathic offenders, particularly in correctional populations. Correctionally institutionalized psychopaths have been found to commit more theft, break and enter, armed robbery, fraud, assault, forcible seizure, weapon possession and use, and drug crimes than mixed groups and/or nonpsychopaths (Hare, 1981; Hare \& Jutai, 1983; Hare \& McPherson, 1984). Violent crimes are especially more common for psychopaths. For example, Hare found that $97 \%$ of psychopaths $(n=104)$ received at least one conviction for a violent crime, compared to only $78 \%$ of a mixed group $(n=64)$ and $75 \%$ of nonpsychopaths $(n=64)$. In Hare and Jutai's study, psychopaths received more charges $(M=5.04)$ than nonpsychopaths $(M=3.25)$, and this was especially true for violent crimes $(M=.91$ versus $M=.27$, respectively). Violence was more prevalent in criminal charges for psychopaths (18\%) than nonpsychopaths (9\%). Hare, McPherson, and Forth (1988) expanded on previous studies through a cross-sectional and longitudinal analysis of psychopathic $(n=204)$ and nonpsychopathic $(n=317)$ inmates, and found that psychopaths experienced longer imprisonment periods and received more convictions for both general and violent crimes. Support for the relationship between psychopathy and sexual violence is rather limited and complex. Although some researchers (i.e, Quinsey, Rice, \& Harris, 1995) found that sex offenders with higher PCL-R scores engaged in a greater number of sexually deviant acts than their counterparts, other studies (Brown \& Forth, 1997; Sjöstedt \& Långström, 2002) did not support these findings. Nevertheless, rapists and mixed rapists/molesters consistently score higher than child molesters on psychopathy measures (Porter et al., 2000; Seto \& 
Barbaree, 1999). Although results are equivocal, MacPherson (2003) suggests that psychopathy still plays an important role in predicting escalations in sexual violence recidivism.

Research also suggests that physical and sexual aggression and violence are successfully committed by psychopaths in community populations, including civil psychiatric patients (DeMatteo et al., 2006; Douglas, Ogloff, Nicholls, \& Grant, 1999; Kosson, Kelly, \& White, 1997; Nicholls, Ogloff, \& Douglas, 2004; Skeem \& Mulvey, 2001). Skeem and Mulvey found that civil psychiatric patients $(N=1,136)$ from the MacArthur Violence Risk Assessment Study (methodology details can be found at MacArthur Research Network on Mental Health and the Law, 2005) who were high in psychopathy engaged in more aggressive and violent behaviour than nonpsychopaths. Kosson et al. administered self-report measures of sexual experiences and scales reflecting narcissism, socialization, and psychopathy to male undergraduate students $(N=$ 378). Participants rated frequency of several behaviours (i.e., flattery, verbal pressure, forced substance use, threats, and physical force) for each outcome - sexual contact, attempted or completed sexual intercourse, and other sexual acts. Men who received higher scores on scales of narcissism and psychopathy, and lower scores on socialization, committed more acts of sexual aggression than the students whose results were the opposite. Furthermore, DeMatteo et al. recruited adult males from Philadelphia $(N=54)$ using newspaper advertisements which described psychopathy in a nonpejorative manner. Most of the sample received moderate PCL-R scores. Forty percent $(n=22)$ of the participants self-reported no history of legal ramifications for crimes committed. Overall, 
psychopaths participate in a wider range of criminal, aggressive, and harmful behaviour than nonpsychopaths.

\section{Recidivism}

Recidivism studies suggest that psychopaths are persistent with their criminal behaviour (Douglas et al., 1999; Leistico, Salekin, DeCoster, \& Rogers, 2008; Nicholls et al., 2004; Rice, Harris, \& Cormier, 1992; Salekin, Rogers, \& Sewell, 1996; Serin, 1996; Skeem \& Mulvey, 2001). A recent meta-analysis of 95 studies $(N=15,826)$ by Leistico et al. relating various Hare checklists to antisocial conduct revealed a moderate association between psychopathy and recidivism (mean $d=0.55$ ). Furthermore, psychopaths are more likely to reoffend than nonpsychopaths, leaving behind many traumatized victims.

\section{Victim Injury}

Psychopaths are highly likely to commit more sadistic (Hare, Cooke, \& Hart, 1999; Holt, Meloy, \& Strack, 1999; Meloy, 2000; Porter, Woodworth, Earle, Drugge, \& Boer, 2003) and persistently brutal (Huss \& Langhinrichsen-Rohling, 2000; Vitacco, Caldwell, Van Rybroek, \& Gabel, 2007; Walsh, 1999; Williamson, Hare, \& Wong, 1987) forms of violence than nonpsychopaths. Sadism, arousal from the physical and/or emotional suffering of victims, is a distinct hallmark of the psychopath's criminal repertoire. Porter and colleagues found that $82.4 \%$ of a sample of Canadian incarcerated psychopathic murderers $(n=18)$ showed sadistic characteristics in their crimes compared to $52.6 \%$ of their nonpsychopathic $(n=20)$ counterparts. Psychopathic violence tends to be brutal and excessive. Vitacco et al. found that for serious adolescent offenders $(N=$ $168), 17 \%$ of the variance in victim injury was explained by psychopathy, criminal 
versatility, and age at first crime. In Williamson et al.'s study, psychopaths were more likely to inflict serious injuries which required medical treatment or hospitalization, particularly on stranger victims. A qualitative analysis by Walsh comparing psychopathic and nonpsychopathic alcoholic offenders revealed that one psychopath blinded a stranger by repeatedly smashing his face into a car's headlights for not apologizing quickly enough for an accidental nudge. Such sadistic and gratuitous violence, without doubt, causes greater physical injury and psychological trauma to survivors.

Motives

The severity of victim injury committed by psychopaths against victims may be partially explained by their tendency towards instrumental versus reactive criminal motives. Instrumental crimes are goal-driven and involve unemotional motives such as power, material, or financial gain, compared to reactive aggression, which is based on emotional provocation, hostility, and arousal. Premeditation is common for instrumental crimes, whereas reactive aggression is typically spontaneous. Several studies have established a positive relationship between psychopathy and instrumental motives (Cornell et al., 1996; Hervé, Mitchell, Cooper, Spidel, \& Hare, 2004; Nouvion, Cherek, Lane, Tcheremissine, \& Lieving, 2007; Porter \& Woodworth, 2007; Williamson et al., 1987; Woodworth \& Porter, 2002). In Williamson and colleagues' study, psychopaths (PCL-R $>21 ; n=55$ ) committed serious violent assaults (i.e., attempted murder, assault causing bodily harm, wounding) and property crimes (i.e., theft, break and enter, possession) with more instrumental motives than nonpsychopaths (PCL-R $<20 ; n=46$ ), whose crimes had a greater likelihood of being motivated by reactive aggression. Woodworth and Porter's study of psychopathic murderers revealed that an overwhelming 
$93.3 \%$ of their homicides were based on instrumental motives compared to $48.4 \%$ of the murders by nonpsychopaths. The association between psychopathy and instrumental violence makes sense given the psychopath's affective features such as callousness, shallow emotions, lack of empathy, guilt, remorse, and concern for the well-being of victims. Furthermore, the degree of injury and violence perpetrated by psychopaths against victims is not constrained by emotional inhibitory states which would prevent harm by most nonpsychopathic individuals (Cornell et al., 1996; Porter et al., 2003). Deception

Given the unemotional nature of psychopaths, deception is a consistent and fundamental factor of psychopathic behaviour found in their relationships with others. Both psychopathy assessments (i.e., PCL-R) and clinical descriptions (i.e., Cleckley, 1976) of psychopathic behaviour include many traits which imply deception, such as glibness, superficial charm, manipulation, and pathological lying. Psychopaths are perceived as social predators because of their ability to deceive, manipulate, and charm people. Hare (1999a) refers to psychopaths as individuals who "ruthlessly plow their way through life, leaving a broad trail of broken hearts, shattered expectations, and empty wallets" (xi). In a further description, Hare (2001) portrayed psychopaths as "natural born takers" due to their deception skills. Additionally, Mealey (1995) suggested that psychopaths are designed such that they are able to successfully execute social deception, take advantage of people, and exploit the cooperation of others. All these views are reflective of the social predator hypothesis (Book, 2005; Hare, 1999a). The social predator hypothesis with respect to psychopaths postulates that they possess an ability to 
detect emotional and behavioural signals of victim vulnerability and to evade deception detection.

Although psychopaths are deficient in understanding and showing emotions (Cleckley, 1976), which would pose challenges to social predators, studies have shown that they are capable of attributing emotional states to others (Blair et al., 1996; Book, Quinsey, \& Langford, 2007; Habel, Kuhn, Salloum, Devos, \& Schneider, 2002; Richell et al., 2003). Psychopaths can attribute emotions to others, but cannot intrinsically experience feelings. Research supports that psychopaths are unable to fully appreciate the semantics of words, but can understand their definitions from a connotative perspective (Blair et al., 2006; Patrick, Cuthbert, \& Lang, 1994). Book (2005) explored both components of the social predator hypothesis: recognition of victim vulnerability and evasion of detection deception. Federally incarcerated male inmates $(n=59)$ in Ontario and people from the general community $(n=60)$ were recruited to identify one of five universal emotions (happy, sad, angry, disgusted, or afraid) or neutral expressions from 24 photographs of Caucasian males and females, and to rate the assertiveness of confederates and acquaintances in videotapes. Participants who scored higher in psychopathy were more accurate at recognizing the intensity of emotions for facial expressions, particularly fearful faces. Additionally, psychopaths were able to correctly rate assertiveness and vulnerability. Although some studies found that psychopaths and nonpsychopaths correctly identified all emotions equivalently, other studies found that psychopaths had difficulty recognizing sadness and/or fear (Blair et al., 2002, 2004).

Research on the psychopath's ability to recognize emotions in others has implications for their victims, particularly with respect to deception. Emotions serve a 
communicative function as cues to the intentions, motivations, and desires of people within interpersonal contexts (Ekman, 1980). The feelings of victims, particularly sadness and fear, are emotionally ambiguous to the psychopaths, or worse, ignored. Deficits in recognizing fear and sadness may block inhibition of harmful and/or criminal actions by psychopaths against victims. Otherwise, psychopaths are not strangers to emotional cues, and may use them to establish effective strategies for attracting or repelling potential targets and victims. In fact, psychopaths utilize prosocial tools or goals, such as empathy and a desire to improve the state of the world, as weapons (Stout, 2005). For example, psychopaths may attempt to instill a sense of familiarity in people whom they are interacting with; an otherwise positive social action with the purpose of building interpersonal relationships.

Emotions and accompanying behaviour can also be illustrators of personality traits. Existing research in victimology supports the notion that it is possible for both offenders and nonoffenders to identify people who exhibit behaviour or personality traits conducive to victimization, such as previous history as a victim or submissiveness (Grayson \& Stein, 1981; Murzynski \& Degelman, 1996; Richards, Rollerson, \& Phillips, 1991). McCormick and Trent (2007) identify several traits which would encourage victimization by a psychopath, such as gullibility, communication difficulties, problems with establishing and maintaining boundaries, low self-confidence, and a strong eagerness to please others. Therefore, the psychopath's ability to recognize vulnerability in others, the first hallmark of the successful social predator, provides them with an opportunity to select and successfully manipulate optimal targets. 
Psychopaths evade detection of deception, the second component of the social predator, through distinct verbal and/or nonverbal behaviours (Cleckley, 1976; Gillstrom \& Hare, 1988; Klaver, Lee, \& Hart, 2007; Kosson, Kirkhart, \& Steuerwald, 1993; Lee, Klaver, \& Hart, 2008; Rimé, Bouvy, Leborgne, \& Rouillon, 1978). Cleckley postulates that psychopaths use speech and gestures as resourceful tools in the effective deception of their audience. The verbal characteristics of psychopaths have not been studied to the extent of which nonverbal gestures were perused. However, one distinctive vocal feature of psychopaths is that they tend to speak at lower volumes than nonpsychopaths (Louth et al., 1998). In comparison to nonpsychopaths, psychopaths tend to provide more appropriate details and spontaneous corrections of false accounts during deception (Lee et al., 2008). Nonverbal gestures are also utilized by the psychopath to lure potential targets and victims. The earliest study on psychopathy and nonverbal behaviour, by Rimé and colleagues examined the facial expressions of male psychopathic $(n=25)$ and nonpsychopathic $(n=25)$ halfway house residents during an open-ended interview about their leisure activities. Psychopaths rarely smiled and were significantly more likely to maintain eye contact, lean forward, and use gestures. Gillstrom and Hare noted a significant increase in beats, gestures which are not associated with semantics of speech.

Klaver et al. found that psychopaths, particularly those who scored higher on interpersonal facets, were more likely to blink, speak longer, and use body movements than their counterparts after comparing accounts of current offences and fictional descriptions of electronic equipment theft, provided by the researchers. Furthermore, Kosson and colleagues designed a measure of verbal and nonverbal interpersonal characteristics of psychopaths, the Interpersonal Measure of Psychopathy, based on a 
literature review, clinical experience, and informal surveys of researchers with expertise in psychopathy. Behaviour that was found to be dominant in psychopaths in comparison to nonpsychopaths included: interruptions, making demands of or comments about interviewers, filling in dead space, perseveration, incorporation of interviewer into personal stories, and impulsive responding. Boundary violations, insertion of tangential comments, frustration with avoidance of arguments, narcissistic expressions, showmanship, unusual calmness, alliance seeking, anger, expressed toughness, and intense eye contact were also common.

As Rogers and Cruise (2000) suggest, psychopaths possess a deceptive presentation style. Many of the verbal and nonverbal behaviours of psychopaths could be construed as specific strategies to compel listeners and/or reduce suspicions in their audiences, particularly for impression management. For example, psychopaths' quiet voices "could be effective in drawing the listener in and convincing her or him of the speaker's sincerity" (Louth, Williamson, Alpert, Pouget, \& Hare, 1998, p. 382). The inclusion of extra details in narratives may decrease listeners' doubts about the truthfulness of the speakers' accounts. Although spontaneous corrections may signal deception, compelling and seemingly sincere gestures such as hand movements, smiles, eye contact and leaning forward may override listeners' suspicions. All these behaviours may serve as strong distractions from deceptive content for victims.

\section{Victims of Psychopaths}

Although research on psychopaths is primarily quantitative, current sources on the victimization experiences of survivors are limited to brief anecdotes and case studies. Hence, caveats should be taken into consideration. For example, generalizability to other 
survivors is threatened; without expanding the number of participants to be inclusive of a variety of victims of psychopaths, the scope of observations is rather narrow.

Documented victimization experiences are limited to the respective victims and cannot be used to describe other survivors in a reliable manner. The inherent subjectivity of idiographic research limits the ability of the anecdotal observations to achieve acceptable reliability and validity. Oftentimes, the anecdotes and case studies are written by external observers such as researchers or counsellors rather than the victims or survivors themselves, therefore, they are vulnerable to researcher bias. Observer biases are apparent by the emphasis of information about the psychopaths in comparison to the victims. Furthermore, qualitative designs do not provide an adequate picture of cause and effect. Despite these limitations, there are advantages. The accounts of victims of psychopaths can provide unique histories and in-depth analyses of their experiences. Secondly, qualitative research methods allow for more flexibility, which result in data that may not have been discovered in quantitative research. Data collected from the qualitative research on victimization caused by psychopaths is rich in detail, because victims can report their experiences in their own words. Thirdly, the victims' responses are less sensitive to socially desirable responding that typically occur under the supervision of researchers in laboratory situations. Finally, as will be illustrated in the current study, these studies can lay the foundation for testable hypotheses, encouraging the development of research in areas which may not have been previously explored.

\section{Victim Stories}

William. Two studies (Kreuter, 2003; 2004) look at the impact of a psychopath, Connie, on the physical, emotional, and financial life of William, a commercial airline 
pilot. William experienced multiple levels of victimization over several years as Connie committed identity theft, extortion, and coercion against him. Connie concocted an elaborate scheme impersonating and co-ordinating several cyber-identities including professional athletes and law enforcement officers. William believed that he was in contact with separate individuals. To invoke sympathy, Connie falsely presented herself as a victim and went to great lengths to show "proof" of her claims. For example, when Connie claimed that that parts of her body were burned by members of the mafia because she possessed knowledge about a professional athlete that they did not want disclosed, she sent photographs of the damage, albeit self-inflicted, to appear genuine. Initially, fear and intimidation altered William's plans to make reports to the local police. When William contacted a federal police agency, Connie also corresponded with the officers involved, claiming that William was psychotic. The federal agency reported Connie's suspicions to William's employers at the aviation company, which resulted in William's suspension. Reported consequences included difficulty trusting authorities, a jeopardized career, loss of home, damaged credibility, and ruined reputation. Furthermore, William suffered financial ruin because he was held accountable for Connie's forged bank accounts. As a result of his experiences with Connie, William suffered posttraumatic stress disorder as well as stigma due to his alleged psychosis.

Sydney. Stout (2005) described the story of Sydney, a woman with a number of academic and professional achievements, such as an epidemiology professorship at a young age and ethnopharmacalogy consultancy experience, who met Luke at her work. Luke, a self-professed city planning graduate, treated Sydney very well with flowers and dinner dates where his charming demeanour and apparent intelligence appealed to her. 
Sydney was initially concerned that he may have been deceiving her with regards to his academic experience because of his tiny apartment and history of short-lived common law relationships, but rationalized this behaviour as his attempt to find the right person and his interest in his building complex's pool. The two married after only a brief period of dating and had a son, Jonathan. Luke quit his job shortly thereafter, expecting Sydney to pay for all expenses. Luke was lethargic around the house and barely paid attention to Jonathan, except for bouts of anger when he cried. Additionally, Luke pretended to suffer from depression, which Sydney doubted because he seemed energetic and refused therapy for his alleged illness. Luke also demonstrated other unusual behaviour, such as intense enthusiasm for hobbies like collecting lithographs, which wavered quickly. Luke's strange actions encouraged Sydney to divorce him. After the divorce, Luke began to spend more time with Jonathan. Sydney felt morose and tense in Luke's presence, and avoided him at all costs. Whenever Sydney asked Luke to leave, he would either ignore her request or initially depart, then return, appearing angry and agitated. Luke also used Jonathan against Sydney in arguments. Sydney often described her interactions with Luke as dreadful because of his predatory stares. Sydney dealt with confusion, fear, self-blame, guilt, and shame. Sydney's life savings were drained, which caused her to go into serious debt. Custody battles also jeopardized a large portion of Sydney's financial resources. An empirical study. Although most studies on survivors of psychopaths used qualitative methods, one empirical investigation thus far at least partially explored the experiences of victims of psychopaths. Through written narrative data and semistructured phone interviews with female victims, Kirkman (2005) aimed to identify the behavioural and personality characteristics of nonincarcerated psychopathic males who may or may 
not have abused their partners. Kirkman recruited nonaccomplice females who were partnered with psychopaths by an advertisement describing Jon Lindsay of the acclaimed British soap opera, Coronation Street. Lindsay, a fictional character who had a woman imprisoned for his fraudulent activities, had psychopathic traits such as superficial charm and deceitfulness. The participants were invited to provide written accounts of their experiences with suspected psychopathic male partners to the researcher. Twenty women in the experimental group rated their partners as high in psychopathic traits on the $\mathrm{P}-$ SCAN (Hare \& Hervé, 1999), a 90-item scale designed to screen for psychopathy in nonclinical situations. During the screening process, women who were considered vulnerable and not competent to provide informed consent, such as substance abusers and others who had mental disorders, were eliminated. One hundred women from a local mall whose partners they had scored as low in psychopathy on the same scale served as a basis for P-SCAN norms and as a control group.

The narrative data and interview transcripts were subjected to a thematic analysis. A theme was defined as experiences recorded by half of the women who formed the experimental group. P-SCAN scores were compared and the experimental group rated their partners as significantly more psychopathic than the control group. Three themes were extracted from the biographical narrative data: superficial charm/high intelligence, pathological lying, and antisocial pursuit of power. Charm and intelligence were identified as characteristics that originally made the psychopaths look attractive. Both traits were also perceived as tools used by the psychopath to manipulate the women and significant people in their lives into believing that despite their shortcomings, they were still trustworthy. Psychopaths provided aliases and false details about themselves (i.e., 
home addresses, marital/relationship status, employment history, financial positions). Additionally, the psychopaths committed fraud, cons, and theft. Controlling behaviour, domestic violence, imprisonment, destruction of belongings, and restricted access to food and/or money were also documented. Eight characteristics of male psychopaths in heterosexual relationships were also extracted from the interviews (see Table 2).

Kirkman's study has several advantages and disadvantages. One advantage is that the study, in comparison to the available qualitative research, is more representative of the population of victims of male psychopaths in heterosexual relationships. Common experiences across participants who were in intimate relationships with psychopathic partners, as documented in the aforementioned data summaries and in Table 2, were able to be extracted. Therefore, Kirkman's study provides a more detailed overview of the relationship dynamics between male psychopaths and their intimate female partner victims. Generalizability of the results in Kirkman's study is stronger than the case studies, but only for victims of heterosexual male psychopaths. Secondly, due to its partially empirical nature, Kirkman's study can be easily replicated, unlike the brief anecdotes and case studies which are unique to the sole participants involved. Thirdly, an empirically validated measurement tool, the P-SCAN, was utilized to measure psychopathic traits, allowing for improved validity over psychopathy assessments or clinical judgments used in the qualitative research, of which is either not acknowledged or solely based on descriptive data. However, some limitations remain. For example, the sample size in the Kirkman study is still relatively low, so statistical power is weak and consequently, results found may be questionable. The experiences documented may or may not apply to a larger sample. Secondly, the Kirkman study only focuses on 
heterosexual relationships and on experiences based on the female victims' perspectives.

This means that the experiences documented can only be generalized to similar victims.

Table 2

Common Characteristics of Male Psychopaths in Heterosexual Relationships Extracted from Participants' Interview Responses in the Kirkman (2005) Study

\begin{tabular}{|c|c|}
\hline Characteristic & Examples \\
\hline Talking victim into victimization & $\begin{array}{l}\text { Used charm; initiated rapid progression of } \\
\text { relationships (i.e., immediate co-habitation) }\end{array}$ \\
\hline Lying & $\begin{array}{l}\text { Used false identities including positions of } \\
\text { authority (i.e., police) }\end{array}$ \\
\hline Economic abuse & $\begin{array}{l}\text { Took advantage of women for money and } \\
\text { living costs; misused names and/or bank } \\
\text { accounts; properties sold without women's } \\
\text { permissions }\end{array}$ \\
\hline Emotional abuse / psychological torture & $\begin{array}{l}\text { Taunts, punishment, humiliation, threats, } \\
\text { property damage, accused victim of } \\
\text { insanity, controlled eating / sleeping, } \\
\text { invaded privacy, character assassination, } \\
\text { emotional withholding, sexual harassment }\end{array}$ \\
\hline Multiple infidelities & $\begin{array}{l}100 \text { extra women among } 20 \text { participants' } \\
\text { partners; particularly those in close } \\
\text { relationships with the participants (i.e., } \\
\text { close friends, relatives, colleagues, } \\
\text { neighbours) }\end{array}$ \\
\hline Isolation and coercion & $\begin{array}{l}\text { Social support networks damaged, } \\
\text { geographical isolation, limited access to } \\
\text { outside world by force (i.e., locked in } \\
\text { houses) }\end{array}$ \\
\hline Assault & Physical assault, sexual assault, rape \\
\hline Mistreatment of children & Used children in arguments, abuse \\
\hline
\end{tabular}




\section{Psychological Consequences}

Although very little is known about victimization by psychopaths, two sources (Brown \& Leedom, 2008; Clarke, 2007) summarize some of the physiological and psychological effects of being involved with a psychopath. For example, survivors of psychopaths experience anxiety and stress symptoms such as insomnia, fast heartrate, fear, panic attacks, headaches, hyperventilation, concentration problems, migraines, pain in muscles and/or joints, and ulcers. Some contracted sexually transmitted diseases. Depression symptomatology such as disruption of sleeping patterns, cognitive difficulties, lack of interest in pleasurable activities, weight issues, irritability, feelings of hopelessness, and suicidal thoughts are also not uncommon. Other consequences include dissociation, emotional numbness, obsessive compulsive disorder, trust issues and problems with interpersonal relationships. McCormick and Trent (2007) confirm that victims of psychopaths experience many of these symptoms, but adds severe mood swings to the list of possible consequences. Although the experiences of survivors of psychopaths may be considered similar to victims of crime, a distinct element is deception and how this influences their physical and psychological functioning.

\section{Purpose of Current Study}

In order to gain a better understanding of survivors' involvement with a psychopath, the current study is designed to document their victimization experiences, coping strategies, and social support. Research questions consist of the following:

(a) What are the common experiences and effects of victimization by psychopaths?

(b) Which factors predict psychological distress in survivors of psychopaths? 
(c) What is the nature of the relationship between psychopathy severity, coping, social support, and psychological distress of survivors of psychopaths?

Hypotheses

Symptoms

Hypothesis 1. Survivors of psychopaths will describe a wide variety of cognitive, biological, behavioural, emotional, and interpersonal effects, similar to what has been reported in the crime victimization literature.

Hypothesis 2. Current victims will rate higher on measures of posttraumatic stress disorder and depression than past survivors.

Deception

A general shortcut versus delayed deception psychopath-victim interaction model (see Figure 1) has been constructed. The shortcut path involves psychopaths who at first encounter immediately threatens, forces or coerces victims, which shatters humans' basic assumption of other people as good, and results in psychological distress. On the other hand, psychopaths on the delayed path tend to engage in impression management (i.e., displaying seemingly positive qualities such as charm and intelligence which may be enhanced by intriguing visual gestures or verbal comments) first. However, over time, such traits will be revealed as manipulative tactics in order to impress victims, which will affect their mental health and interpersonal relationships with others (i.e., significant problems with trusting others), and the cycle will continue. 


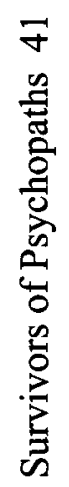

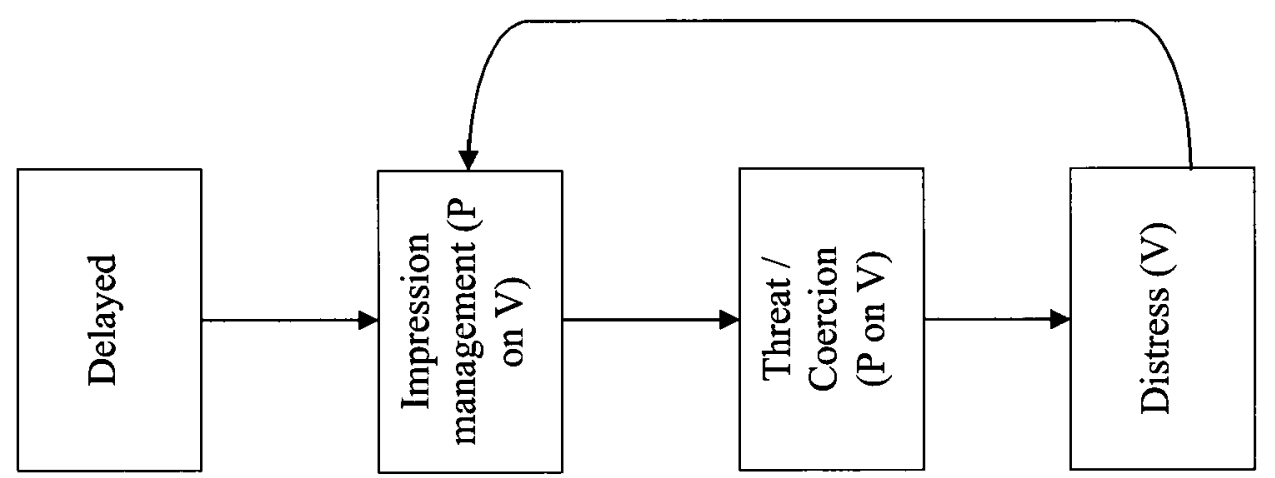

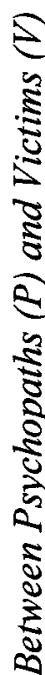

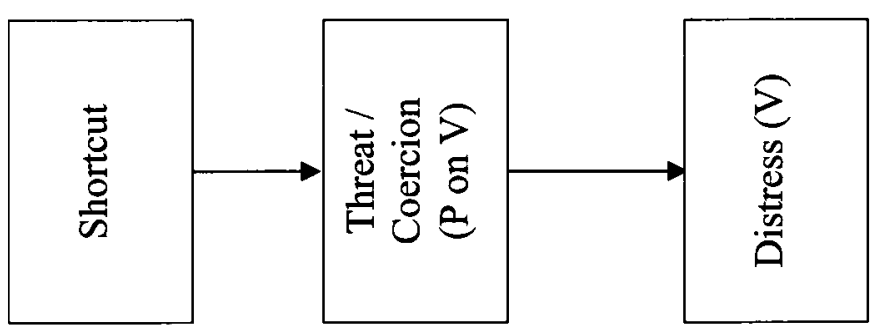


Hypothesis 3. Psychopaths who take the shortcut path will likely be strangers, neighbours, acquaintances, or roommates involved with victims on an isolated basis (i.e., one-time or few encounters). On the other hand, psychopaths who take the delayed deception pathway will be more likely involved on a repeated or chronic basis (i.e., several or frequent encounters) with victims in closer relationships (i.e., friendships, intimate connections, or business partnerships).

Hypothesis 4. Victims who express thoughts, emotions, and feelings about psychopaths' behaviours will receive either deceptive affective responses, such as fake empathy, or no acknowledgement whatsoever.

Hypothesis 5. Shortcut path psychopaths will rate higher on Affective, Social Deviance, and Antisocial Lifestyle facets, whereas delayed path psychopaths will score higher on Interpersonal facets.

\section{Distress Predictors}

Hypothesis 6. Victim-offender relationship will have an impact on distress. Victims in closer relationships with the psychopaths will have more PTSD and depression symptomatology than if victimized by strangers, neighbours, room-mates, or acquaintances.

Hypothesis 7. Frequency of exposure to psychopaths will have an impact on distress. Victims who had isolated encounters with psychopaths will be less likely to experience more PTSD and depression than survivors who had chronic or repeated exposure. 
Hypothesis 8 . Physical injury severity will have an impact on distress. Increases in physical injury severity will be associated with more PTSD and depression symptoms for survivors of psychopaths.

Hypothesis 9. Type of crime will have an impact on distress. Survivors of physically violent crimes will experience more PTSD and depression symptomatology than victims of nonphysically violent actions.

Relationships Between Psychopathy Severity, Coping, Social Support, and Distress

A series of hypotheses (structurally modeled in Figure 2) regarding the relationships between primary variables were generated, based on the available research literature:

(a) Psychopathy severity will be associated with more distress.

(b) Psychopathy severity will be associated with less social support.

(c) Use of problem-focused coping will be associated with less distress.

(d) Use of emotion-focused coping will be associated with more distress.

(e) Use of avoidance-focused coping will be associated with more distress.

(f) Problem-focused coping will be positively related to social support.

(g) Emotion-focused coping will be negatively related to social support.

(h) Avoidance-focused coping will be negatively related to social support.

(i) Social support will be negatively related to distress. 


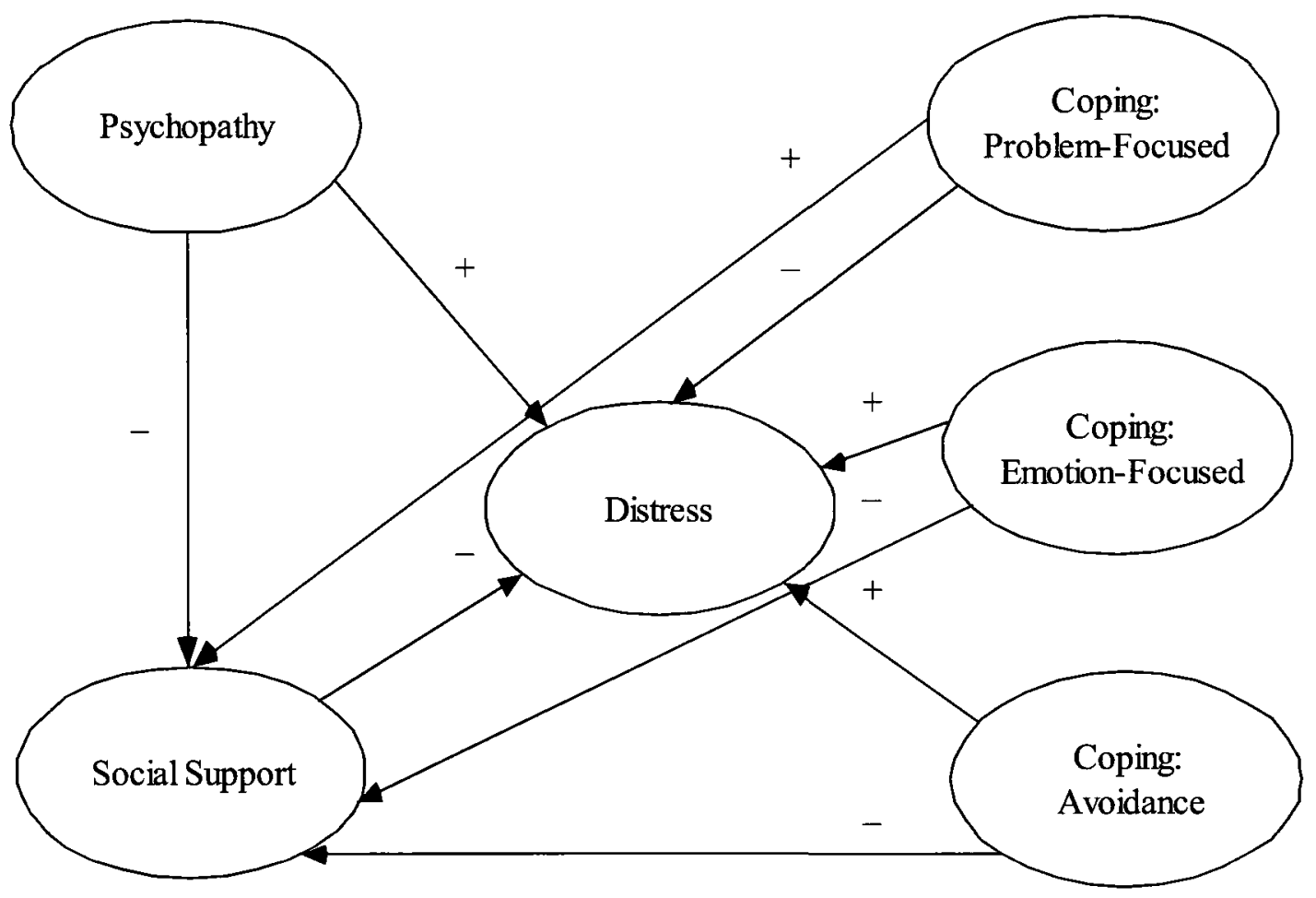

Figure 2

Hypothesized Structural Model of the Relationships Between Psychopathy, Problem-,

Emotion-, and Avoidance-Focused Coping, Social Support, and Distress, for Survivors of Psychopaths 
Method

\section{Participants}

Demographics. Participants were English-speaking males $(n=75,11.96 \%)$ and females $(n=552,88.03 \%)$ between the ages of 18 and $71(N=627, M=44.93, S D=$ 9.66) with Internet access and some degree of computer literacy, who were involved with a psychopath before or during their participation. Involvement was defined as exposure to or interaction, not necessarily intimate, with a psychopath for any period of time.

Participants were involved with male $(n=530,84.55 \%)$ and female $(n=97,15.45 \%)$

psychopaths. Table 3 represents the ethnicity or race of the participants and the psychopaths whom they were involved with. Caucasians made up the majority of both groups, but there were small percentages of people from other ethnic or backgrounds. The "Other" category included nonspecified identifications or mixed ethnic or racial identifications such as Pacific Islander or African-European.

Table 3

Ethnicity or Race of Survivors and Psychopaths

\begin{tabular}{lcccccc}
\hline & \multicolumn{2}{c}{ Survivors $(N=627)$} & & \multicolumn{2}{c}{ Psychopaths $(N=627)$} \\
\cline { 2 - 3 } \cline { 5 - 6 } Ethnicity or race & $n$ & Percent & & & $n$ & Percent \\
\hline Caucasian & 544 & 86.76 & & & 492 & 78.47 \\
African-American & 21 & 3.35 & & & 32 & 5.10 \\
Asian & 16 & 2.55 & & & 19 & 3.03 \\
Hispanic & 8 & 1.28 & & & 22 & 3.51 \\
Aboriginal & 2 & 0.32 & & & 0 & 0.00 \\
Other (i.e., mixed) & 36 & 5.74 & & & 62 & 9.89 \\
\hline
\end{tabular}


Participants were more likely to be from North America, full-time workers, employed in service / support, and have university as their highest degree of education completed (see Table 4). Many participants $(N=627)$ rated themselves as middle class (i.e., can afford basic needs, have some extra resources; $n=479,76.40 \%$ ), followed by upper (i.e., can afford well beyond basic needs, have many extra resources, ability to live luxurious lifestyle if desired; $n=78,12.44 \%$ ) then lower (i.e., below the poverty line, struggling with basic needs such as food, shelter, and medical care; $n=70,11.16 \%$ ) class. A significant majority of participants were referred to the study through Love Fraud (refer to Table 5). A wide variety of motives for participation in the study were reported in open-ended responses. Key themes included simply telling their stories, acquiring an understanding of victimization and/or psychopathy, education and awareness, redemption, curiosity about the study and its results, helping people, recovery, validation of experiences, evaluating psychopathic traits in others, and fascination with psychopathy (see Table 6). Many participants covered several of these themes. 
Table 4

Location, Employment, and Education Status of Survivors of Psychopaths

\begin{tabular}{|c|c|c|}
\hline Demographic variable & $n$ & Percent \\
\hline \multicolumn{3}{|l|}{ Location $(N=627)$} \\
\hline Canada & 57 & 9.09 \\
\hline United States & 458 & 73.05 \\
\hline Europe (UK) & 42 & 6.70 \\
\hline Europe (non-UK) & 26 & 4.15 \\
\hline Other (i.e., Australia, Asia) & 44 & 7.02 \\
\hline \multicolumn{3}{|l|}{ Employment status $(N=621)$} \\
\hline Not employed (not looking) & 73 & 11.76 \\
\hline Not employed (looking) & 60 & 9.66 \\
\hline Part-time & 79 & 12.72 \\
\hline Full-time & 348 & 56.04 \\
\hline Seasonal or contract & 33 & 5.31 \\
\hline Retired & 28 & 4.51 \\
\hline \multicolumn{3}{|l|}{ Occupational background $(N=627)$} \\
\hline Information technology / Computing & 72 & 11.48 \\
\hline Service / Support & 145 & 23.13 \\
\hline Engineering / Science & 23 & 3.67 \\
\hline Medical / Government & 108 & 17.22 \\
\hline Student & 36 & 5.74 \\
\hline Other (i.e., media, finance, education) & 243 & 38.76 \\
\hline \multicolumn{3}{|l|}{ Education $(N=624)$} \\
\hline Elementary school & 2 & 0.32 \\
\hline Secondary school & 91 & 14.58 \\
\hline Community college & 125 & 20.03 \\
\hline Technical or trade school & 55 & 8.81 \\
\hline University & 207 & 33.17 \\
\hline Graduate school & 144 & 23.08 \\
\hline
\end{tabular}




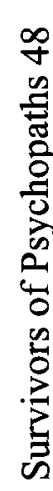

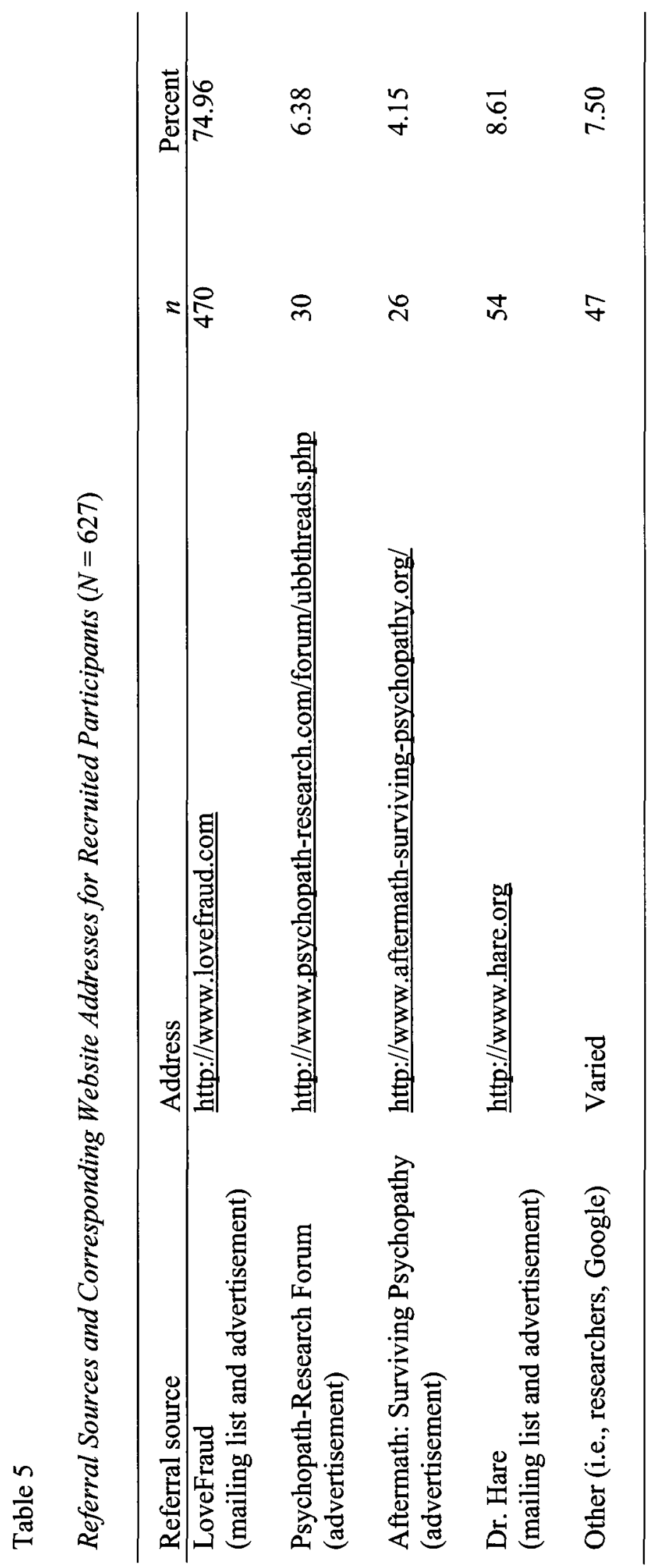


Table 6

Participants' Motives for Participation and Descriptive Examples

\begin{tabular}{|c|c|}
\hline Motive & Examples \\
\hline Storytelling & $\begin{array}{l}\text { "For over a year my ex has been stalking me and the } \\
\text { people around me she knew...posted pictures and photo } \\
\text { shopped them... opened blogs and craigslist } \\
\text { postings...impersonated us online in websites, and } \\
\text { forums... been maintaining her smear campaign for a } \\
\text { while now..." }\end{array}$ \\
\hline Understanding victimization & $\begin{array}{l}\text { "I am hoping to learn more about my situation by } \\
\text { answering your questions." }\end{array}$ \\
\hline Understanding psychopathy & $\begin{array}{l}\text { "Interested in learning as much as possible about what } \\
\text { makes individuals like this so "successful" (in conning } \\
\text { others)." }\end{array}$ \\
\hline Education and awareness & $\begin{array}{l}\text { "Humanity needs to know what sociopathy is, how it } \\
\text { behaves, how it thinks and the harm it can do if left } \\
\text { uncensored and undetected." }\end{array}$ \\
\hline Redemption & "I despise my former son-in-law." \\
\hline Curiosity & "Just to see what the outcome would be..." \\
\hline Helping others & $\begin{array}{l}\text { "If by completing this questionnaire I can throw some } \\
\text { light on it, and perhaps protect others from its } \\
\text { insidiousness, then I would feel I have done a little of my } \\
\text { part toward honouring my fellow man." }\end{array}$ \\
\hline Recovery & "To help me work through my feelings..." \\
\hline Validation & $\begin{array}{l}\text { "...interest in seeing if survey inspired feelings of } \\
\text { familiarity with regard to experience..." }\end{array}$ \\
\hline Evaluation & "Determining if my husband is a psychopath" \\
\hline Fascination & $\begin{array}{l}\text { "... since then I have read a lot of the research on } \\
\text { psychopathy and find it very interesting." }\end{array}$ \\
\hline Other & $\begin{array}{l}\text { "Also, for a more "real" portrait of psychopathy and not } \\
\text { as it is portrayed in movies or TV." }\end{array}$ \\
\hline
\end{tabular}




\section{Materials}

Informed consent form. The informed consent form, included in Appendix A, provided information about the study and research personnel involved. Protection of survivors' identities were essential, especially due to the sensitive nature of involvement with a psychopath, therefore participants checked a box to indicate their agreement to participate in the study instead of providing real names or pseudonyms.

Self-Report Psychopathy scale-III. The Self-Report Psychopathy scale-III (SRPIII; Paulhus, Hemphill, \& Hare, in press) is a 64-item dimensional inventory which measures psychopathic traits in general populations (see Appendix B). On a 5-point Likert scale $(1=$ disagree strongly, $2=$ disagree, $3=$ neutral, $4=$ agree, $5=$ agree strongly), people rate the extent to which they agree or disagree about each statement in reference to themselves. However, for the current study, all statements were modified from first person to third person to allow ratings by survivors, who are external observers, and a "don't know" $(0)$ option was added since some items required intimate familiarity with perpetrators. Participants who had encounters with more than one psychopath were asked to choose the most recent. There are 16 statements per subscale: Interpersonal Manipulation (IPM; i.e., "I purposefully flatter people to get them on my side"), Callous Affect (CA; i.e., "People say that I'm cold-hearted"), Erratic Lifestyle (ELS; i.e., "I like to have sex with people I barely know"), and Criminal Tendencies (CT; i.e., "I have tricked someone into giving me money"). Final scores for each subscale range from 16 to 80 , and total possible values run from 64 to 320 . Although there are no diagnostic cutoffs for psychopathy on the SRP-III, higher scores suggest the presence of psychopathic 
traits. For the purpose of the current study, low (1-127), medium (128-255), and high (256-320) SRP-III scores were designated for corresponding psychopathy severity.

Overall, the SRP-III demonstrates good reliability and validity (Paulhus et al., in press; Williams, Nathanson, \& Paulhus, 2003; Williams, Paulhus, \& Hare, 2007). In Paulhus and colleagues' original sample based on 194 undergraduate students, high internal consistency coefficients were achieved: IPM $(\alpha=.81), \operatorname{CA}(\alpha=.79), \operatorname{ELS}(\alpha=$ $.74)$, CT $(\alpha=.82)$, and overall SRP-III $(\alpha=.81)$. The SRP-III demonstrates good predictive validity as higher scores indicate a greater likelihood of a variety of antisocial behaviours and attitudes, including bullying $(r=.37)$, drug use $(r=.24)$, criminal actions $(r=.27)$, and anti-authority $(r=.29)$. Convergent validity for the SRP-III is strong, due to the moderate positive correlations, ranging from $r=.34$ to $r=.62$, with other selfreport psychopathy scales. More specifically, the SRP-III adequately measures subclinical psychopathy, without duplicating other assessments. Furthermore, the SRPIII illustrates good construct validity through its positive correlations with narcissism $(r=$ $.46)$ and Machiavellianism $(r=.58)$, two separate sets of traits that can overlap with psychopathy. Narcissism is characterized by grandiosity, egocentricity, and an exaggerated sense of self-importance, whereas Machiavellian personalities tend to manipulate others and possess extreme cynical attitudes. Williams et al. (2007) found that the four factor structure represented by the subscales achieved moderate to strong convergent and construct validity with other psychopathy scales (i.e., PPI, at $r=.60$ ) and similar personality traits (i.e., narcissism at $r=.46$ and Machiavelliannism at $r=.48$ ) in a sample of university students $(N=274)$. Correlations between psychopathy and offensive 
behaviour (i.e., misconduct, interest in aggressive, violent, and antisocial media) were also found.

Questionnaire protocol. The questionnaire protocol (refer to Appendix C) consisted of three components: (a) basic demographics, (b) relationship and experience, and (c) open-ended inquiries about experiences with deception with the most recent psychopath in respective participants' lives. Brief instructions were provided for each component. Participants were also informed that they could leave answers to any questions blank if they prefered not to disclose any information, or to mark them as $\mathrm{N} / \mathrm{A}$ (not applicable) in appropriate cases. The demographics questions revolved around age, gender, race/ethnicity, location, employment status and background, highest level of education, and socioeconomic status of the victim. Questions about the psychopath's gender and race/ethnicity were also asked. Furthermore, participants were asked to indicate the source of their referral to the study and motivations for participation. In the second component, participants were given questions, generally with corresponding rating scales, about their relationship, recency and duration of involvement, level of exposure, most serious degree of injury, type of victimization, and perceived impact of the psychopath on their life, including their physical and mental health. Participants were divided into current (i.e., still involved) and past (i.e., no longer involved) survivors according to their answers to whether or not they were still in contact with the psychopath. The open-ended questions in the final section of the questionnaire protocol primarily derived from research and the current study's hypotheses on psychopathy and deception. Participants were asked to use pseudonyms or general statements (i.e., I met the psychopath at an university versus I met the psychopath at the University of [City]] to 
ensure further anonymity. Inquiries included questions about occurrences at initial encounters, first impressions, subsequent encounters, worrisome or unusual behaviours and attempts to explain them, believability of explanations for troublesome actions, deception, feelings about deceitfulness, and psychopaths' responses to survivors' concerns about them.

Impact of Event Scale-Revised. Based on DSM-IV criteria for PTSD, the Impact of Event Scale-Revised (IES-R; Weiss \& Marmar, 1997) is a self-report scale for assessing situation-specific posttraumatic stress symptomatology (refer to Appendix D). The IES-R has 22 items covering intrusion ( 8 items; i.e., "Any reminder brought back feelings about it"), avoidance ( 8 items; i.e., "I tried not to think about it"), and hyperarousal (6 items; i.e., "I was jumpy and easily startled") symptoms. Respondents rated each item according to the degree of distress it caused since their last contact with the most recent psychopath in their life on a 5-point Likert Scale $(0=$ not at all, $1=a$ little bit, $2=$ moderately, $3=$ quite a bit, $4=$ extremely). The mean item response to each subscale, ranging from 0 to 4 , is calculated, therefore, total possible scores can be from 0 to 12. No diagnostic cutoffs for PTSD were intended for the IES-R, however, higher scores indicate greater symptomatology. According to Weiss (2004), normative data has not been presented for the IES-R since its conception, because of the complexity of PTSD (i.e., symptomatic status in reference to a specific event that is not fixed in time, normative groups do not translate to PTSD measures, varied clinical diagnoses).

The IES-R is widely used, especially as it has sound psychometric properties. The original validation samples consisted of emergency personnel working with freeway collapse (Time $1 N=429$, Time $2 N=317$ ) and earthquake (Time $1 N=197$, Time $2 N=$ 
175) victims (Weiss \& Marmar, 1997). High internal consistency was found for these samples: intrusion ( $\alpha=.87$ to $\alpha=.92$ ), avoidance $(\alpha=.84$ to $\alpha=.85$ ), and hyperarousal $(\alpha=.79$ to $\alpha=.90$ ). Test-retest reliability coefficients ranged from moderate (intrusion $\alpha$ $=.57$, avoidance $\alpha=.51$, hyperarousal $\alpha=.59$ ) for the freeway collapse emergency personnel sample to very high in the earthquake workers sample (intrusion $\alpha=.94$, avoidance $\alpha=.89$, hyperarousal $\alpha=.92$ ). All subscales show good predictive validity. Hyperarousal subscales on the IES-R are good predictors of trauma (Briere, 1997). Intrusion and avoidance subscales can detect response differences between events of various trauma severity and signify changes in respondents' clinical status (Horowitz, Wilner, \& Alvarez, 1979; Weiss \& Marmar, 1997). Convergent validity has been demonstrated across many studies by comparing the IES-R and its subscales with other PTSD assessments. Correlations of the IES-R's subscales with other PTSD test instruments range from $r=.53$ to $r=.84$ (Creamer, Bell, \& Failla, 2003; Weiss, 2004).

Beck Depression Inventory-II. The Beck Depression Inventory-II (BDI-II; Beck, Steer, \& Brown, 1996), in Appendix E, is a self-report measure of depressive symptomatology in psychiatric and nonpsychiatric populations. The 21 items on the BDI-II, which parallel DSM-IV criteria, include symptoms such as negative feelings about oneself (i.e., failure, guilt, worthlessness, and self-hatred), physical changes (i.e., disruptions in sleeping patterns and appetite), mood indicators (i.e., agitation and extreme sadness), cognitive difficulties (i.e., concentration problems), and reduced pleasure (i.e., loss of interest in sex). Respondents rated the severity of symptoms during the last point of contact with the most recent psychopath in their life. Each item uses a 4-point scale ranging from 0 to 3 with corresponding symptom descriptors increasing in severity. Total 
BDI-II scores, calculated by summing the highest ratings for each item, can range from 0 to 63. Depression is categorized in terms of minimal (0-13), mild (14-19), moderate (2028), and severe (29-63) intensity. However, one item, which addresses suicidal ideation, will be eliminated from the BDI-II in order to circumvent the difficult need for intervention on an anonymous and international web-based survey. Therefore, criteria for minimal (0-10), mild (11-16), moderate (17-25), and severe (26-60) depression were prorated.

The BDI-II has consistently demonstrated high reliability and validity across various populations. High internal consistency coefficients were found for the pilot sample of college students $(N=120, \alpha=.93)$ and psychiatric outpatients $(N=500, \alpha=$ .92) recruited by Beck et al. (1996). The overall BDI consistency $(\alpha=.91)$ is also high (Beck, Steer, Ball, \& Ranieri, 1996). As reported in Dozois, Dobson, and Ahnberg (1998), and Steer, Ball, Ranieri, and Beck (1997), strong convergent validity is demonstrated by the correlation between the BDI-II and its predecessor $(r=.93)$, as well as other depression inventories $(r=.71)$.

Other effects. The open-ended questions, "If you experienced other physical and / or mental health symptoms not possibly mentioned in either of the two scales (IES-R and BDI-II) you just filled out, what were they?" and "How has your involvement with a psychopath affected your relationships with others?" (see Appendix F) were asked in order to gain an idea of other effects of involvement with a psychopath.

Brief COPE. Carver (1997) developed the Brief COPE (illustrated in Appendix G), a 28-item self-report instrument by integrating a wide variety of coping behaviours reported in the literature. Table 7 portrays examples of items for each coping type 
(problem-, emotion-, and avoidance-focused) on the Brief COPE and the subscales which comprise them.

Table 7

Examples of Items for Each Coping Strategy on the Brief COPE and Corresponding Subscales

\begin{tabular}{|c|c|}
\hline Coping strategy & Examples - "I've been..." \\
\hline \multicolumn{2}{|l|}{ Problem-focused } \\
\hline Active coping & trying to take action to make the situation better \\
\hline Planning & trying to come up with a strategy about what to do \\
\hline Seeking tangible support & getting help and advice from other people \\
\hline \multicolumn{2}{|l|}{ Emotion-focused } \\
\hline Seeking emotional support & getting emotional support from others \\
\hline Positive reframing & looking for something good in what is happening \\
\hline Acceptance & learning to live with it \\
\hline Turning to religion & praying or meditating \\
\hline Substance use & using alcohol / other drugs to help me get through it \\
\hline Self-blame & criticizing myself \\
\hline Venting & expressing my negative feelings \\
\hline Humour & making jokes about it \\
\hline \multicolumn{2}{|l|}{ Avoidance-focused } \\
\hline Denial & refusing to believe that it has happened \\
\hline Self-distraction & turning to activities to take my mind off things \\
\hline Behavioural disengagement & giving up the attempt to cope \\
\hline
\end{tabular}

Participants rated the extent to which they have been doing each coping strategy on a 4-point Likert scale $(1=$ not at all, $2=$ a little bit, $3=$ a medium amount, $4=$ a lot $)$. For the purpose of the current study, participants rated the frequency of engagement in each strategy since they were last involved with the most recent psychopath in their life. There are no overall coping scores for the Brief COPE, but summing items for each 
subscale gives a picture of frequency of usage for the respective problem-, emotion-, and avoidance-focused coping strategy. The following is the range of total possible values for the type of coping strategies: problem- (24), emotion- (64), and avoidance-oriented (24). The Brief COPE can be modified to be either situation-specific or dispositional, the former of which was more suitable for the current study. The instructions stated that participants were to rate each item with regards to involvement with a psychopath.

The initial sample was comprised of community residents who were recovering from Hurricane Andrew. Participants were assessed at 3-6 $(N=168), 9-12(N=124)$ months, and 1 year $(N=126)$ after the hurricane. All subscales had moderate to high internal consistency coefficients averaged over the three time periods, ranging from $\alpha$ $=.54$ to $\alpha=.90$. Although no validity information was provided in the pilot study, the Brief COPE's predecessor was reported to have achieved acceptable convergent and divergent validity, particularly for situation-specific formats (Carver, Scheier, \& Weintraub, 1989).

Perceived Support Scale. The Perceived Support Scale (PSS), shown in Appendix $H$, was specifically designed by Kaniasty (1988) for assessing the perceived availability of social support for victims of crime. Perceived support is measured in general, and not necessarily related to criminal victimization. The PSS includes 3 items each representing perceived tangible (i.e., "If I were sick and needed someone to take me to the doctor, I would have trouble finding someone"), emotional (i.e., "There is no one that I feel comfortable talking to about intimate personal problems"), or informational (i.e., "There is someone I can turn to for advice about handling problems with my family") social support, for a total of twelve. Participants answered each item using a 4-point Likert scale 
$(1=$ definitely false, 2 = probably false, $3=$ probably true, $4=$ definitely true $)$. The range of possible values for each subscale is 4 to 16 , and for overall, 12 to 48 . Higher scores indicate greater perceived social support.

The PSS items were based on the Interpersonal Support Evaluation List (ISEL; Cohen \& Hoberman, 1983). Items which were particularly relevant to victims of crime, and which paralleled tangible, emotional, and informational support were chosen. The ISEL has been reported to have moderate to strong psychometric characteristics, and is particularly sensitive to the stress-buffering properties of social support. Internal consistency coefficients for subscales particularly on the PSS have ranged from $\alpha=.76$ to $\alpha=.83$, with an overall $\alpha=.77$ (Cohen $\&$ Hoberman, 1983; Cohen $\&$ Wills, 1985). Furthermore, the ISEL has a moderate positive correlation $(r=.46)$ with another inventory of social support, suggesting similar adequate convergent validity for the PSS.

Received Support Scale. The Received Support Scale (RSS; Kaniasty, 1988), demonstrated in Appendix I, was also specifically designed for victims of crime. The items on the RSS originated from the highest factor loadings on the Inventory of Socially Supportive Behaviours (ISSB; Barrera, Sandler, \& Ramsey, 1981), and statements relevant to crime victims. The RSS also has 4 items each (12 items total) of which reflect tangible (i.e., "did anyone give, loan, or offer you some money?"), emotional (i.e., "did anyone comfort you by showing you some physical affection?"), and informational (i.e., "did anyone give you some information to help you understand a situation you were in?") support, but the focus is on actual assistance received. Participants used a 4-point Likert scale $(1=$ never, 2 once or twice, $3=$ a few times, $4=$ many times $)$ to report the frequency of each supportive behaviour. Participants were instructed to report the 
frequency from the last time they were in contact with the most recent psychopath in their life to the present. Each subscale has a total range of 4 to 16 , whereas overall scores can be from 12 to 48 . According to Kaniasty and Norris (1992), adequate to high internal consistency coefficients were achieved for all subscales ( $\alpha$ range $=.58-80)$. Furthermore, over a four-week period between the time of a crime and the present, test-retest coefficients remained at a moderate level ( $\alpha$ range $=.45-65)$. Currently, validity has not been examined.

Debriefing form. The debriefing form, presented in Appendix J, provided more details about the purpose of the study, resources for more information on victims of psychopaths, contact details, Internet security instructions, and how to obtain brief reports of the final results if interested.

\section{Design and Procedure}

The research proposal for the current study was submitted and accepted by Carleton University's psychology department ethics committee. The study's website, (https://www.surveymonkey.com/s.aspx?sm=tkKgwTr 2fZ4Ehy4i 2b0h6ngQ 3d 3d) was advertised in online venues dedicated either to the scientific study of psychopathy or support for survivors of psychopaths (refer to Table 5 for details). All online groups were acknowledged on Dr. Hare's site, which suggests a likelihood of inclination towards seriousness rather than sensationalism. Contact was made with the owners and maintainers of the aforementioned venues to provide information about the current research and to request permission to post a link on their respective websites for the duration of the study (see Appendix $\mathrm{K}$ for initial correspondence template), between November $1^{\text {st }}, 2008$ and December $31^{\text {st }}, 2008$. Furthermore, since some psychopathy 
researchers may have come into contact with survivors, an e-mail (see Appendix L) asking for the web link to the current study to be passed on was sent to members of the Society for the Scientific Study of Psychopathy. The informed consent form was attached to all e-mail correspondences to allow recipients a chance to familiarize themselves with the study. Although the advertisements, presented in Appendices $\mathrm{M}$ to $\mathrm{P}$, were different in style, basic information about the researcher and study were included in each of them. People who suspected or knew that they dealt with a psychopath went to the website from Internet-accessible locations at their own convenience, and either viewed, partially completed, finished, or opted out of the survey. The survey in its entirety took approximately an hour to complete. Participants were informed that they could e-mail the researcher with an anonymous e-mail with "want psurvivorstudy results" in the subject line to indicate an interest in receiving a brief summary (see Appendix Q). Additionally, for more psychologically- and statistically-minded participants and other individuals interested in the study's outcomes, a poster in PowerPoint format was attached to the summary (details can be found at Pagliaro \& Forth, 2009). No compensation was provided for participation.

\section{Results}

\section{Data Treatment}

First of all, complete missing data across all variables, which illustrates viewing the survey rather than participation, were eliminated from the final data. Many active participants $(N=703)$ remained after this procedure. Secondly, missing values for individual SRP-III scores were replaced with a 0 for unknown. The rationale for these substitutions were that it was likely that the SRP-III, a self-report scale, contained items 
which survivors may have been unfamiliar with as observers of the psychopaths. Thirdly, cases with extremely low scores on the SRP-III, defined as between 0 and 127 , were also eliminated. Limited familiarity with test items may explain these low scores, and doesn't necessarily indicate a lack of psychopathic traits. Additionally, as shown by responses to motives for participation, some participants filled out the survey to determine whether or not an individual they were assessing was psychopathic. Furthermore, labeling individuals as psychopathic has strong implications in society. This selection procedure also ensures that analyses were focused on participants who were involved with individuals who were at least moderate in psychopathy, not to undermine its original dimensionality-based scoring or to invalidate survivors' experiences.

After elimination of low psychopathy scores, 643 cases remained, which accounted for $75 \%$ of total participants and viewers of the study. Missing values for distress, coping, and social support variables for each case were substituted with subscale (if applicable) or total means. Between 490 and 643 participants provided responses for various study variables, comprising $76-100 \%$ of selected cases (i.e., moderate to severe in psychopathy) and $57-75 \%$ of participants and viewers combined. Missing Value Analyses (MVAs) were conducted for each hypothesis' set of variables. Where data was missing completely at random as indicated by the non-significance of the Little's MCAR test, listwise deletion which SPSS performs by default was considered appropriate. One noticeable and consistent feature of the complete data set upon exploration was the existence of outliers. Outlier values were transformed to the next lowest or highest nonoutlier scores, thus maintaining their respective ranks within measures and improving the normality of distributions. Unequal group sizes were also not uncommon, so a caveat is 
that this reduced statistical power for corresponding analyses with this assumption violated. Some multivariate distributions slightly deviated from normality (i.e., still within acceptable ranges of plus or minus two skewness and/or kurtosis), but since outliers were handled appropriately and there were large sample sizes for the applicable hypotheses, MANOVA results were robust to such violations. Significance levels were used at $\alpha=.05$ for all hypotheses except where indicated otherwise.

Survivors' Ratings of Psychopathy

Table 8 illustrates the means and standard deviations of survivors' ratings of psychopaths' Callous Affect (CA), Interpersonal Manipulation (IPM), Erratic Lifestyle (ELS), and Criminal Tendencies (CT) by gender. Not surprisingly, male psychopaths scored higher than female psychopaths on all factors. No statistically significant differences were found between males and females on IPM: $t(625)=1.06, n s$, or CA: $t(625)=1.62, n s$. On the other hand, males scored higher than females for ELS: $t(625)=$ $2.07, p<.05$, CT: $t(625)=2.44, p<.05$, and overall: $t(625)=2.54, p<.05$. As to be expected with a community-based sample, the majority of male and female psychopaths were rated higher by survivors on IPM, whereas CT had the opposite effect of being the lowest. This also rang true when collapsing across gender $(N=643)$ : IPM $(M=62.23, S D$ $=9.61), \mathrm{CA}(M=52.54, S D=10.42), \mathrm{ELS}(M=57.11, S D=16.18), \mathrm{CT}(M=37.63, S D$ $=16.18)$. For total scores, psychopaths were on average moderate in psychopathy $(M=$ 209.51, $S D=34.86)$. 


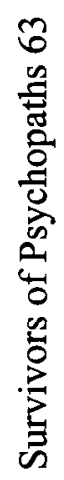

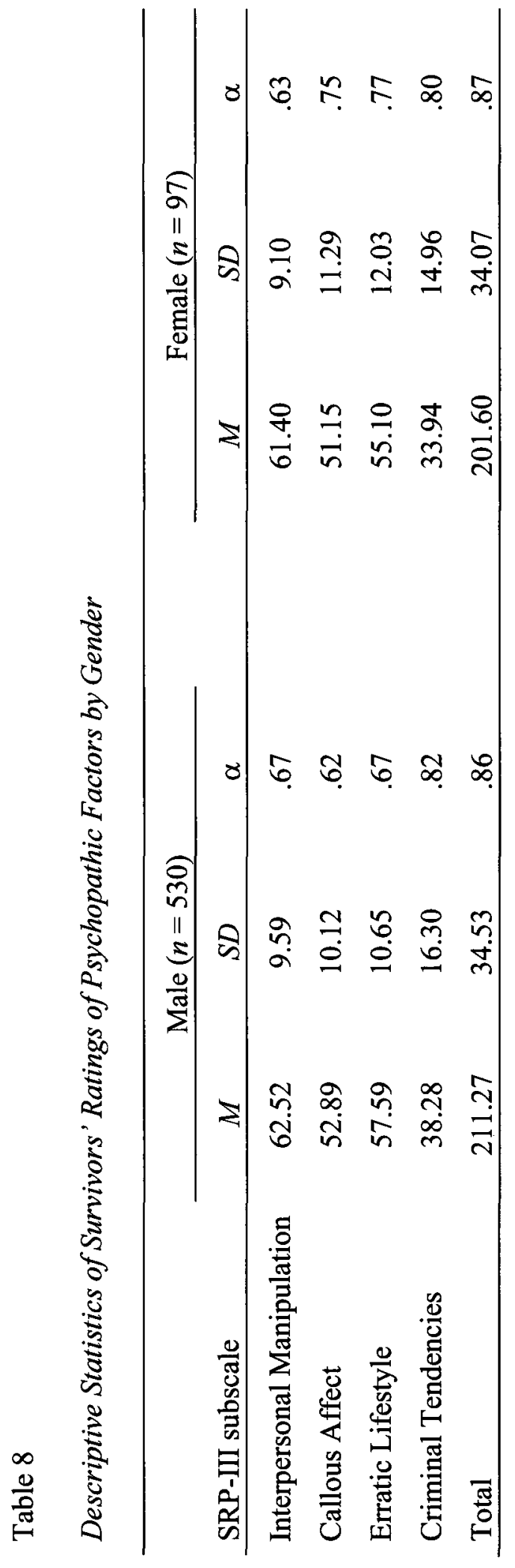




\section{Relationships and Experiences}

Victim-offender relationship. About $75 \%$ of participants were in past or present intimate relationships with the psychopaths (refer to Table 9). Some participants provided descriptions of their simultaneous or concurrent multiple roles, such as coworker and lover or friend and employer. Other relationships included patients or therapists, private investigators, significant others of partner's employers, students, etc.

Table 9

Relationships of Survivors $(N=623)$ to Psychopaths

\begin{tabular}{lcc}
\hline Relationship & $n$ & Percent \\
\hline Stranger & 5 & 0.80 \\
Neighbour & 3 & 0.48 \\
Acquaintance & 12 & 1.93 \\
Room-mate & 2 & 0.32 \\
Friend & 22 & 3.53 \\
Significant other & 229 & 36.76 \\
Ex-significant other & 239 & 38.36 \\
Employer & 7 & 1.12 \\
Employee & 4 & 0.64 \\
Coworker & 3 & 0.48 \\
Family member & 57 & 9.15 \\
Other & 40 & 6.42 \\
\hline
\end{tabular}

Timing of involvement. Of the 619 who reported whether they were currently involved with the psychopath or not at the time of the study, the majority reported past ( $n$ $=476,76.90 \%)$ versus current involvement $(n=143,23.10 \%)$. Participants in current and past relationships were more likely to be involved with psychopaths for a period of between two and five years, as illustrated in Table 10. Most of the participants who were 
involved with psychopaths in the past had only recently stopped contact (i.e., within the last six months since participation in the study), as shown in Table 11.

Exposure. When asked to rate the frequency of their exposure to the psychopath, participants $(N=613)$ mainly reported extreme $(n=500,81.57 \%)$ exposure, followed by moderate $(n=83,13.54 \%)$, mild $(n=22,3.59 \%)$, and rare $(n=8,1.30 \%)$.

Table 10

Duration of Survivors' Past and Current Involvement with Psychopaths

\begin{tabular}{|c|c|c|c|c|}
\hline \multirow[b]{2}{*}{ Duration } & \multicolumn{2}{|c|}{ Past $(N=462)$} & \multicolumn{2}{|c|}{ Current $(N=143)$} \\
\hline & $n$ & Percent & $n$ & Percen \\
\hline Less than 6 months & 32 & 6.93 & 7 & 4.90 \\
\hline 6-12 months & 59 & 12.77 & 9 & 6.29 \\
\hline $1-2$ years & 86 & 18.61 & 9 & 6.29 \\
\hline $2-5$ years & 103 & 22.29 & 40 & 27.97 \\
\hline $5-10$ years & 62 & 13.42 & 28 & 19.58 \\
\hline $10-20$ years & 58 & 12.55 & 32 & 22.38 \\
\hline More than 20 years & 62 & 13.42 & 18 & 12.59 \\
\hline
\end{tabular}

Table 11

Time Lapsed Since Past-Involved Survivors' Last Contact with Psychopaths $(N=440)$

\begin{tabular}{lcc}
\hline Time lapsed since last contact & $n$ & Percent \\
\hline Less than 6 months & 139 & 31.59 \\
6-12 months & 77 & 17.50 \\
1-2 years & 87 & 19.77 \\
2-5 years & 82 & 18.64 \\
5-10 years & 34 & 7.73 \\
10-20 years & 14 & 3.18 \\
More than 20 years & 7 & 1.59 \\
\hline
\end{tabular}


Harm and violence. None to mild harm (i.e., requiring no medical treatment; $n=$ $459,74.03 \%$ ), were more often indicated than moderate (i.e., needing first aid or outpatient medical treatment), and extreme (i.e., hospitalization) abuse $(n=161,25.97 \%)$ when participants $(N=620)$ were asked about the most serious degree of physical injury caused by the psychopaths. In terms of physical violence, participants mostly either experienced no assault, followed by physical abuse, with a small but not insignificant proportion having experienced sexual abuse (refer to Table 12). Emotional violence, financial abuse, and deception were commonly reported by survivors compared to spiritual, substance, and property crimes, also illustrated in Table 12.

Table 12

Type of Physical and Non-physical but Harmful Acts Experienced by Survivors of Psychopaths $(N=643)$

\begin{tabular}{lcc}
\hline Type of violence & $n$ & Percent \\
\hline Physical & & \\
None & 282 & 43.86 \\
Physical & 284 & 44.17 \\
Sexual & 179 & 27.84 \\
Non-physical & & \\
None & 5 & 0.78 \\
Emotional & 607 & 94.40 \\
Spiritual & 358 & 55.68 \\
Financial & 474 & 73.72 \\
Substance & 71 & 11.04 \\
Deceit & 589 & 91.60 \\
Property & 254 & 39.50 \\
\hline
\end{tabular}


Impact on health. Victimization generally had a moderate impact on physical functioning of victims, but extremely affected survivors' mental health according to their ratings (see Table 13).

Table 13

Impact of Victimization on Physical and Mental Health of Survivors of Psychopaths

\begin{tabular}{lccccc}
\hline & \multicolumn{2}{c}{ Physical Health $(N=601)$} & & \multicolumn{2}{c}{ Mental Health $(N=613)$} \\
\cline { 2 - 3 } \cline { 5 - 6 } Degree of impact & $n$ & Percent & & $n$ & Percent \\
\hline Rare & 102 & 16.97 & & 5 & 0.82 \\
Mild & 128 & 21.30 & & 18 & 2.94 \\
Moderate & 213 & 35.44 & & 111 & 18.11 \\
Extreme & 158 & 26.29 & & 479 & 78.14 \\
\hline
\end{tabular}

Psychological Distress

Table 14 explores survivors' ratings of PTSD and depression since the last contact with the psychopaths in their lives.

Table 14

Survivors of Psychopaths' Ratings of PTSD and Depression on the Impact of Event Scale

- Revised (IES-R) and Beck Depression Inventory-II (BDI-II)

\begin{tabular}{lcccc}
\hline Distress scale & $n$ & $M$ & $S D$ & $\alpha$ \\
\hline IES-R & & & & \\
$\quad$ Avoidance & 530 & 2.05 & .82 & .76 \\
$\quad$ Intrusion & 530 & 2.90 & .89 & .89 \\
Hyperarousal & 530 & 2.84 & .98 & .84 \\
$\quad$ Total $(N)$ & 530 & 7.79 & 2.26 & .91 \\
Depression & & & & \\
$\quad$ BDI-II Total $(N)$ & 519 & 21.18 & 12.84 & .94 \\
\hline
\end{tabular}


Since there is no normative data available for the IES-R, eyeballing subscale and total scores suggests placement in a moderate range in comparison to the maximum of 4 and 12 , respectively. Survivors rated themselves as more affected by intrusive and hyperarousal symptoms than avoidance. Survivors also rated themselves as falling into the pro-rated moderate range (17-25) for depression.

\section{Coping}

Survivors used more problem- focused coping strategies compared to emotionand avoidance-oriented techniques when taking into consideration the maximum possible values for each of these subscales - 24, 64, and 24, respectively, on the Brief COPE (see Table 15). In terms of problem-focused strategies, survivors tended to use more active coping and engage in planning than seek tangible support. Emotion-focused coping strategies primarily consisted of acceptance, seeking emotional support, and venting, whereas in comparison, substance use, self-blame, and humour were uncommonly reported. Survivors were more likely to distract themselves from their situations with psychopaths rather than denial or avoid coping altogether.

\section{Social Support}

Table 16 represents descriptive statistics for emotional, tangible, and informational perceived and received support as reported by survivors of psychopaths. Overall, participants perceived themselves as having decent emotional, tangible, and informational perceived support in their day-to-day lives. In terms of actual assistance, tangible support was rather poor compared to emotional and informational help. Total received support was much less than perceived assistance. 
Table 15

Survivors of Psychopaths' Ratings of Coping Strategies on the Brief COPE $(N=505)$

\begin{tabular}{|c|c|c|c|}
\hline Coping strategy & $M$ & $S D$ & $\alpha$ \\
\hline \multicolumn{4}{|l|}{ Problem-focused } \\
\hline Active coping & 6.27 & 1.68 & .65 \\
\hline Planning & 6.41 & 1.66 & .77 \\
\hline Seeking tangible support & 5.79 & 1.93 & .84 \\
\hline Total & 18.47 & 4.27 & .82 \\
\hline \multicolumn{4}{|l|}{ Emotion-focused } \\
\hline Seeking emotional support & 5.70 & 1.92 & .85 \\
\hline Positive reframing & 5.06 & 1.91 & .72 \\
\hline Acceptance & 6.37 & 1.59 & .65 \\
\hline Turning to religion & 5.23 & 2.25 & .87 \\
\hline Substance use & 3.42 & 1.95 & .96 \\
\hline Self-blame & 4.73 & 1.92 & .82 \\
\hline Venting & 5.50 & 1.71 & .68 \\
\hline Humour & 4.09 & 1.98 & .87 \\
\hline Total & 40.16 & 7.01 & .70 \\
\hline \multicolumn{4}{|l|}{ Avoidance-focused } \\
\hline Denial & 3.11 & 1.56 & .71 \\
\hline Self-distraction & 5.81 & 1.58 & .50 \\
\hline Behavioural disengagement & 3.37 & 1.60 & .67 \\
\hline Total & 12.29 & 3.11 & .56 \\
\hline
\end{tabular}


Table 16

Survivors of Psychopaths' Ratings of Perceived and Received Social Support

\begin{tabular}{lccc}
\hline Social support type & $M$ & $S D$ & $\alpha$ \\
\hline Perceived $(N=504)$ & & & \\
Emotional & 11.84 & 3.28 & .77 \\
Tangible & 12.62 & 3.14 & .80 \\
Informational & 12.31 & 3.29 & .84 \\
Total & 36.77 & 8.49 & .90 \\
Received $(N=494)$ & & & \\
Emotional & 11.43 & 3.47 & .84 \\
Tangible & 7.90 & 3.46 & .79 \\
Informational & 10.70 & 3.73 & .82 \\
Total & 30.03 & 8.71 & .90 \\
\hline
\end{tabular}

\section{Checking for Redundancy}

Between coping and social support, some subscale constructs appeared to overlap (i.e., posttraumatic stress disorder's avoidance symptoms and coping's avoidanceoriented techniques). In order to check for redundancy, bivariate correlations were examined for potentially overlapping constructs (see Table 17). For the construct of avoidance, posttraumatic stress disorder's avoidance symptoms and avoidance-oriented coping were moderately positively correlated. There was a small, but nonsignificant and negligible positive correlation between the construct of coping and perceived assistance's tangible support. A significant positive, but small correlation existed between coping and received assistance's tangible support. There were moderate positive associations between coping and social support's emotional support. Although correlations between potentially overlapping constructs generally ranged from small to moderate, none demonstrated strong redundancy. 


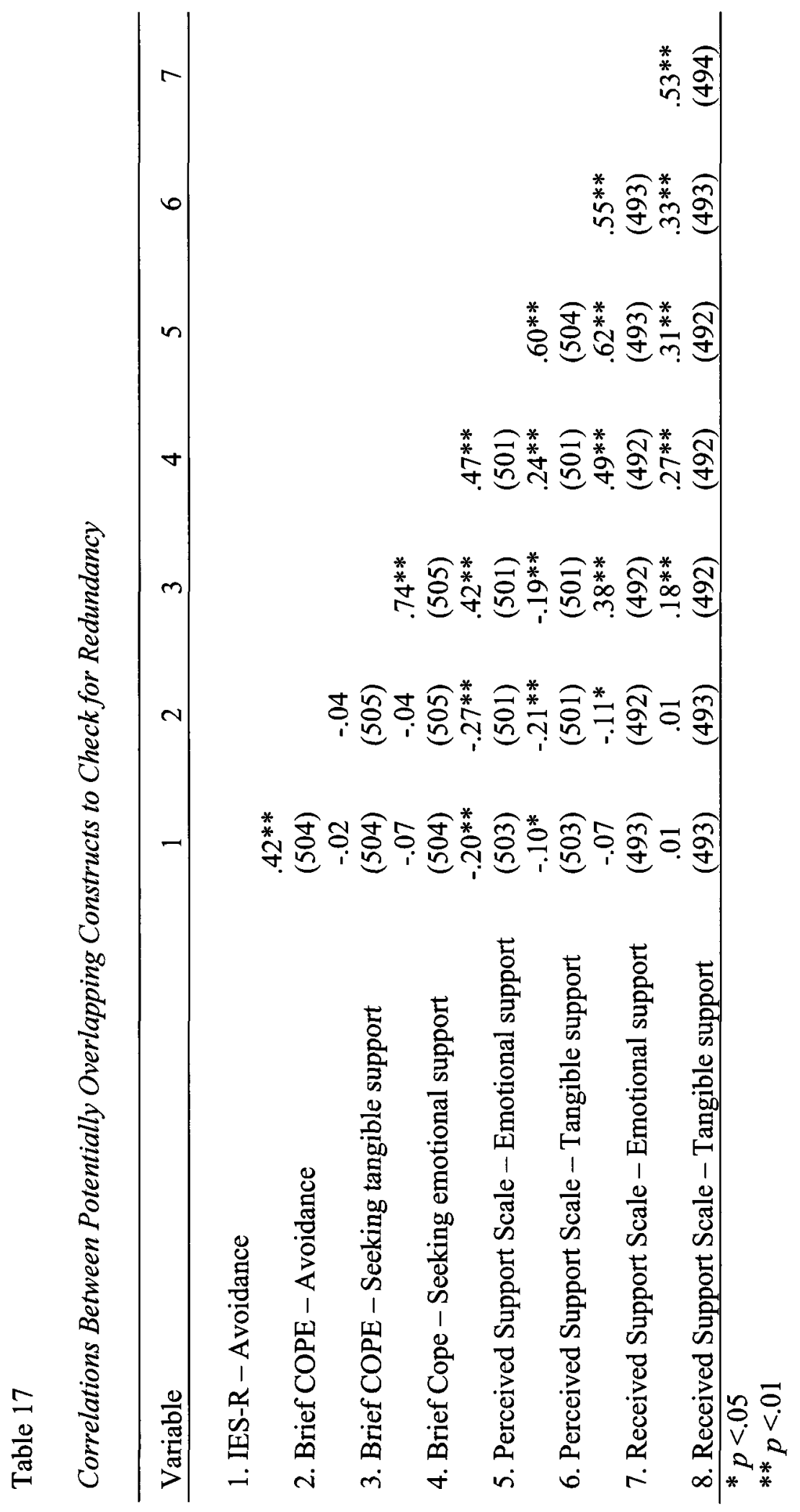




\section{Data Analyses}

Hypotheses were analyzed with various statistics: content analyses (Hypotheses 1 and 4), chi-square (Hypothesis 3), one-way MANOVAs (Hypotheses 2, 5, 6, 7, and 9), bivariate correlations (Hypothesis 8), and structural equation modeling (last set of hypotheses). Summary statistics and patterns of missing data were described for Hypotheses 2, 5-9, and the last set of hypotheses. Quantitative data analyses were performed in SPSS Version 16, whereas the last set of hypotheses, represented in Figure 2, was examined through AMOS Version 16. Open-ended responses were examined in Excel. Content analyses include exploration and organization of open-ended data. For hypotheses on descriptions of distress consequences and methods of deception by psychopaths, text-based coding was used. Text-based coding is an analytical technique which involves examining data by particular sections (i.e., lines, paragraphs) and attaching one- to two- word codes to each segment and then grouping together similar words to identify themes. Chi-square analyses establish the significance of proportions of relationships of categorical data, hence its inclusion for hypotheses on the associations between deception pathway, closeness of victim-offender relationship, and frequency of exposure. One-way MANOVAs examine the influence of one categorical variable (i.e., victim status) on multiple dependent variables (i.e., PTSD and depression). Bivariate correlations is a measure of the strength of relationships between two variables (i.e., physical injury severity and distress). Finally, structural equation modeling is a flexible statistical technique that allows for a separate estimation of the relationship between latent variables and the theorized relationships among constructs (Muthén \& Muthén, 2006), hence its suitability for the final set of hypotheses. 


\section{Symptoms}

Hypothesis 1. It was hypothesized that survivors of psychopaths would describe a wide variety of mental and physical health effects, similar to what has been reported in the crime victimization literature. Consequences were analyzed by organizing answers to the open-ended interview questions on distress using the McCann et al. (1988) model. Survivors reported many negative direct and indirect effects of victimization (see Table 18). Cognitive changes included intrusive, dissociative, cognitive bias, and concentration symptoms. Biological consequences involved disorders of the central or peripheral nervous systems (i.e., multiple sclerosis, trigeminal neuralgia, sleep apnea), skin effects (i.e., eczema, hives, numbness, alopecia), dental issues (i.e., grinding teeth), heart problems (palpitations, cardiomyopathy, angina), and difficulties with respiratory systems (i.e., asthma, bronchitis, lung disease). Weak immune systems, as illustrated by frequent minor or major infections and regular flu-like symptoms, autoimmune diseases (i.e., rheumatoid arthritis, lupus), and soft/connective tissue disorders (i.e., fibromyalgia) were also mentioned. Involvement with psychopaths was problematic for digestive (i.e., diarrhea, irritable bowel syndrome, Crohn's disease) and endocrine (i.e., diabetes, hypothyroidism) systems. The reproductive system was also affected, as portrayed by reports of infertility, sexually transmitted diseases, miscarriages, amenorrhoea, and sexual dysfunction. Urologic system disorders such as chronic cystitis and frequent urination were recounted. Body tension or aches such as migraines/headaches and stiff necks were common, along with physical injuries. Other symptoms included psychogenic seizures, strokes, arthritis, sweaty palms, tremors, nausea, dizziness, fatigue, high blood pressure, weight changes, elevated white blood cell counts, and dehydration. 
Survivors reported numerous behavioural changes, including changes to sleeping. speech, physical self-care, social activities and/or interaction, and work. Other effects included hypervigilance, ADHD, and compulsiveness. Many emotional consequences were reported along spectrums of anger (i.e., irritability, frustration, rage, furiousness, aggravation), hatred (i.e., of self, misogyny), anxiety (i.e., tense, nervousness, restlessness, wired, feeling not in control, anguish, fear, panic, paranoia), depression (i.e., emptiness, loneliness, hopelessness, apathetic, numbness, low self-esteem, helplessness, powerlessness, spiritual devestation), embarrassment (i.e., guilt, shame), denial (i.e., disbelief), grief, and disappointment. Mood fluctuations were also reported.

Involvement with a psychopath had devastating effects on survivors' interpersonal relationships. Survivors were no longer trusted because of falsified allegations against them of fraud by psychopaths and/or legal authorities. Alternately, survivors were considered by others as having poor judgment in relationships and therefore unworthy of further acquaintance. In fact, some survivors feared that they were less respected, particularly if they made choices to stay with psychopaths. Many survivors illustrated a loss of trust in others through descriptions of questioning people's motives, checking out their backgrounds, withholding personal information, testing or pushing buttons, and fear of betrayal or abandonment. Survivors perceived their own judgments of others as faulty due to their relationship with a psychopath.

Survivors interacted differently with people as a result of victimization by psychopaths. For example, tolerance of others for substance use or forgiveness for even small mistakes became less frequent. Such interpersonal changes affected their relationships with others in various ways. Social activities such as raising children, 
initiating conversations, and obtaining academic scholarships were examples of some difficulties described by survivors. Sex was either obsessively sought after or withheld from others. One survivor mentioned that they had to re-learn how to interact with people because their socialization upbringing was completely removed from the norm and they noticed negative effects of their behaviour on the people around them. Some survivors recognized that they took on abusive traits or didn't treat others well because of their experiences with psychopaths, while others continuously found themselves in harmful relationships with others.

Occasionally, positive behavioural, emotional, and interpersonal changes were reported. Active pursuit of hobbies, participating in self-defense courses, adopting and caring for animals, and joining support groups were some examples of behavioural advantages. Survivors felt relieved, confident, independent, proud, dignified, and empowered due to not being involved with psychopaths. Some survivors reported an improvement in their relationships through exploring ways to incorporate experiences with helping others, better awareness of danger signs, repairing safe friendships, standing up for themselves, resuming interest in intimate relations - sexual or otherwise, and more appreciation of the good in people, such as the supportive nature of colleagues, friends and families. Closer and stronger social networks were developed with people who were on the survivors' sides (i.e., friends who warn survivors if they are consumed by unhealthy thoughts and behaviour and protect them physically). Therapists have helped some survivors define healthier relationship and sexual boundaries. These positive effects have enabled some survivors to maintain fulfilling lives. 


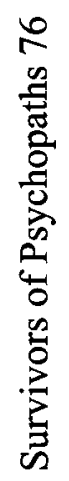

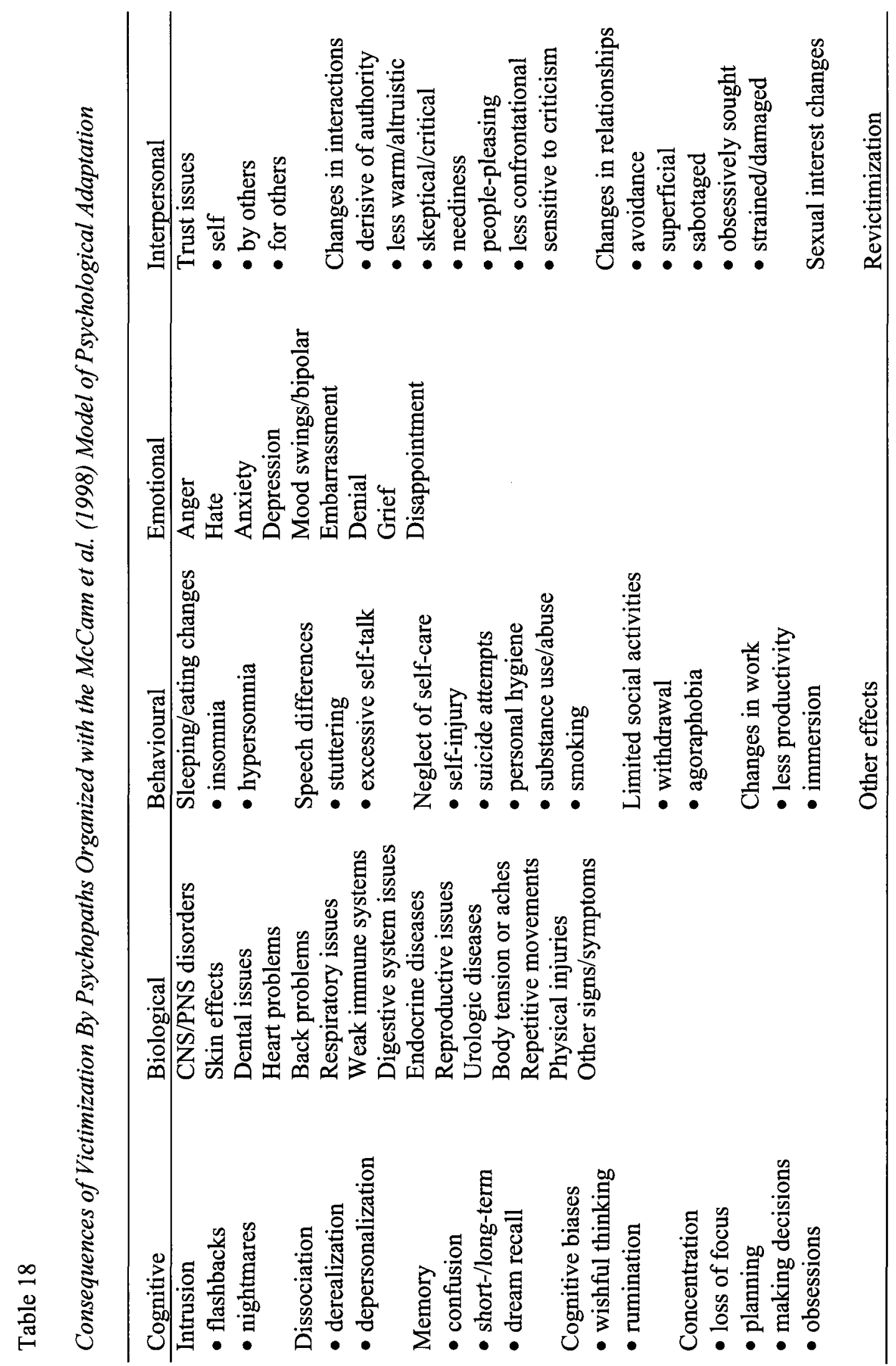


Hypothesis 2. It was expected that current victims would rate higher on distress measures than past survivors. A one-way MANOVA on the effect of victim status (current, past) on psychological distress (posttraumatic stress disorder, depression) was performed to address this hypothesis. Missing Value Analysis suggested that data was missing completely at random as demonstrated by Little's MCAR test: $\chi^{2}=3.14(d f=2$, $n s)$. Five hundred and fourteen participants responded to victim status and distress measures. Results indicated that current victims $(n=122$, PTSD $M=7.50, S D=2.18$; depression $M=21.98, S D=11.75)$ and past survivors $(n=392$, PTSD $M=7.86, S D=$ 2.28; depression $M=20.93, S D=12.97$ ) were similar in their levels of psychological distress: PTSD $\left[F(1,512)=2.34, n s\right.$, partial $\eta^{2}=.01$, power $\left.=.33\right]$ and depression $\left[F(1,512)=.64, n s\right.$, partial $\eta^{2}=.00$, power $\left.=.13\right]$.

\section{Deception}

Hypothesis 3. It was hypothesized that shortcut-path psychopaths would likely be strangers involved with victims on an isolated basis, whereas those on the delayed deception path would have repeated exposure to survivors in closer relationships. First of all, answers to the open-ended questions on deception were coded in terms of a deception pathway $(1=$ shortcut, $2=$ delayed $)$ according to their respective descriptions. To estimate inter-rater reliability, an undergraduate student was provided a coding manual and random samples of cases identified as either shortcut $(n=15)$ or delayed $(n=85)$, which were approximately twenty percent of each coded pathway. The coding manual consisted of a description of each pathway, Figure 1 without the caption, and the aforementioned coding scheme. According to Landis and Koch (1977) criteria for categorical data $(\mathrm{small}=.01-.39$, moderate $=.40-.59$, substantial $=.60-.79$, outstanding $=$ 
$>.80$ ), there were strong interrater agreements on the route of deception psychopaths took for the cases: Kappa $=.83,(p<.01)$. Secondly, exposure frequency (rare, mild, moderate, extreme) was already reported by participants. Closeness of survivor-offender relationship was categorized as either yes (friend, significant other, ex-significant other, employer, employee, family member) or no (stranger, neighbour, acquaintance, roommate). Descriptions in "other" were read and decisions were made about the closeness of respective survivor-offender relationships depending on their answers.

In order to look at the relationships between deception pathways, closeness of relationship and frequency of exposure, contingency tables, represented in Tables 19 and 20 respectively, and corresponding chi-square analyses were calculated. The Fisher's Exact Test is used for analyzing two dichotomous variables (i.e., deception pathway = shortcut, delayed; closeness = yes, no) which may have especially uneven values. A significant relationship between deception pathways and closeness of relationships existed: ( $p<.05$, Fisher's Exact Test). For the 78 psychopaths classified as having taken the shortcut route of deception, it is expected that $8 \%(n=6)$ would not be in a close relationship with the victim, whereas $92 \%(n=72)$ would be close to survivors. Psychopaths $(N=407)$ who engaged in the delayed path of deception are $97 \%(n=396)$ more likely to be in a close relationship, than be in a non-close relationship ( $n=11,3 \%)$. Chi-square analyses suggested that there was also a significant relationship between deception pathway and frequency of exposure: [Linear-by-linear association $\chi^{2}$ $(3,516)=4.89, p<.05]$. The proportion of participants increased by order of exposure frequency for each pathway, but psychopaths who engaged in delayed deception were more likely to be involved with survivors on an extreme basis. Proportions for shortcut 
were as follows: rare $(1 \%)$ mild $(6 \%)$, moderate $(21 \%)$, and extreme $(72 \%)$, whereas delayed deception by frequency's pattern was rare $(1 \%)$, mild $(3 \%)$, moderate $(13 \%)$, and extreme $(83 \%)$.

Table 19

A $2 \times 2$ Contingency Table of the Association between Closeness of Relationship and Deception Pathways

\begin{tabular}{lccc}
\hline & \multicolumn{2}{c}{ Close Relationship } & \\
\cline { 2 - 3 } Deception pathway & Yes & No & Total \\
\hline Shortcut & 72 & 6 & 78 \\
Delayed & 396 & 11 & 407 \\
Total & 468 & 17 & 485 \\
\hline
\end{tabular}

Table 20

A $2 \times 4$ Contingency Table of the Association between Frequency of Exposure and Deception Pathways

\begin{tabular}{lccccc}
\hline & \multicolumn{5}{c}{ Frequency of Exposure } \\
\cline { 2 - 5 } Deception pathway & Rare & Mild & Moderate & Extreme & Total \\
\hline Shortcut & 1 & 5 & 19 & 65 & 90 \\
Delayed & 4 & 12 & 55 & 355 & 426 \\
Total & 5 & 17 & 74 & 420 & 516 \\
\hline
\end{tabular}

Hypothesis 4. It was expected that victims who expressed their thoughts and feelings about psychopaths' deceptive behaviours would receive either false affective responses or no acknowledgement whatsoever. Answers to the open-ended questions about the psychopaths' responses to deception exposure were read, summarized, and made into a list. Redundant items were eliminated and remaining answers were thematically organized. Themes which emerged from the data included: avoidance, 
reverse victimization, and abuse (see Table 21). Psychopaths avoided confrontation about their deception. One psychopath refused to assist a survivor involved in a small accident, stating that they thought providing support was unnecessary. Some psychopaths portrayed themselves as victims; a phenomenon typically described in the stalking literature as false victimization syndrome (FVS). In FVS, perpetrators attempt to convince others of their victimization by victims through accusations and invention of victimization scenarios (Zona, Palarea, \& Lane, 1998). Psychopaths even went as far as to send "evidence" of their claims to others, including law enforcement.

Not surprisingly, abuse was also a response. In some cases, psychiatric commitment was threatened or rumours were spread. Victim blaming and emotional deception were especially strong components. For example, survivors were accused of having overactive imaginations or warped realities, blowing things out of proportion, and being too emotional or sensitive. Psychopaths twisted survivors' words and shifted blame through statements such as "I must have misunderstood - that happens a lot with you" or "you're the messed up one". On the other hand, psychopaths also acted appalled, infuriated, or shocked at being questioned, and attempted to gauge sympathy through self-injury, claims of innocence or being unloved and hurt, anxiety attacks, and justifying offensive behaviours as due to experiencing violence in childhood, mental health issues, substance abuse, stress, or trying to figure themselves out. Psychopaths used one or more of any of the aforementioned responses, and as one survivor remarked, "responses always changed with the wind". Finally, it must be noted that some survivors did not express thoughts and feelings due to anticipating negative consequences, particularly abuse, or were simply refused opportunities to do so. 


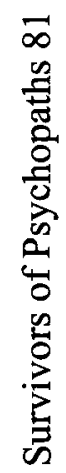

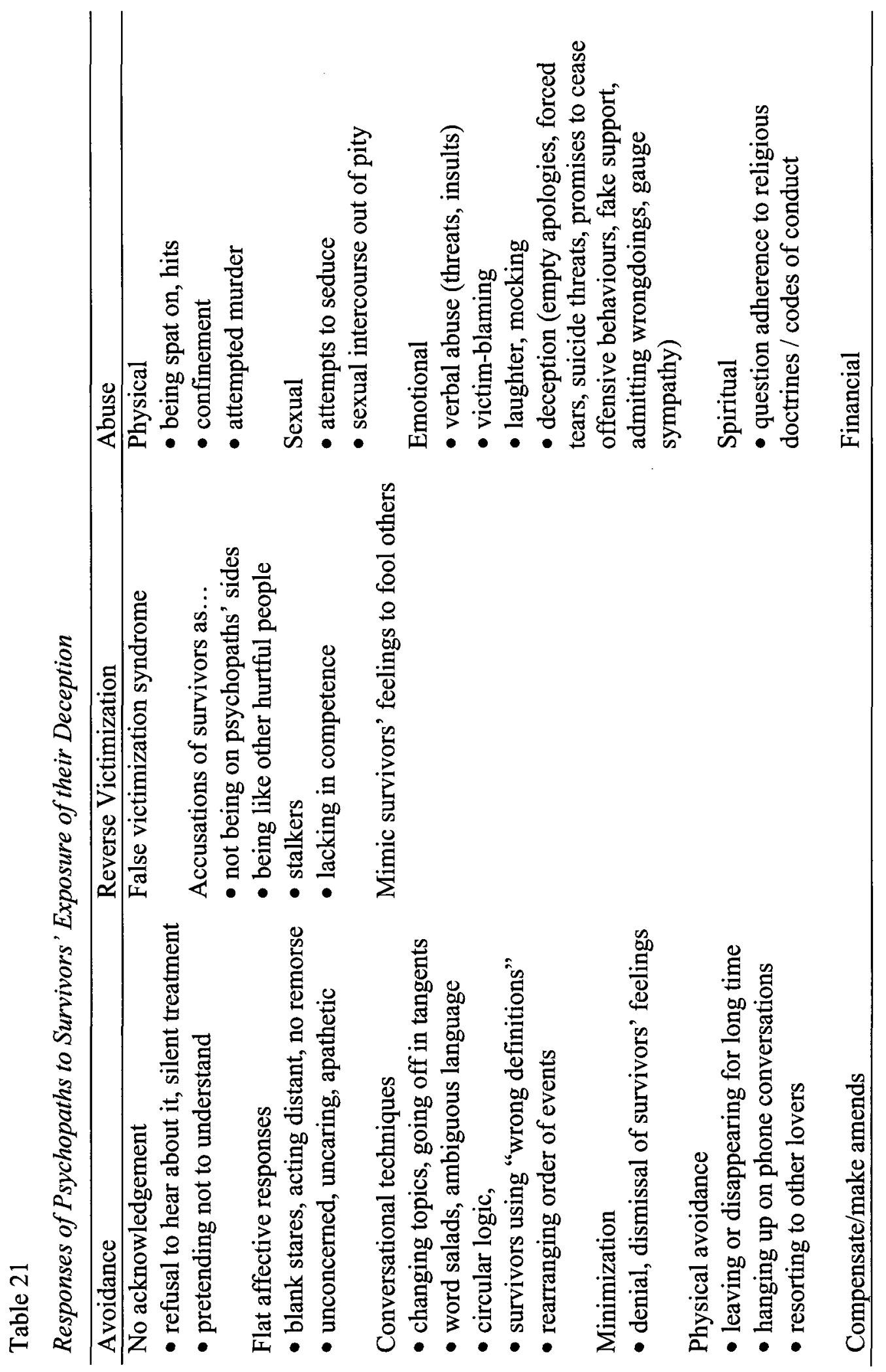


Hypothesis 5. It was assumed that shortcut-path psychopaths would rate higher on Affective, Social Deviance, and Antisocial Lifestyle facets, whereas delayed-path psychopaths would score higher on Interpersonal facets. This was tested using a one-way MANOVA. Summary statistics of psychopathic factors for shortcut and delayed-path psychopaths are represented in Table 22. Since the assumption of Homogeneity of Variance was violated for the Interpersonal Manipulation variable [Levene's $F(1,523)=$ 4.86, $p<.05$ ], a more stringent significance level, $\alpha=.025$, was used. Data was also missing completely at random: Little's MCAR test: $\chi^{2}=5.47(d f=4, n s)$. No significant differences were found in psychopathic traits between shortcut and delayed-path psychopaths for Interpersonal Manipulation $\left[F(1,523)=1.32, n s\right.$, partial $\eta^{2}=.00$, power $=.14]$, Callous Affect $\left[F(1,523)=1.86, n s\right.$, partial $\eta^{2}=.00$, power $\left.=.19\right]$, Erratic Lifestyle $\left[F(1,523)=.25, n s\right.$, partial $\eta^{2}=.00$, power $\left.=.04\right]$, or Criminal Tendencies $\left[F(1,523)=.47, n s\right.$, partial $\eta^{2}=.00$, power $\left.=.06\right]$.

Table 22

Summary Statistics of Psychopathic Factors for Shortcut and Delayed-Path Psychopaths

\begin{tabular}{|c|c|c|c|c|}
\hline \multirow[b]{2}{*}{ SRP-III Subscale } & \multicolumn{2}{|c|}{ Shortcut $(N=92)$} & \multicolumn{2}{|c|}{ Delayed $(N=433)$} \\
\hline & $M$ & $S D$ & $M$ & $S D$ \\
\hline Interpersonal Manipulation & 63.58 & 7.78 & 62.38 & 9.30 \\
\hline Callous Affect & 53.98 & 10.55 & 52.37 & 10.19 \\
\hline Erratic Lifestyle & 56.94 & 12.10 & 57.54 & 10.31 \\
\hline Criminal Tendencies & 38.92 & 16.57 & 37.64 & 16.36 \\
\hline
\end{tabular}

Distress Predictors

Hypothesis 6. A one-way MANOVA on the effect of victim-offender relationship closeness (yes, no) on psychological distress (posttraumatic stress disorder, depression) 
was performed to address the hypothesis that survivors in closer relationships with the psychopaths would have more PTSD and depression symptomatology than if victimized by strangers, neighbours, room-mates, or acquaintances. Preliminary exploration revealed more than slight non-normality even after outlier value transformation. Little's MCAR test revealed no significance, indicating that data was missing completely at random: $\chi^{2}=$ $3.257(d f=4, n s)$. Analyses were conducted with variables transformed and not transformed, but similar effects occurred. This suggested that the distribution was accounted for by the genuine nature of the sample, so non-transformed variables are reported subsequently. Survivors $(N=479)$ in close relationships $(n=461)$ had significantly higher PTSD scores $(M=7.85, S D=2.22)$ than victims with little familiarity $(n=18, M=6.51, S D=2.59)$ with the psychopaths: $[F(1,477)=6.18, p<.05$, partial $\eta^{2}=.01$, power $\left.=.70\right]$. However, there was no significant relationship in depression scores for victims in close relationships $(M=21.46, S D=12.95)$ and survivors with little familiarity $(M=18.06, S D=9.61)$ with the psychopaths: $[F(1,477)=$ $1.22, n s$, partial $\eta^{2}=.00$, power $\left.=.20\right]$

Hypothesis 7. To determine whether victims who had isolated encounters with psychopaths would be less likely to experience more PTSD and depression than survivors who had repeated exposure, a one-way MANOVA was performed. PTSD and depression results for survivors with rare and mild exposure were recoded into "isolated". The other types of exposure (moderate, extreme) were recoded into "repeated". Summary statistics for frequency of exposure and distress are in Table 23. The pattern of data was missing completely at random: Little's MCAR: $\chi^{2}=3.11(d f=2, n s)$. Overall, there was a statistically significant difference between frequency of exposure for both psychological 
distress variables: $\operatorname{PTSD}\left[F(1,508)=26.52, p<.05\right.$, partial $\eta^{2}=.05$, power $\left.=.99\right]$, and depression: $F(1,508)=5.00, p<.05$, partial $\eta^{2}=.01$, power $\left.=.61\right]$. Survivors with repeated exposure to psychopaths experienced significantly more PTSD and depression symptoms than victims who had isolated encounters (also see Table 23).

Table 23

Summary Statistics for Frequency of Exposure and Psychological Distress

\begin{tabular}{lcccccc}
\hline & \multicolumn{2}{c}{ Isolated $(n=22)$} & & & \multicolumn{2}{c}{ Repeated $(n=488)$} \\
\cline { 2 - 3 } \cline { 5 - 6 } Psychological Distress & $M$ & & & & $M$ & $S D$ \\
\hline \multirow{2}{*}{ PTSD } & 5.46 & 2.42 & & & 7.91 & 2.16 \\
Depression & 15.41 & 9.67 & & & 21.54 & 12.69 \\
\hline
\end{tabular}

Hypothesis 8 . Bivariate correlations were computed to determine whether increases in physical injury severity would be associated with more PTSD and depression symptoms. Little's MCAR test revealed no significance, suggesting the pattern of data was missing completely at random: $\chi^{2}=2.54(d f=2, n s)$. There were small positive associations between physical injury severity and $\operatorname{PTSD}(r=.18, N=527, p<.01)$ as well as depression $(r=.16, N=516, p<.01)$. These results indicated that increases in physical injury severity were mildly likely to increase PTSD and depression symptoms.

Hypothesis 9. A one-way MANOVA on the effect of type of physically violent crime (none, physical and/or sexual) on psychological distress (posttraumatic stress disorder, depression) was performed to address the hypothesis that survivors of physically violent crimes would experience more PTSD and depression symptomatology than victims of nonphysically violent actions. As suggested by the Little's MCAR nonsignificance results, $\chi^{2}=3.05(d f=2, n s)$, data was missing completely at random. There were statistically significant results for the effect of type of crime on PTSD $[F(1,506)=$ 
$13.49, p<.01$, partial $\eta^{2}=.03$, power $\left.=.96\right]$ and depression $[F(1,506)=13.51, p<.01$, partial $\eta^{2}=.03$, power $\left.=.96\right]$. Out of 508 participants who responded to the question about type of crime, survivors of physically violent crimes $(n=279)$ were more likely to experience increased PTSD $(M=8.12, S D=2.20)$ and depression $(M=23.02, S D=$ 13.01) symptoms than victims of no physically violent crimes $(n=229 ; \operatorname{PTSD} M=7.39$, $\mathrm{SD}=2.21 ;$ depression $M=18.87, S D=12.24)$.

\section{Relationships Between Psychopathy Severity, Coping, Social Support, and Distress}

Hypotheses regarding the concurrent relationships between psychopathy severity, coping, social support, and psychological distress, were evaluated within a structural equation modeling framework. Structural equation modeling (SEM) has several advantages over multiple regression analyses. For example, SEM has more flexible assumptions, appealing graphical interfaces, includes confirmatory factor analyses to reduce measurement errors, tests models overall as opposed to individually, examines multiple coefficients, takes error into account, and has the ability to handle difficult data (Garson, n.d.). SEM provides an overall picture of the relationships between latent and observed variables. Latent variables are unobserved or unmeasured concepts (i.e., psychopathy severity) which are typically analyzed with observed, measured, or manifest variables (i.e., Interpersonal Manipulation, Callous Affect, Erratic Lifestyle, and Criminal Tendencies).

Preliminary analyses. Preliminary analyses involved screening for outliers, examining the pattern of missing data, testing whether the data met assumptions for structural equation modeling, and internal reliabilities with Cronbach's. The original dataset had 643 participants. Outlier values for individual variables were transformed to 
next lowest or highest non-outlier scores. Mahalanobois distance did not reveal any multivariate outliers. All variables in the model contained between $0-23 \%$ of missing data. Little's MCAR test did not reach significance, $\chi^{2}=136.54(d f=132, n s)$, suggesting that data was missing completely at random. Cases with missing data were eliminated through listwise deletion, reducing $N$ to 490 . Thirdly, skewness and kurtosis were explored through statistics and histograms. None of the variables exceeded the conventional acceptable values of plus or minus two skewness and kurtosis. Therefore, the data was suitable for Maximum Likelihood Estimation (MLE), the most common SEM method. This technique establishes estimates based on optimal probabilities that observed covariances are drawn from a population assumed to be the same as that reflected in coefficient estimates (Garson, n. d.).

Reliability analyses. The internal consistency for all the measured indices were calculated using the Cronbach's alpha reliability coefficient, known as Cronbach's $\alpha$ (see Table 24). The majority of scales approximated or exceeded the acceptable reliability criterion ( $\alpha=.70)$ established by Nunally (1978). Although the Interpersonal Manipulation and Callous Affect subscales of the SRP-III did not meet the exact established criterion, all values were close enough and were reasonable considering the scale's original purpose as self-report rather than observer-based. Originally, the Avoidance-Focused Coping scale of the Brief COPE reached poor reliability $(N=490$, number of items $=6, \alpha=.56$ ). Deletion of two items (\#1 - I have been turning to work or other activities to take my mind off things, and \#19 - I have been doing something to think about it less) resulted in a substantial improvement of reliability for AvoidanceFocused Coping. 
Table 24

Cronbach's Alpha Coefficients ( $\alpha$ ) for the Measured Variables

\begin{tabular}{lcc}
\hline Scale & Number of items & Cronbach's $\alpha$ \\
\hline Interpersonal Manipulation & 16 & .68 \\
Callous Affect & 16 & .65 \\
Erratic Lifestyle & 16 & .70 \\
Criminal Tendencies & 16 & .83 \\
IES-R & 22 & .91 \\
BDI-II & 20 & .94 \\
Problem-Focused Coping & 6 & .82 \\
Emotion-Focused Coping & 16 & .70 \\
Avoidance-Focused Coping & 4 & .66 \\
Perceived Social Support & 12 & .90 \\
Received Social Support & 12 & .90 \\
\hline
\end{tabular}

Structural equation modeling. Structural equation modeling (SEM) is comprised of two models, structural and measurement. The structural model represents theorized relationships between latent constructs, such as the effect of psychopathy severity experienced by survivors on distress (see Figure 2). The measurement model, illustrated in Figure 3, is comprised of indicator or measured variables for each construct. For example, psychopathy severity is measured by four indicator variables (IPM = Interpersonal Manipulation, $\mathrm{CA}=$ Callous Affect, $\mathrm{ELS}=$ Erratic Lifestyle, and CT = Criminal Tendencies). Confirmatory factor models were tested for latent constructs before testing the full model. 


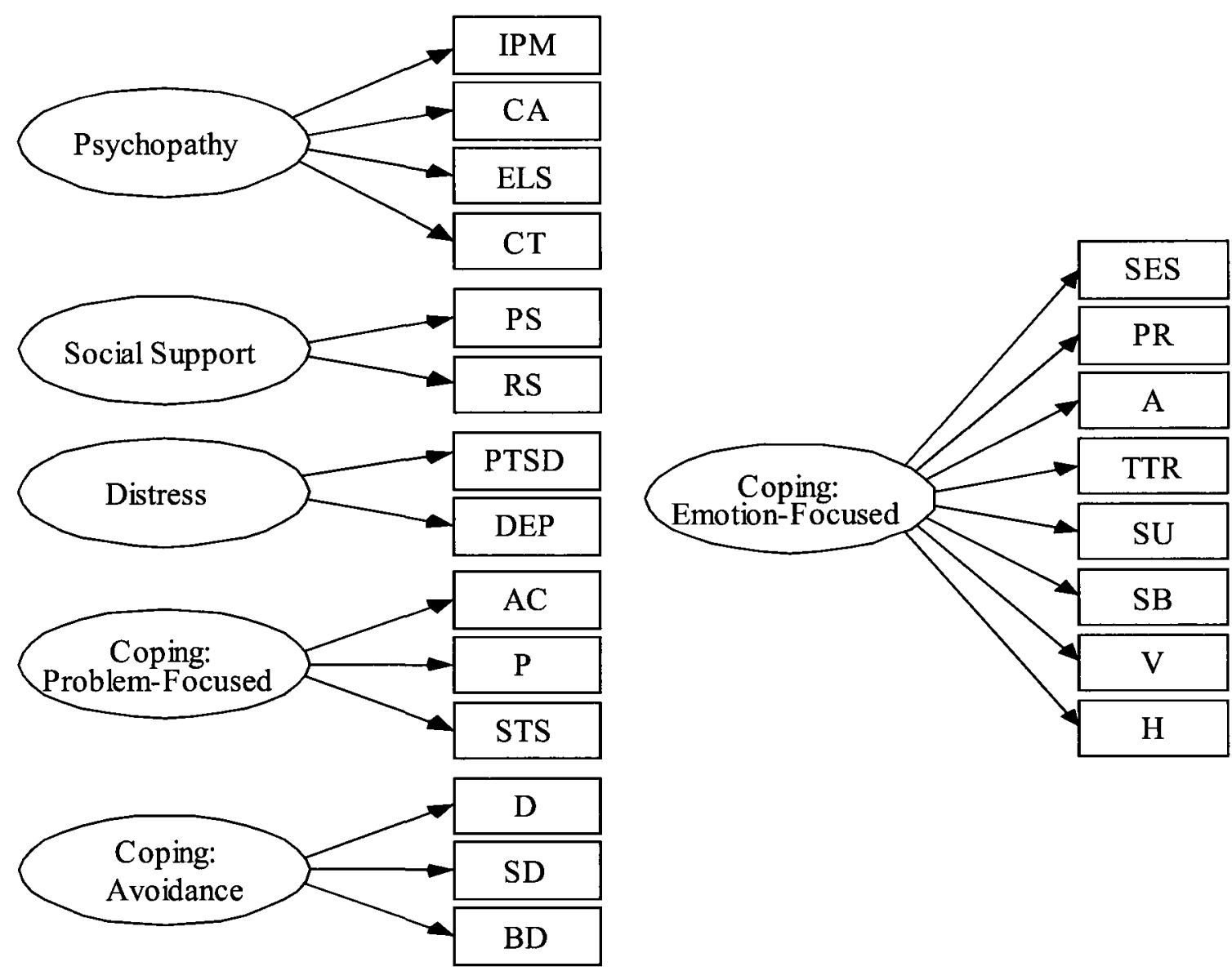

Figure 3

Measurement Model of Psychopathy $(\mathrm{IPM}=$ Interpersonal Manipulation, $\mathrm{CA}=$ Callous Affect, $\mathrm{ELS}=$ Erratic Lifestyle, $\mathrm{CT}=$ Criminal Tendencies $),$ Social Support $(\mathrm{PS}=$ Perceived Support, RS = Received Support $),$ Distress $(\mathrm{PTSD}=$ posttraumatic stress disorder, $\mathrm{DEP}=$ depression), Coping (Problem-Focused: $\mathrm{AC}=$ Active Coping, $\mathrm{P}=$ Planning, STS = Seeking Tangible Support; Emotion-Focused: SES = Seeking Emotional Support, $\mathrm{PR}=$ Positive Reframing, $\mathrm{A}=$ Acceptance, $\mathrm{TTR}=$ Turning to Religion, $\mathrm{SU}=$ Substance Use, $\mathrm{SB}=$ Self-Blame, $\mathrm{V}=$ Venting, $\mathrm{H}=$ Humour $;$ Avoidance: $\mathrm{D}=$ Denial, $\mathrm{SD}$ $=$ Self-Distraction, $\mathrm{BD}=$ Behavioural Disengagement $)$ 
Models are assessed with numerous goodness of fit indices (Byrne, 2001; Cheung \& Rensvold, 2002), including (a) chi-square goodness of fit statistic, (b) normed chisquare (CMIN/DF, Wheaton, Muthén, Alwin, \& Summers, 1977), (c) goodness-of-fit index (GFI, Jöreskog \& Sörbom, 1984), (d) the root mean square of approximation (RMSEA, Browne \& Cudeck, 1993), and (e) baseline comparisons such as the comparative fit index (CFI, Bentler, 1990) and incremental fit index (IFI, Bollen, 1989); each of which provide different information. The chi-square goodness of fit index is an absolute index, or a measure of overall fit. High $\chi^{2}$ values, indicated by significant $p$ statistics, signify that the model does not fit the data well. However, large samples tend to increase the $\chi^{2}$ values substantially. The normed chi-square, a ratio of $\chi^{2}$ / degrees of freedom, addresses this issue. A CMIN/DF of 4 or less is considered a good fit (Wheaton et al., 1977), whereas greater statistics suggest poorness of fit. Another absolute index is the GFI, which assesses the discrepancy between sample covariance matrices and implied fitted model covariance matrices, and acceptable fits are greater than .90. The RMSEA is a relative measure that estimates lack of fit compared to a perfect model (i.e., RMSEA $p$ $=0$ ), and reflects the size of residuals when using the model to predict data. A RMSEA of $p<.05$ indicates a close fit whereas $p=.05-.08$ is considered reasonable and $p>.10$ is poor (Browne \& Cudeck, 1989). Baseline comparisons such as CFI and IFI are also relative measures. The former compares models to a baseline worst fit, whereas the latter incorporates values from various fit indices. Both are utilized to address issues of sample size, have values between 0.00 and 1.00 , and have the same criteria for establishing fits $(.95=$ close fit, $.90=$ acceptable fit; Hu \& Bentler, 1999) 
Confirmatory factor analyses. Before testing the conceptual models, confirmatory factor models were performed to assess the suitability of latent variables with more than three indicators (see Table 25). See Figure 3 for measurement models. Psychopathy received poor CMIN/df and RMSEA values, but had close fits for GFI, CFI, and IFI. Correlating error terms for IPM and CA improved the measurement model significantly. Since correlated error terms are the result of systematic measurement errors and can be due to item (i.e., small omitted factors, high degree of overlap in item content) or respondent (i.e., yea-/nay-saying, social desirability) characteristics, allowing them to exist has to be justified (Byrne, 2001). Given that the sample mainly comprised of significant others or ex-significant others of psychopaths, IPM and CA items could elicit similar response sets. More specifically, familiarity with the psychopaths could encourage some extreme responding for items on both scales, particularly as they go hand-in-hand (i.e., having flat affect allows for manipulation).

Parceling Problem-Focused Coping into three factors was problematic as covariance matrices were not positive definite. After modifications of data entry errors, this issue still remained. This error is typically due to multicollinearity (Byrne, 2001). When exploring the correlations between these three variables, Active Coping and Planning were moderately correlated $(r=.62, p<.01)$, but this value wasn't sufficient enough to suggest multicollinearity. Additionally, Seeking Tangible Support was redundant with Tangible Perceived and Received Social Support. Therefore, ProblemFocused Coping was reduced to a two factor model.

Emotion-Focused Coping was parceled into eight factors. This particular model achieved mixed results. A close fit was indicated by the GFI, whereas values for 
CMIN/df, GFI, and RMSEA were reasonable or on the cusp of acceptableness, however, there were poor fit statistics for the IFI and CFI. Eliminating Substance Use and Self Blame improved fit. Seeking Emotional Support was also deleted due to its redundancy with Emotional Perceived and Received Support. The resulting five factor model for Emotion-Focused Coping was a substantial improvement on the eight factor version, overall, with close and reasonable fits.

Revised full model. Considering the various issues with the confirmatory factor analyses, the model was revised (see Figure 4). The revised model received acceptable fit for CMIN/df and RMSEA, but not for GFI, CFI, and IFI. Allowing correlated error terms between Self-Distraction and PTSD improved the model with better absolute fit index and RMSEA values, but not CFI or IFI. This was justified by the avoidance cluster for PTSD and similarities to attempts to distract oneself from victimization experiences.

Structural model and correlations. Figure 5 demonstrates the relationships between each of the latent variables. Psychopathy severity, emotion- and avoidancefocused coping were expected to correlate positively with more psychological distress and less social support. Problem-oriented coping and social support were hypothesized to be associated with less distress. Finally, it was assumed that problem-focused coping was positively related to social support. Five of these hypotheses were confirmed. Psychopathy and avoidance were positively associated with distress, whereas social support had a negative relationship. Problem-focused coping was negatively associated with social support. However, problem-focused coping had positive associations with distress, emotion-focused coping had a negative correlation with distress and a positive effect on social support, all of which was not expected. 


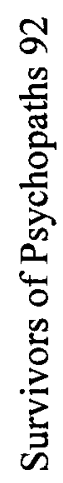

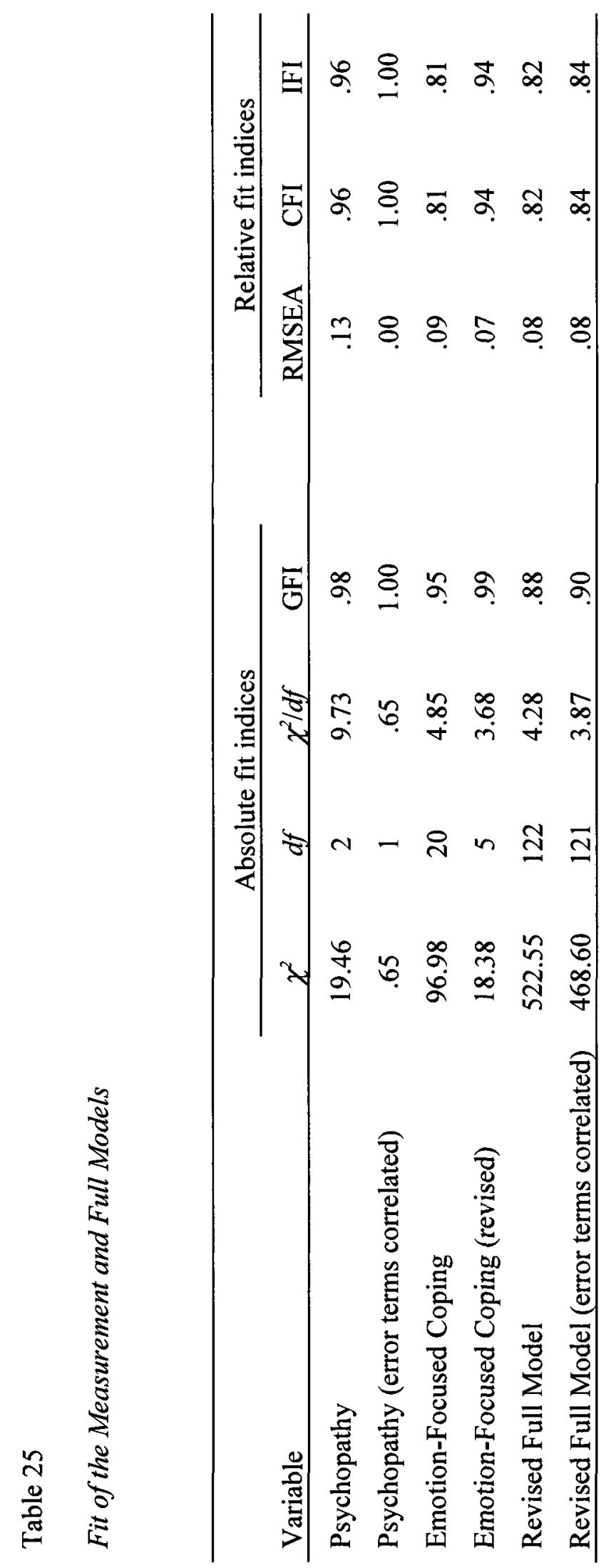




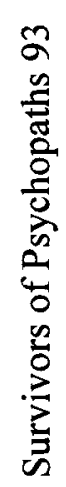
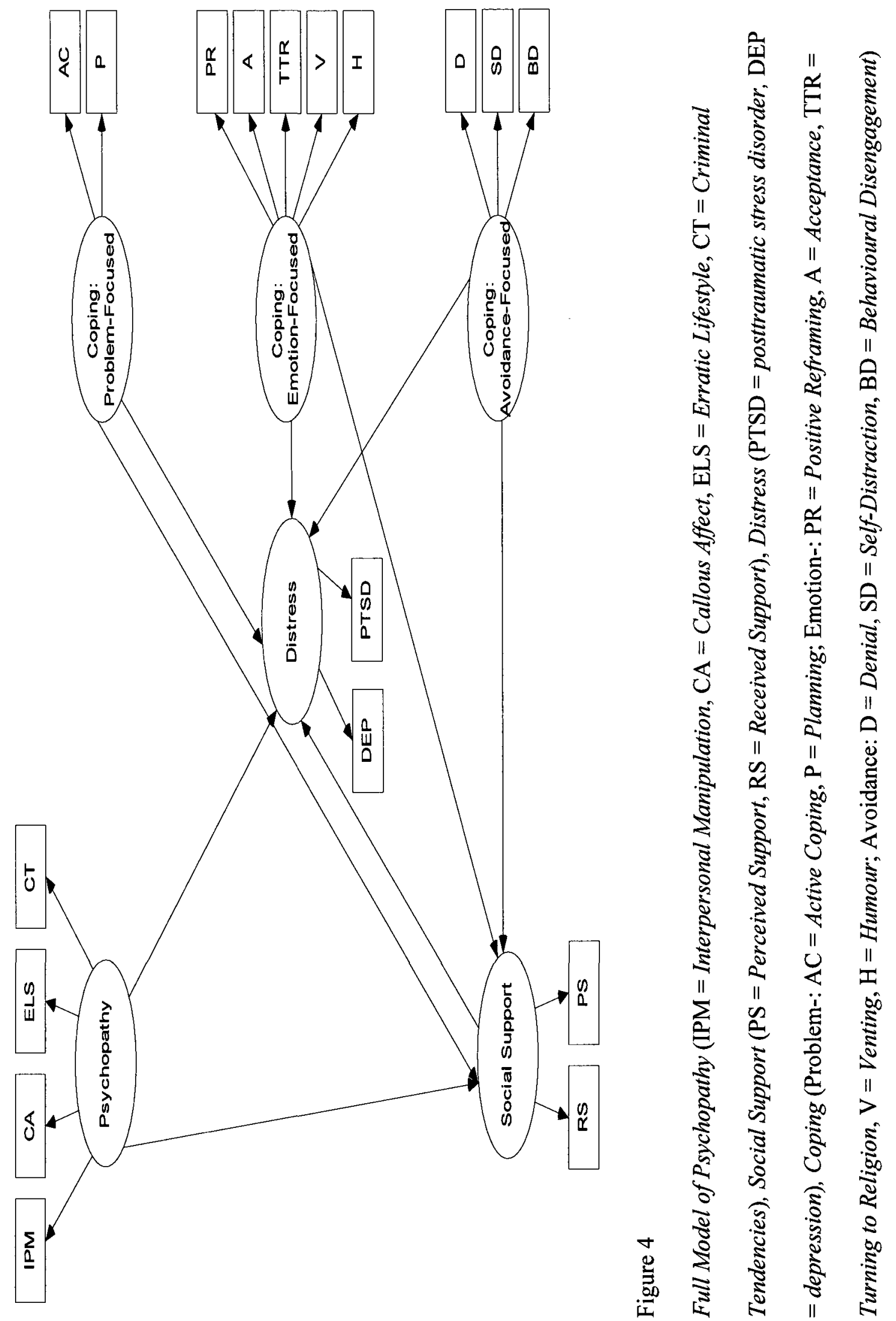


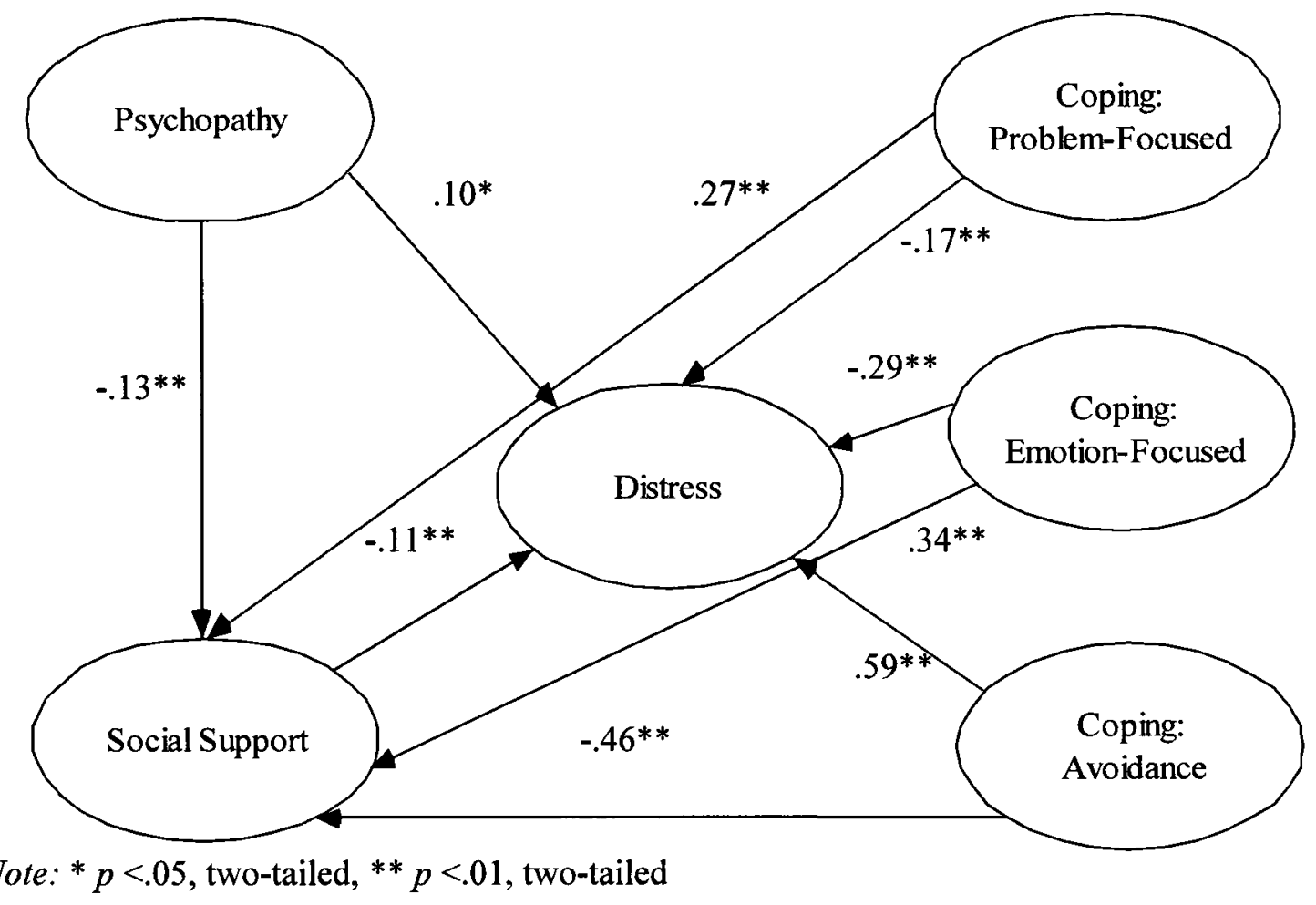

Figure 5

Relationships between Coping Strategies (Problem-, Emotion-, and Avoidance-Focused) and Psychopathy on Distress and Social Support for Survivors of Psychopaths 


\section{Discussion}

To address the lack of victimcentric studies in psychopathy research and bridge the gap in knowledge of community-based psychopaths, the current study explored psychological consequences, deception, distress predictors, and the relationships between psychopathy severity, coping, social support, and distress for survivors of psychopaths. The crime-based victimization literature, knowledge of psychopaths' crimes, recidivism, motives, victim injury, and deception, and extant research with survivors of psychopaths, comprised the background for hypotheses. Although the current study wasn't without its limitations, survivors' experiences generated more pressing questions warranting further research, and have implications for medical, psychological, and legal services.

Descriptive findings of consequences of involvement with psychopaths mirrored the crime victimology research. Effects ranged from cognitive symptoms such as flashbacks and dissociation to interpersonal difficulties, including maintaining relationships and changes in sexual interests. Survivors of psychopaths perceived their psychological symptoms to have more impact on their daily functioning than physiological consequences. No differences in PTSD and depression symptoms were found between current victims and past survivors, but this could be due to individual or situational differences (i.e., prior mental health history, length of involvement, time lapsed since last contact), or the nature of the sample (i.e., people who use the Internet to obtain support, large proportion of past versus present victims). Nevertheless, reports of positive influences, which particularly described strong social support networks, lead credence to the notion that victims eventually come to terms with their status as survivors. The similarities in physical and mental health effects between crime victims 
and survivors of psychopaths made sense given psychopaths' propensity towards physical aggression and violence.

Although a strong relationship between psychopathy and physical violence exists, survivors more commonly reported financial losses, emotional harm, and deception compared to physical and sexual abuse. Loss of trust of others, due to allegations of fraud, may be particularly unique to survivors of psychopaths. One means of emotional harm was through deception. Survivors' accounts of delayed-path psychopaths often interspersed positive qualities (i.e., "sincere", "charming", "seemed to know all the right things to say") and unappealing factors (i.e., "unusually secretive", "too brash", "nervous") even during first encounters. Impression management may be more complicated than a straightforward display of solely positive characteristics as initially hypothesized. Unappealing traits may be part of psychopaths' ploys to gauge survivors' interest. Brown and Leedom (2008) defined these confusing and contradictory behaviours as dichotomies. Delayed-path psychopaths were more likely to be closely and frequently involved with victims, hence their opportunities to partake in cycles of impression management and threatening or coercing survivors. No significant differences in psychopathic traits were found between shortcut- and delayed-path psychopaths. Conceptually, this hypothesis made sense, but the lack of significant findings may be due to the disproportionately small sample of the former compared to the latter.

According to the current study, psychopaths responded to exposure of their deception through avoidance, reverse victimization, and abuse. These findings supported previous research regarding psychopaths' ability to attribute emotions to others without intrinsically experiencing feelings. Survivors' emotions were ignored or avoided by 
psychopaths, suggesting their inability to grasp victims' feelings. However, psychopaths were adept at mimicry, which further supported the notion of an abstract understanding of others' emotional states. Additionally, psychopaths took advantage of prosocial tools, such as apologies, compensation, or making amends for wrongdoings, to further their agendas of exploitation of others. Abuse as a response to exposure of deception indicates that psychopaths may be familiar with specific negative emotional states, particularly anger and hostility.

Psychopaths caused a substantial amount of psychological distress, particularly if they were in close relationships with survivors, frequently involved with them, committed more physical injury, and engaged in more physically violent crimes. All of these factors were confirmed as contributing to increased severity of psychological symptoms in the victimology literature. Again, this supported similarities between survivors of psychopaths and victims of crime.

Findings on the relationships between psychopathy severity, coping, social support, and distress were mixed when comparing them to the victimology research, particularly general psychopathy literature and the work of Green and Pomeroy (2007a; 2007b). As expected, increases in psychopathy severity were associated with more distress and less social support. Psychopaths were more aggressive and violent, which lead to distress. Additionally, psychopaths were interested in power, often controlling the support systems of survivors. Problem-focused coping was associated with more distress for survivors of psychopaths, which did not support crime victimology results. This may be because many survivors were involved in an intimate or ex-significant other relationship, and they may have anticipated that problem-focused coping techniques 
would lead to negative outcomes. Another explanation may be that such strategies may lead to exhaustion, which is a component of depression. The hypothesis that emotionfocused coping is associated with more distress was not supported, and this may be a function of temporal location of stressor (i.e., no contact versus actual contact within last six months). Avoidance-focused coping was moderately positively associated with distress, which made sense as not concentrating on problems can increase stressors. Problem- and avoidance-focused coping were associated with decreases in social support. Survivors may be taking action alone or have difficulty working with social support systems because psychopaths may have deceived them. Avoidance-focused coping lead to decreases in social support because survivors withdrew from social situations. Finally, decreases in social support were associated with increases in distress. Limited social support networks made it difficult to cope with stressors.

\section{Advantages and Limitations}

Although there were advantages with respect to this study's topic and its research design, some limitations also existed. Methodological issues associated with the assessment of psychopaths, such as generalizability, were improved through interviews with survivors. Psychopaths in research tend to be exclusively Caucasian males, although there are non-Caucasian (Walsh \& Kosson, 2007; Walsh, Swogger, \& Kosson, 2004), and female (see Nicholls et al., 2005, for a review) psychopaths. Diverse demographics and traits of psychopaths, particularly noncriminal and noninstitutionalized types, were captured. For example, there were noticeable gender differences in baserates and psychopathic traits. Male psychopaths were more prevalent and were rated higher than women on social deviance, antisocial lifestyles, and overall psychopathy scores, although 
not for interpersonal or affective features. These findings are generally supported by the literature (Nicholls, Ogloff, Brink, \& Spidel, 2005).

The potential for deception is much greater among psychopaths, so interviews with survivors resulted in access to potentially more accurate information about reported and/or unreported harmful actions and crimes. This closer examination of psychopaths in the community provided more insight on the commission of violence and aggression by psychopathic individuals who may not have not been accosted by the criminal justice system or referred to a forensic psychiatric facility. The current study's open-ended data captured diverse, richly detailed, and unique experiences, whereas quantitative aspects formed more solid evaluations that could be generalized to a wider group. Web-based studies significantly reduced participant response time, allowed for easy access to specific groups, and improved anonymity over traditional pen-and-paper formats (Granello \& Wheaton, 2004).

Specific methodological disadvantages included participant, instrument, and design characteristics. Non-English speakers, illiterate people, and individuals without access to the Internet were not able to participate; therefore results from the current study could not be generalized to such populations. Sample bias was inherent in a number of ways. There were a substantial proportion of individuals with familiarity and frequent exposure to psychopaths. Unexpected findings may be explained by perhaps a relatively well-adjusted sample. The majority of participants were already part of support groups, thus receiving some coping and social support resources. Finding survivors with limited coping resources and support networks in order to establish physiological, psychological, 
and interpersonal health, deception experience, coping, and social support differences from the current study sample may be a challenge, however.

Since many self-report measures were used along with a retrospective design, there were opportunities for intentional or unintentional deception. Psychopaths may have easily masqueraded themselves as survivors, due to the anonymous nature of the Internet. Another caveat is that although victims are less likely to be deceptive than psychopaths, there is always a possibility that pertinent information was missing, due to forgetfulness, denial, repression, or lack of knowledge about particular items, thus resulting in erroneous data. The coping scale used for the current study posed problems, likely due to redundancy in item content. However, most measures had moderate to strong reliability and validity, and effort was made to check and reduce the impact of redundancy, which improved the quality of the results. Finally, online surveys limited representativeness, discouraged response rates, resulted in occasional computer errors, and may have still posed confidentiality concerns (Granello \& Wheaton, 2004). The Internet is a hotbed of self-diagnoses and diagnosing others, without medical opinions, although this was controlled for, to some extent, through the use of a psychopathy scale.

\section{Future Directions}

Considering the current study's exploratory nature, there are many recommendations for future research in the areas of victimization, coping, and social support of survivors of psychopaths. Improving sample characteristics in terms of diversity is one major suggestion, which has been implied throughout this discussion. The impact of previous victimization, potentially by multiple psychopaths, could be also explored in future studies. Of importance is looking specifically at how survivors of 
psychopaths lose the trust of others due to fraud allegations and other accusations by psychopaths. Similarly, the nonphysically violent yet harmful actions of psychopaths need to studied in more detail in order to broaden knowledge of the noncriminal or noninstitutionalized psychopath. Future research could examine the chronological progression and reduction of distress symptoms, to establish whether or not a model like Casarez-Levison (1992) proposed would apply to survivors of psychopaths. Health benefits reported imply resilient personalities or protective factors which speed recovery, which research could also address.

Deception from survivors' points of view offers perspectives that research with psychopaths has not tapped into. First, psychopathic dichotomies (Brown \& Leedom, 2008) and their impact need to be better understood. Secondly, definitions of shortcutand delayed-path psychopaths may need to be solidified, revised, and expanded into profiles after replications. Thirdly, the success, or lack thereof, of deception by psychopaths needs to be looked at, as dichotomies suggest that findings may be complicated. Fourth, future research could compare and contrast false victimization syndrome in psychopaths versus stalkers. Last, but not least, psychopaths' possible intrinsic understanding of negative emotional states such as anger may lead to methods of application to positive, prosocial behaviour, which has implications for treatment. If researchers could determine how to get psychopaths to understand, intrinsically, prosocial and positive emotions, treatment prognosis, which is currently perceived as dire and even impossible, may be improved.

In terms of coping and social support, the current study needs replication, particularly with its scale redundancy issues. Other scales could be administered as they 
may be more useful in measuring coping and social support, without overlapping constructs. Factors which may affect coping and social support, such as temporal location of the stressor and perceived controllability, need to be examined as well. To address effectiveness of coping and social support, well-being scales could also be included in future research. Moreover, qualitative research may be more beneficial, particularly with survivors of psychopaths, for more in-depth and flexible exploration of victimization experiences.

\section{Implications and Conclusions}

This study provided information about the victimization experiences, coping, and social support of survivors of psychopaths, using crime victimology research as its foundation. Research with victims and survivors contributes to more knowledge of community-based psychopaths, and possibly predictive, preventative, and treatment measures. Psychopaths inevitably commit harm in the community and within prisons, and cause cognitive, biological, behavioural, emotional, and interpersonal distress to victims and survivors. Severity of psychopathic traits, coping, and social support all affect distress symptoms. Many of these areas could be targeted in therapy and judicial institutions. Understanding victimization experiences and psychopathic deception techniques may be crucial for the public so that they may be aware of potential warning signs. The current study and future research in similar veins can go a long way in assisting the general public, victims, and survivors. 
Survivors of Psychopaths 103

\section{References}

Aftermath: Surviving Psychopathy. (2008). Aftermath: Surviving psychopathy. Retrieved May 7, 2008, from http://www.aftermath-surviving-psychopathy.org/

American Psychiatric Association. (1994). Diagnostic and statistical manual of mental disorders ( $4^{\text {th }}$ ed.). Washington, DC: Author.

Andershed, H., Hodgins, S., \& Tengström, A. (2007). Convergent validity of the Youth Psychopathic Traits Inventory (YPI): Association with the Psychopathy Checklist: Youth Version (PCL:YV). Assessment, 14, 144-154.

Babiak, P. (1995). When psychopaths go to work: A case study of an industrial psychopath. Applied Psychology: An International Review, 44, 171-178.

Babiak, P. (1996). Psychopathic manipulation in organizations: Pawns, patrons, and patsies. In D. J. Cooke, A. E. Forth, J. P. Newman, \& R. D. Hare (Eds.), Issues in criminological and legal psychology: No. 24, International perspective on psychopathy (pp. 12-17). Leicester, UK: British Psychological Society.

Babiak, P. (2000). Psychopathic manipulation at work. In C. Gacono (Ed.), The clinical and forensic assessment of psychopathy: A practitioner's guide (pp. 287-311). Mahwah, NJ: Lawrence Erlbaum Associates.

Babiak, P., \& Hare, R. D. (2006). Snakes in suits: When psychopaths go to work. New York: HarperCollins Publishers, Inc.

Barkas, J. K. (1978). Victims. New York: Charles Scribner.

Barrera, M. (1986). Distinctions between social support concepts, measures, and models. American Journal of Community Psychology, 14, 413-445.

Barrera, M., Sandler, I. N., \& Ramsey, T. B. (1981). Preliminary development of a scale 
of social support: Studies on college students. American Journal of Community Psychology, 9, 435-447.

Barry, K. (1979). Female sexual slavery. Englewood Cliffs, NJ: Prentice-Hall.

Beck, A. T., Steer, R. A., Ball, R., \& Ranieri, W. F. (1996). Comparison of Beck Depression Inventories - IA and -II in psychiatric outpatients. Journal of Personality Assessment, 67, 588-597.

Beck, A. T., Steer, R. A., \& Brown, G. K. (1996). Manual for the Beck Depression Inventory-II. San Antonio, TX: Harcourt Brace \& Company.

Becker, J. V., Skinner, L. J., Abel, G. G., \& Treacy, E. C. (1982). Incidence and types of sexual dysfunctions in rape and incest victims. Journal of Sex \& Marital Therapy, $8,65-74$.

Belmore, M. E., \& Quinsey, V. L. (1994). Correlates of psychopathy in a noninstitutional sample. Journal of Interpersonal Violence, 9, 339-349.

Bentler, P. M. (1990). Comparative fit indices in structural models. Psychological Bulletin, 107, 238-246.

Billings, A. G., \& Moos, R. H. (1981). The role of coping responses and social resources in attenuating the stress of life events. Journal of Behavioral Medicine, 4, 139157.

Blaauw, E., Winkel, F. W., Arensman, E., Sheridan, L., \& Freeve, A. (2002). The toll of stalking: The relationship between features of stalking and psychopathology of victims. Journal of Interpersonal Violence, 17, 50-63.

Blair, R. J. R., Mitchell, D. G. V., Peschardt, K. S., Colledge, E., Leonard, R. A., Shine, J. H., Murray, L. K., \& Perrett, D. I. (2004). Reduced sensitivity to others' fearful 
expressions in psychopathic individuals. Personality and Individual Differences, $37,1111-1122$.

Blair, R. J. R., Mitchell, D. G. V., Richell, R. A., Kelly, S., Leonard, A., Newman, C., et al. (2002). Turning a deaf ear to fear: Impaired recognition of vocal affect in psychopathic individuals. Journal of Abnormal Psychology, 111, 682-686.

Blair, K. S., Richell, R. A., Mitchell, D. G. V., Leonard, A., Morton, J., \& Blair, R. J. R. (2006). They know the words, but not the music: Affective and semantic priming in individuals with psychopathy. Biological Psychology, 73, 114-123.

Blair, J., Sellars, C., Strickland, I., Clark, F., Williams, A., Smith, M., \& Jones, L. (1996). Theory of mind in the psychopath. Journal of Forensic Psychiatry, 7, 15-25.

Boddy, C. R. (2006). The dark side of management decisions: Organisational psychopaths. Management Decision, 44, 1461-1475.

Bollen, K. A. (1989). A new incremental fit index for general structural models. Sociological Methods \& Research, 17, 303-316.

Book, A. (2005). Psychopaths as social predators. Dissertation Abstracts International: Section B: The Sciences and Engineering, 66, 2B, 1216.

Book, A. S., Quinsey, V. L., \& Langford, D. (2007). Psychopathy and the perception of affect and vulnerability. Criminal Justice and Behavior, 34, 531-544.

Boudreaux, E., Kilpatrick, D. G., Resnick, H. S., Best, C. L., \& Saunders, B. E. (1998). Criminal victimization, posttraumatic stress disorder, and comorbid psychopathology among a community sample of women. Journal of Traumatic Stress, 11, 665-678.

Briere, J. (1997). Psychological assessment of adult posttraumatic states. Washington, 
D.C.: American Psychological Association.

Brown, S. L., \& Forth, A. E. (1997). Psychopathy and sexual assault: Static risk factors, emotional precursors, and rapist subtypes. Journal of Consulting and Clinical Psychology, 65, 848-857.

Brown, S. L., \& Leedom, L. J. (2008). Women who love psychopaths: Inside the relationships of inevitable harm. Fairfield, CT: Health and Well-Being Publications.

Browne, M. W., \& Cudeck, R. (1989). Single sample cross-validation indices for covariance measures. Multivariate Behavioral Research, 24, 445-455.

Browne, M. W., \& Cudeck, R. (1993). Alternative ways of assessing model fit. In K. A. Bollen \& J. S. Long (Eds.), Testing structural equation models (pp. 136-162). Newbury Park, CA: Sage.

Byrne, B. M. (2001). Structural Equation Modeling with AMOS: Basic concepts, applications, and programming. Mahwah, NJ: Lawrence Erlbaum Associates Publishers.

Caplan, G. (1974). Support systems and community mental health: Lectures on concept development. New York: Behavioral Publications.

Carver, S. (1997). You want to measure coping but your protocol's too long: Consider the Brief COPE. International Journal of Behavioral Medicine, 4, 92-100.

Carver, C. S., Scheier, M. F., \& Weintraub, J. K. (1989). Assessing coping strategies: A theoretically based approach. Journal of Personality and Social Psychology, 56, 267-283.

Casarez-Levison, R. (1992). An empirical investigation of the coping strategies used by 
victims of crime: Victimization redefined. In E. Viano (Ed.), Critical issues in victomology: International perspectives (pp. 46-57). New York: Springer Publishing Company.

Cassel, J. (1976). The contribution of the social environment to host resistance. American Journal of Epidemiology, 104, 107-123.

Cheung, G. W., \& Rensvold, R. B. (2002). Evaluating goodness-of-fit indices for testing measurement invariance. Structural Equation Modeling, 9, 233-255.

Clarke, J. (2007). Workplace psychopaths. Lecture presented at the Institute of Internal Auditors International Conference, July 8-11, 2007.

Cleckley, H. (1976). The mask of sanity ( $5^{\text {th }}$ ed.). St. Louis, MO: Mosby.

Cobb, S. (1976). Social support as a moderator of life stress. Psychosomatic Medicine, $38,300-314$.

Cohen, J. (1992). A power primer. Psychological Bulletin, 112, 155-159.

Cohen, S., \& Hoberman, H. M. (1983). Positive events and social supports as buffers of life change stress. Journal of Applied Social Psychology, 13, 99-125.

Cohen, S., \& McKay, G. (1984). Social support, stress, and the buffering hypothesis: A theoretical analysis. In A. Baum, J. E. Singer, \& S. E. Taylor (Eds.), Handbook of psychology and health (Vol. IV, pp. 253-267). Hillsdale, NJ: Erlbaum.

Cohen, S., \& Wills, T. A. (1985). Stress, social support and the buffering hypothesis. Psychological Bulletin, 98, 310-357.

Cook, R., Smith, B., \& Harrell, A. (1987). Helping crime victims: Levels of trauma and effectiveness of services. Washington, DC: US Department of Justice, National Institute of Justice. 
Cornell, D. G., Warren, J., Hawk, G., Stafford, E., Oram, G. \& Pine, D. (1996).

Psychopathy in instrumental and reactive violent offenders. Journal of Consulting and Clinical Psychology, 64, 783-790.

Cosway, R., Endler, N. S., Sadler, A. J., \& Deary, I. J. (2000). The Coping Inventory for Stressful Situations: Factorial structure and associations with personality traits and psychological health. Journal of Applied Biobehavioral Research, 5, 121-143.

Creamer, M., Bell, R., \& Failla, S. (2003). Psychometric properties of the Impact of Event Scale-Revised. Behaviour Research and Therapy, 41, 1489-1496.

Culbertson, K. A., \& Dehle, C. (2001). Impact of sexual assault as a function of perpetrator type. Journal of Interpersonal Violence, 16, 992-1007.

Cutrona, C. E., \& Russell, D. (1987). The provisions of social relationships and adaptation to stress. In W.H. Jones \& D. Perlman (Eds.), Advances in personal relationships (Vol. 1, pp. 37-67). Greenwich, Conn.: JAI Press.

Dakof, G. A., \& Taylor, S. E. (1990). Victims' perceptions of social support: What is helpful from whom? Journal of Personality and Social Psychology, 58, 80-89.

DeMatteo, D., Heilbrun, K., \& Marczyk, G. (2006). An empirical investigation of psychopathy in a noninstitutionalized and noncriminal sample. Behavioral Sciences and the Law, 24, 133-146.

Denkers, A. J. M. (1999). Factors affecting support after criminal victimization: Needed and received support from the partner, the social network, and distant support providers. The Journal of Social Psychology, 139, 191-201.

Denkers, A. J. M., \& Winkel, F. W. (1998). Crime victims' well-being and fear in a 
prospective and longitudinal study. International Review of Victimology, 5, 141162.

Douglas, K. S., Ogloff, J. R. P., Nicholls, T. L., \& Grant, I. (1999). Assessing risk for violence among psychiatric patients: The HCR-20 assessment scheme and the Psychopathy Checklist: Screening Version. Journal of Consulting and Clinical Psychology, 67, 917-930.

Dozois, D. J. A., Dobson, K. S., Ahnberg, J. L. (1998). A psychometric evaluation of the Beck Depression Inventory-II. Psychological Assessment, 10, 83-89.

Driscoll, R. J., Worthington, K. A., \& Hurrell, J. J. (1995). Workplace assault: An emerging job stressor. Consulting Psychology Journal: Practice and Research, $47,205-211$.

Dunn, J. L. (2001). Victims' and survivors: Emerging vocabularies of motives for 'battered women who stay'. Sociological Inquiry, 75, 1-30.

Ekman, P. (1980). Biological and cultural contributions to body and facial movement in the expression of emotions. In A. O. Rorty (Ed.), Explaining emotions (pp. 73102). Berkeley: University of California Press.

Elklit, A. (2002). Acute stress disorder in victims of robbery and victims of assault. Journal of Interpersonal Violence, 17, 872-887.

Elklit, A., \& Brink, O. (2004). Acute stress disorder as a predictor of post-traumatic stress disorder in physical assault victims. Journal of Interpersonal Violence, 19, 709726.

Ellis, E. M. (1983). A review of empirical rape research: Victim reactions and response to treatment. Clinical Psychology Review, 3, 473-490. 
Ellis, E., M., Atkeson, B., \& Calhoun, K. (1981). An assessment of long-term reactions to rape. Journal of Abnormal Psychology, 90, 263-266.

Endler, N. S., \& Parker, J. D. (1990). Multidimensional assessment of coping: A critical evaluation. Journal of Personality and Social Psychology, 58, 844-854.

Fields, R. (1977). Northern Ireland: Society under siege. Philadelphia: Temple University Press.

Folkman, S. (1997). Positive psychological states and coping with severe stress. Social Science and Medicine, 45, 1207-1221.

Folkman, S., Lazarus, R. S., Dunkel-Schetter, C., DeLongis, A., \& Gruen, R. J. (1986). Dynamics of a stressful encounter: Cognitive appraisal, coping, and encounter outcomes. Journal of Personality and Social Psychology, 50, 992-1003.

Forth, A. E., Brown, S. L., Hart, S. D., \& Hare, R. D. (1996). The assessment of psychopathy in male and female noncriminals: Reliability and validity. Personality and Individual Differences, 20, 531-543.

Frank, E., \& Stewart, B. D. (1984). Depressive symptoms in rape victims: A revisit. Journal of Affective Disorders, 7, 77-85.

Freedy, J. R., Resnick, H. S., Kilpatrick, D. G., Dansky, B. S., \& Tidwell, R. P. (1993). The psychological adjustment of recent crime victims in the criminal justice system. Journal of Interpersonal Violence, 9, 450-468.

Frick, P. J., Bodin, S. D., \& Barry, C. T. (2000). Psychopathic traits and conduct problems in community and clinic-referred samples of children: Further development of the Psychopathy Screening Device. Psychological Assessment, $12,382-393$. 
Frieze, I. H., Hymer, S., \& Greenberg, M. S. (1987). Describing the crime victim: Psychological reactions to victimization. Professional Psychology: Research and Practice, 18, 299-315.

Garson, G. D. (n.d.). In Structural Equation Modeling. Retrieved April 4, 2009, from Statnotes: Topics in Multivariate Analysis: http://www2.chass.ncsu.edu/garson/pa765/statnote.htm.

Gillstrom, B. J., \& Hare, R. D. (1988). Language-related hand gestures in psychopaths. Journal of Personality Disorders, 2, 21-27.

Golding, S. (1999). Intimate partner violence as a risk factor for mental disorders: A meta-analysis. Journal of Family Violence, 14, 99-132.

Granello, D. H., \& Wheaton, J. E. (2004). Online data collection: Strategies for research. Journal of Counseling \& Development, 82, 387-393.

Grayson, B., \& Stein, M. I. (1981). Attracting assault: Victims' nonverbal cues. Journal of Communication, $31,68-75$.

Green, D. L., \& Diaz, N. (2007). Predictors of emotional stress in crime victims: Implications for treatment. Brief Treatment and Crisis Intervention, 7, 194-205.

Green, D. L., \& Pomeroy, E. C. (2007a). Crime victimization: Assessing differences between violent and nonviolent experiences. Victims \& Offenders, 2, 63-76.

Green, D. L., \& Pomeroy, E. C. (2007b). Crime victims: What is the role of social support? Journal of Aggression, Maltreatment \& Trauma, 15, 97-113.

Green, D. L., Street, C., \& Pomeroy, E. (2005). A multivariate model of the stress and coping process for victims of crime. Stress, Trauma and Crisis: An International Journal, 8, 61-73. 
Gutner, C. A., Rizvi, S. L., Monson, C. M., \& Resick, P. A. (2006). Changes in coping strategies, relationship to the perpetrator, and posttraumatic distress in female crime victims. Journal of Traumatic Stress, 19, 813-823.

Habel, U., Kuhn, E., Salloum, J. B., Devos, H., \& Schneider, F. (2002). Emotional processing in psychopathic personality. Aggressive Behavior, 28, 394-400.

Hanson, R. K. (1990). The psychological impact of sexual assault on women and children: A review. Annals of Sex Research, 3, 187-232.

Hare, R. D. (n.d.). Welcome to "Without Conscience": Robert Hare's website devoted to the study of psychopathy. Retrieved May 7, 2008, from http://www.hare.org

Hare, R. D. (1981). Psychopathy and violence. In J. R. Hays, T. K. Roberts, \& K. S. Soloway (Eds.), Violence and the violent individual (pp. 53-74). Jamaica, NY: Spectrum.

Hare, R. D. (1996). Psychopathy: A clinical construct whose time has come. Criminal Justice and Behavior, 23, 25-49.

Hare, R. D. (1999a). Without conscience: The disturbing world of the psychopaths among us. New York: Guilford Press.

Hare, R. D. (1999b). Psychopathy as a risk factor for violence. Psychiatric Quarterly, 70, 181-197.

Hare, R. D. (2001). Psychopaths and their nature: Some implications for understanding human predatory violence. In A. Raine and J. Sanmartin (Eds.), Violence and psychopathy (pp. 5-34). New York: Kluwer Academic/Plenum Publishers.

Hare, R. D. (2003). Manual for the Revised Psychopathy Checklist ( $2^{\text {nd }}$ ed.). Toronto, ON: Multi-Health Systems. 
Hare, R. D., Cooke, D. J., \& Hart, S. D. (1999). Psychopathy and sadistic personality disorder. In T. Millon, P. H. Blanney., \& R. D. Davies (Eds.), Oxford textbook of psychopathology (pp 555-584). New York: Oxford University.

Hare, R. D., \& Hervé, H. F. (1999). Hare P-SCAN. New York: Multi-Health Systems.

Hare, R. D., \& Jutai, J. W. (1983). Criminal history of the male psychopath: Some preliminary data. Prospective Studies of Crime and Delinquency, 225-236.

Hare, R. D., \& McPherson, L. E. (1984). Violent and aggressive behavior by criminal psychopaths. International Journal of Law and Psychiatry, 7, 35-50.

Hare, R. D., McPherson, L. E., \& Forth, A. E. (1988). Male psychopaths and their criminal careers. Journal of Consulting and Clinical Psychology, 56, 710-714.

Hart, S. D., Cox, D. N., \& Hare, R. D. (1995). The Hare Psychopathy Checklist: Screening Version. Toronto, ON: Multi-Health Systems.

Hart, S. D., \& Hare, R. D. (1997). Psychopathy: Assessment and association with criminal conduct. In D. M. Stoff, J. Maser, \& J. Brieling (Eds.), Handbook of antisocial behavior (pp 22-35). New York: Wiley.

Hemphill, J. F., Hare, R. D., \& Wong, S. (1998). Psychopathy and recidivism: A review. Legal and Criminological Psychology, 3, 141-172.

Hervé, H. F., Mitchell, D., Cooper, B. S., Spidel, A., \& Hare, R. D. (2004). Psychopathy and unlawful confinement: An examination of perpetrator and event characteristics. Canadian Journal of Behavioural Science, 36, 137-145.

Hobfoll, S. E., Freedy, J., Lane, C., \& Geller, P. (1990). Conservation of social resources: Social support resource theory. Journal of Social and Personal Relationships, 7, 465-478. 
Hobfoll, S. E., \& Stokes, J. P. (1988). The process and mechanics of social support. In S. Duck, D. F. Hay, S. E. Hobfoll, W. Ickes, \& B. M. Montgomery (Eds.), Handbook of personal relationships: Theory, research, and interventions (pp. 497-517). Mahwah, NJ: Lawrence Erlbaum Associates.

Holahan, C. J., \& Moos, R. H. (1981). Social support and psychological distress: A longitudinal analysis. Journal of Abnormal Psychology, 90, 365-370.

Holt, S. E., Meloy, J. R., \& Strack, S. (1999). Sadism and psychopathy in violent and sexually violent offenders. Journal of the American Academy of Psychiatry and Law, 27, 23-32.

Horowitz, M., Wilner, M., and Alvarez, W. (1979). Impact of Event Scale: A measure of subjective stress. Psychosomatic Medicine, 41, 209-218.

House, J. S. (1981). Work stress and social support. Reading, MA: Addison-Wesley. Hu, L., \& Bentler, P. M. (1999). Cutoff criteria for fit indexes in covariance structure analysis: Conventional criteria versus new alternatives. Structural Equation Modeling: A Multidisciplinary Journal, 6, 1-55.

Huss, M. T., \& Langhinrichsen-Rohling, J. (2000). Identification of the psychopathic batterer: The clinical, legal, and policy implications. Aggression and Violent Behavior, 5, 403-422.

Janoff-Bulman, R., \& Frieze, I. H. (1983). A theoretical perspective for understanding reactions to victimization. Journal of Social Issues, 39, 1-17.

Johansen, V. A., Wahl, A. K., Eilertsen, D. E., Hanestad, B. R., \& Weisaeth, L. (2006). 
Acute psychological reactions in assault victims of non-domestic violence:

Peritraumatic dissociation, post-traumatic stress disorder, anxiety and depression. Nordic Journal of Psychiatry, 60, 452-462.

Jones, L., Hughes, M., \& Unterstaller, U. (2001). Post-traumatic stress disorder (PTSD) in victims of domestic violence. Trauma, Violence, \& Abuse, 2, 99-119.

Jöreskog, K. G., \& Sörbom, D. (1984). LISREL-VI user's guide ( $3^{\text {rd }}$ ed.). Mooresville, IN: Scientific Software.

Kaniasty, K. (1988). Pretest of candidate measures: Results of two studies. "Violence: Psychological reactions and consequences". Louisville, KY: University of Louisville, Urban Studies Center.

Kaniasty, K., \& Norris, F. (1992). Social support and victims of crime: Matching event, support, and outcome. American Journal of Community Psychology, 20, 211-241.

Kilpatrick, D. G., \& Acierno, R. L. (2003). Mental health needs of crime victims: Epidemiology and outcomes. Journal of Traumatic Stress, 16, 119-132.

Kilpatrick, D. G., Acierno, R.. L., Resnick, H. S., Saunders, B. E., \& Best, C. L. (1997). A 2-year longitudinal analysis of the relationships between violent assault and substance use in women. Journal of Consulting and Clinical Psychology, 65, 834847.

Kilpatrick, D. G., Best, C. L., Veronen, L. J., Amick, A. E., Villeponteaux, L. A., \& Ruff, G. A. (1985). Mental health correlates of criminal victimization: A random community survey. Journal of Consulting and Clinical Psychology, 53, 866-873.

Kimerling, R., \& Calhoun, K. S. (1994). Somatic symptoms, social support, and 
treatment seeking among sexual assault victims. Journal of Consulting and Clinical Psychology, 62, 333-340.

Kirkman, C. A. (2005). From soap opera to science: Towards gaining access to the psychopaths who live among us. Psychology and Psychotherapy: Theory, Research, and Practice, 78, 379-396.

Klaver, J. R., Lee, Z., \& Hart, S. D. (2007). Psychopathy and nonverbal indicators of deception in offenders. Law and Human Behavior, 31, 337-351.

Kocot, T., \& Goodman, L. (2003). The roles of coping and social support in battered women's mental health. Violence Against Women, 9, 323-346.

Kosson, D. S., Kelly, J. C., \& White, J. W. (1997). Psychopathy-related traits predict selfreported sexual aggression among college men. Journal of Interpersonal Violence, 12, 241-254.

Kosson, D. S., Kirkhart, K. J., \& Steuerwald, B. L. (1993, October). Assessment of the interpersonal behavior of psychopaths. Paper presented at the meeting of the American Society of Criminology, Phoenix, AZ.

Kreuter, E. A. (2003). The impact of identity theft through cyberspace. The Forensic Examiner, 12, 30-35.

Kreuter, E. A. (2004). Continued investigation of a psychopathic criminal's behavior as the wheels of justice slowly turn. The Forensic Examiner, 13, 28-36.

Kreuter, E. A. (2006). The psychopathic criminal mother: A case study of her two adult daughters' expression of basic mistrust. In A. Columbus (Ed.), Advances in psychology research (Vol. 41, pp. 75-89). Hauppauge, NY: Nova Science Publishers. 
Landis, J. R., \& Koch, G. G. (1977). The measurement of observer agreement for categorical data. Biometrics, 33, 159-174.

Lawyer, S. R., Ruggiero, K. J., Resnick, H. S., Kilpatrick, D. G., \& Saunders, B. E. (2006). Mental health correlates of the victim-perpetrator relationship among interpersonally victimized adolescents. Journal of Interpersonal Violence, 21, 1333-1353.

Lazarus, R., \& Folkman, S. (1984). Stress, appraisal and coping. New York: Springer.

Lee, Z., Klaver, J. R., \& Hart, S. D. (2008). Psychopathy and verbal indicators of deception in offenders. Psychology, Crime \& Law, 14, 73-84.

Leistico, A. R., Salekin, R. T., DeCoster, J., \& Rogers, R. (2008). A large-scale metaanalysis relating the Hare measures of psychopathy to antisocial conduct. Law and Human Behavior, 32, 28-45.

Lepore, S. J., Evans, G. W., \& Schneider, M. L. (1991). Dynamic role of social support in the link between chronic stress and psychological distress. Journal of Personality and Social Psychology, 61, 899-909.

Letourneau, E. J., Resnick, H. S., Kilpatrick, D. G., Saunders, B. E., Best, C. L. (1996). Comorbidity of sexual problems and posttraumatic stress disorder in female crime victims. Behavior Therapy, 27, 321-336.

Levenson, M. R., Kiehl, K. A., \& Fitzpatrick, C. M. (1995). Assessing psychopathic attributes in a noninstitutionalized population. Journal of Personality and Social Psychology, 68,151-158.

Lilienfeld, S. O., \& Andrews, B. P. (1996). Development and preliminary validation of a 
self-report measure of psychopathic personality traits in noncriminal populations. Journal of Personality Assessment, 66, 488-524.

Louth, S. M., Williamson, S., Alpert, M., Pouget, E. R., \& Hare, R. D. (1998). Acoustic distinctions in the speech of male psychopaths. Journal of Psycholinguistic Research, 27, 375-384.

Lovefraud. (2008). Lovefraud: How to know when love is a con. Retrieved May 7, 2008, from http://www.lovefraud.com

MacArthur Research Network on Mental Health and the Law. (2005). The MacArthur violence risk assessment study. Retrieved November 13, 2007 from http://www.macarthur.virginia.edu/read me file.html

MacPherson, G. J. D. (2003). Predicting escalation in sexually violent recidivism: Use of the SVR-20 and PCL: SV to predict outcome with non-contact recidivists and contact recidivists. Journal of Forensic Psychiatry and Psychology, 14, 615-627.

McCann, I. L., Sakheim, D. K., \& Abrahamson, D. J. (1988). Trauma and victimization: A model of psychological adaptation. The Counseling Psychologist, 16, 531-594.

McCormick, J., \& Trent, M. (2007). The sociopathic style: Personality traits in victims. Retrieved May 8, 2008 from http://www.sociopathicstyle.com/traits/victims.htm

McLeer, A. (1998). Saving the victims: Recuperating the language of the victim and reassessing global feminism. Hypatia, 13, 41-55.

Mealey, L. (1995). The sociobiology of sociopathy: An integrated evolutionary model. Behavioral and Brain Sciences, 18, 523-599.

Meloy, J. R. (1997). Violent attachments. Northvale, NJ: Jason Aronson Inc.

Meloy, J. R. (2000). The nature and dynamics of sexual homicide: An integrative review. 
Aggression and Violent Behavior, 5, 1-22.

Mitchell, R. E., \& Hodson, C. A. (1983). Coping with domestic violence: Social support and psychological health among battered women. American Journal of Community Psychology, 11, 629-654.

Monahan, J., Steadman, H., Silver, E., Appelbaum, P., Robbins, P., Mulvey, E., et al. (2001). Rethinking risk assessment: The MacArthur study of mental disorder and violence. New York: Oxford University Press.

Mullen, B., \& Sulls, J. (1982). The effectiveness of attention and rejection as coping styles: A meta-analysis of temporal differences. Journal of Psychosomatic Research, 26, 43-49.

Murzynski, J., \& Degelman, D. (1996). Body language of women and judgments of vulnerability to sexual assault. Journal of Applied Social Psychology, 26, 16171626.

Muthén, L. K., \& Muthén, B. O. (2006). Mplus user's guide: Statistical analysis with latent variables $\left(4^{\text {th }}\right.$ ed.). Los Angeles: Muthén \& Muthén.

Nicastro, A., M., Cousins, A. V., \& Spitzberg, B. H. (2000). The tactical face of stalking. Journal of Criminal Justice, 28, 69-82.

Nicholls, T. L., Ogloff, J. R. P., Brink, J., \& Spidel, A. (2005). Psychopathy in women: A review of its clinical usefulness for assessing risk for aggression and criminality. Behavioral Sciences and the Law, 23, 779-802.

Nicholls, T. L., Ogloff, J. R. P., \& Douglas, K. S. (2004). Assessing risk for violence among male and female civil psychiatric patients: The HCR-20, PCL: SV, and VSC. Behavioral Sciences and the Law, 22, 127-158. 
Norris, F. H., \& Kaniasty, K. (1994). Psychological distress following criminal victimization in the general population: Cross-sectional, longitudinal, and prospective analyses. Journal of Consulting and Clinical Psychology, 62, 111123.

Norris, F. H., \& Kaniasty, K. (1996). Received and perceived support in times of stress: A test of the social support deterioration deterrence model. Journal of Personality and Social Psychology, 71, 498-511.

Nouvion, S. O., Cherek, D. R., Lane, S. D., Tcheremissine, O. V., \& Lieving, L. M. (2007). Human proactive aggression: Association with personality disorders and psychopathy. Aggressive Behavior, 33, 552-562.

Nunally, J. C. (1978). Psychometric theory ( $2^{\text {nd }}$ ed.). New York: McGraw-Hill.

Orlando, J. A., \& Koss, M. P. (1983). The effects of sexual victimization on sexual satisfaction: A study of the negative-association hypothesis. Journal of Abnormal Psychology, 92, 104-106.

Pagliaro, M. J. L., \& Forth, A. (2009). Survivors of psychopaths: An investigation of victimization experiences, coping strategies, and social support. Poster presented at the Society for the Scientific Study of Psychopathy $3^{\text {rd }}$ Biannual Conference, New Orleans, LA, April 17, 2009.

Pathé, M., \& Mullen, P. E. (1997) The impact of stalkers on their victims. British Journal of Psychiatry, 170, 12-17.

Patrick, C. J., Cuthbert, B. N., \& Lang, P. J. (1994). Emotion in the criminal psychopath: Fear image processing. Journal of Abnormal Psychology, 103, 523-534.

Paulhus, D.L., Hemphill, J.D., \& Hare, R.D. (in press). Manual for the Self-Report 
Psychopathy scale-III. Toronto: Multi-Health Systems.

Porter, S., \& Woodworth, M. (2007). "I'm sorry I did it... but he started it": A comparison of the official and self-reported homicide descriptions of psychopaths and nonpsychopaths. Law and Human Behavior, 21, 91-107.

Porter, S., Fairweather, D., Drugge, J., Hervé, H., Birt, A., \& Boer, D. P. (2000). Profiles of psychopathy in incarcerated sexual offenders. Criminal Justice and Behavior, $27,216-233$.

Porter, S., Woodworth, M., Earle, J., Drugge, J., \& Boer, D. (2003). Characteristics of sexual homicides committed by psychopathic and nonpsychopathic offenders. Law and Human Behavior, 27, 459-470.

Psychopath-Research. (2006). Psychopath-Research forum. Retrieved May 7, 2008, from http://www.psychopath-research.com/forum/ubbthreads.php

Purcell, R., Pathé, M., \& Mullen, P. E. (2005). Association between stalking victimisation and psychiatric morbidity in a random community sample. British Journal of Psychiatry, 187, 416-420.

Quinsey, V. L., Rice, M. E., \& Harris, G. T. (1995). Actuarial prediction of sexual recidivism. Journal of Interpersonal Violence, 10, 85-105.

Resick, P. A. (1993). The psychological impact of rape. Journal of Interpersonal Violence, 8, 223-255.

Resnick, H. S., Kilpatrick, D. G., Dansky, B. S., Saunders, B., \& Best, C. L. (1993). Prevalence of civilian trauma and posttraumatic stress disorder in a representative national sample of women. Journal of Consulting and Clinical Psychology, 61, 984-991. 
Rice, M. E., Harris, G. T., \& Cormier, C. A. (1992). Evaluation of a maximum security therapeutic community for psychopaths and other mentally disordered offenders. Law and Human Behavior, 16, 399-412.

Richards, L., Rollerson, B., \& Phillips, J. (1991). Perceptions of submissiveness: Implications for victimization. Journal of Psychology: Interdisciplinary and Applied, 125, 407-411.

Richell, R. A., Mitchell, D. G. V., Newman, C., Leonard, A., Baron-Cohen, S., \& Blair, R. J. R. (2003). Theory of mind and psychopathy: Can psychopathic individuals read the 'language of the eyes'? Neuropsychologia, 41, 523-526.

Riggs, D. S., Rothbaum, B. O., \& Foa, E. B. (1995). A prospective examination of symptoms of posttraumatic stress disorder in victims of nonsexual assault. Journal of Interpersonal Violence, 10, 201-214.

Rimé, B., Bouvy, H., Leborgne, B., \& Rouillon, F. (1978). Psychopathy and nonverbal behavior in an interpersonal situation. Journal of Abnormal Psychology, 87, 636643.

Rogers, R., \& Cruise, K. R. (2000). Malingering and deception among psychopaths. In C. B. Gacono (Ed.), The clinical and forensic assessment of psychopathy: A practitioner's guide (pp. 269-284). Mahwah, NJ: Lawrence Erlbaum Associates.

Ross, S. R., \& Rausch, M K. (2001). Psychopathic attributes and achievement disposition in a college sample. Personality and Individual Differences, 30, 471-480.

Roth, S., \& Cohen, L. J. (1986). Approach, avoidance, and coping with stress. American Psychologist, 41, 813-819.

Salekin, R. T., Rogers, R., \& Sewell, K. W. (1996). A review and meta-analysis of the 
Psychopathy Checklist-Revised: Predictive validity of dangerousness. Clinical Psychology: Science and Practice, 3, 203-215.

Salekin, R. T., Trobst, K. K., \& Krioukova, M. (2001). Construct validity of psychopathy in a community sample: A nomological net approach. Journal of Personality Disorders, $15,425-441$.

Scarpa, A., Haden, S. C., \& Hurley, J. (2006). Community violence victimization and symptoms of posttraumatic stress disorder: The moderating effects of coping and social support. Journal of Interpersonal Violence, 21, 446-469.

Schat, A. C. H., \& Kelloway, E. K. (2003). Reducing the adverse consequences of workplace aggression and violence: The buffering effects of organizational support. Journal of Occupational Health Psychology, 8, 110-122.

Serin, R. C. (1996). Violent recidivism in criminal psychopaths. Law and Human Behavior, 20, 207-217.

Seto, M. C., \& Barbaree, H. E. (1999). Psychopathy, treatment behavior, and sex offender recidivism. Journal of Interpersonal Violence, 14, 1235-1248.

Sjöstedt, G., \& Långström, N. (2002). Assessment of risk for criminal recidivism among rapists: A comparison of four different measures. Psychology, Crime \& Law, 8, 25-40.

Skeem, J. L., \& Mulvey, E. P. (2001). Psychopathy and violence among civil psychiatric patients: Results from the MacArthur violence risk assessment study. Journal of Consulting and Clinical Psychology, 69, 358-374.

Skilling, T. A., Quinsey, V. L., \& Craig, W. M. (2001). Evidence of a taxon underlying serious antisocial behavior in boys. Criminal Justice and Behavior, 28, 450-470. 
Society for the Scientific Study of Psychopathy. (2007). Society for the Scientific Study of Psychopathy home page. Retrieved May 7, 2008, from http://www.psychopathysociety.com

Sorenson, S. B., \& Golding, J. M. (1990). Depressive sequelae of recent criminal victimization. Journal of Traumatic Stress, 3, 337-350.

Steer, R. A., Ball, R., Ranieri, W. F., \& Beck, A. T. (1997). Further evidence for the construct validity of the Beck Depression Inventory-II in psychiatric outpatients. Psychological Reports, 80, 443-446.

Steketee, G., \& Foa, E. B. (1987). Rape victims: Post-traumatic stress responses and their treatment: A review of the literature. Journal of Anxiety Disorders, 1, 69-86.

Stermac, L., Del Bove, G., \& Addison, M. (2001). Violence, injury, and presentation patterns in spousal sexual assaults. Violence Against Women, 7, 1218-1233.

Stout, M. (2005). The sociopath next door. New York: Broadway Books.

Straight, E. S., Harper, F. W. K., \& Arias, I. (2003). The impact of partner psychological abuse on health behaviors and health status in college women. Journal of Interpersonal Violence, 18, 1035-1054.

Survey Monkey. (1999). SurveyMonkey.com: Because knowledge is everything. Retrieved August 6, 2008, from http://www.surveymonkey.com

Temple, J. R., Weston, R., Rodriguez, B. F., \& Marshall, L. L. (2007). Differing effects of partner and nonpartner sexual assault on women's mental health. Violence Against Women, 13, 285-297.

Thoits, P. A. (1986). Social support as coping assistance. Journal of Consulting and Clinical Psychology, 54, 416-423. 
Thompson, M. P., \& Kaslow, N. J. (2000). Partner violence, social support, and distress among inner-city African American women. American Journal of Community Psychology, 28, 127-143.

Titus, R. M., Heinzelmann, F., \& Boyle, J. M. (1995). Victimization of persons by fraud. Crime \& Delinquency, 41, 54-72.

Ullman, S. E. (1999). Social support and recovery from sexual assault: A review. Aggression and Violent Behavior, 4, 343-358.

Valentiner, D. P., Foa, E. B., Riggs, D. S., \& Gershuny, B. S. (1996). Coping strategies and posttraumatic stress disorder in female victims of sexual and nonsexual assault. Journal of Abnormal Psychology, 105, 455-458.

Victim. (2005). In Merriam-Webster Online Dictionary. Retrieved November 10, 2007, from Merriam-Webster Online: http://www.m-w.com/dictionary/victim

Victim. (2006). In The Concise Oxford English Dictionary (11 ${ }^{\text {th }}$ ed. revised). Oxford University Press. Retrieved November 10, 2007, from Oxford Reference Online: http://www.oxfordreference.com/views/ENTRY.html?subview=Main\&entry=t23. e63289

Vitacco, M. J., Caldwell, M. F., Van Rybroek, G. J., \& Gabel, J. (2007). Psychopathy and behavioral correlates of victim injury in serious juvenile offenders. Aggressive Behavior, 33, 537-544.

Vitale, J. E., \& Newman, J. P. (2001). Using the Psychopathy Checklist-Revised with female samples: Reliability, validity, and implications for clinical utility. Clinical Psychology: Science and Practice, 8, 117-132.

Walsh, T. C. (1999). Psychopathic and nonpsychopathic violence among alcoholic 
offenders. International Journal of Offender Therapy and Comparative Criminology, 43, 34-48.

Walsh, Z., \& Kosson, D. S. (2007). Psychopathy and violent crime: A prospective study of the influence of socioeconomic status and ethnicity. Law and Human Behavior, 31, 209-229.

Walsh, Z., Swogger, M. T., \& Kosson, D. S. (2004). Psychopathy, IQ, and violence in European American and African American county jail inmates. Journal of Consulting and Clinical Psychology, 72, 1165-1169.

Weaver, T. L., \& Clum, G. A. (1995). Psychological disorders associated with interpersonal violence: A meta-analysis. Clinical Psychology Review, 15, 115140.

Weiss, D. S. (2004). The Impact of Event Scale-Revised. In J. P. Wilson, \& T. M. Keane (Eds.), Assessing psychological trauma and PTSD: A handbook for practitioners (pp. 168-189). New York: Guilford Press.

Weiss, D. S., \& Marmar, C. R. (1997). The Impact of Event Scale-Revised. In J. P. Wilson, \& T. M. Keane (Eds.), Assessing psychological trauma and PTSD: A handbook for practitioners (pp. 399-411). New York: Guilford Press.

Wethington, E., \& Kessler, R. C. (1986). Perceived support, received support, and adjustment to stressful life events. Journal of Health and Social Behavior, 27, 7889.

Wheaton, B., Muthén, B., Alwin, D. F., \& Summers, G. F. (1977). Assessing reliability and stability in panel models. Sociological Methodology, 8, 84-136.

Wieclaw, J., Agerbo, E., Mortensen, P. B., Burr, H., Tüchsen, F., \& Bonde, J. P. (2006). 
Work related violence and threats and the risk of depression and stress disorders. Journal of Epidemiology and Community Health, 60, 771-775.

Wilcox, B. L. (1981). Social support, life stress, and psychological adjustment: A test of the buffering hypothesis. American Journal of Community Psychology, 9, 371386.

Williams, K. M., Nathanson, C., \& Paulhus, D. L. (2003). Structure and validity of the Self-Report Psychopathy scale-III in normal populations. Poster presented at the meeting of the American Psychological Association, Toronto, Canada.

Williams, K. M., Paulhus, D. L., \& Hare, R. D. (2007). Capturing the four-factor structure of psychopathy in college students via self-report. Journal of Personality Assessment, 88, 205-219.

Williamson, S., Hare, R. D., \& Wong, S. (1987). Violence: Criminal psychopaths and their victims. Canadian Journal of Behavioural Science, 19, 454-462.

Wirtz, P. W., \& Harrell, A. V. (1987a). Assaultive versus nonassaultive victimization: A profile analysis of psychological response. Journal of Interpersonal Violence, 2, 264-277.

Wirtz, P. W., \& Harrell, A. V. (1987b). Victim and crime characteristics, coping responses, and short- and long-term recovery from victimization. Journal of Consulting and Clinical Psychology, 55, 866-871.

Woodworth, M., \& Porter, S. (2002). In cold blood: Characteristics of criminal homicide as a function of psychopathy. Journal of Abnormal Psychology, 111, 436-445.

Yap, M. B. H., \& Devilly, G. J. (2004). The role of perceived social support in crime victimization. Clinical Psychology Review, 24, 1-14 
Zona, M. A., Palarea, R. E., \& Lane, J. C. (1998). In J. R. Meloy (Ed.), The psychology of stalking: Clinical and Forensic Perspectives (pp. 85-112). New York: Academic Press. 


\section{Appendix A}

\section{Informed Consent Form}

Informed consent forms are designed to ensure that you understand the study's purpose and requested tasks, and that you have enough information to determine whether or not you wish to participate.

Research title: Victimization, coping, and social support of adult survivors of psychopaths.

Research personnel: This study is being conducted by Masters student, Melissa, under the supervision of Dr. Adelle Forth from the Department of Psychology at Carleton University in Ottawa, Ontario, Canada.

Purpose and tasks: The purpose of this study is to gain an understanding of the victimization experiences of adult (18+) survivors of psychopaths, in an attempt to raise awareness amongst the general public, and mental health and criminal justice professionals. One web-based interview with brief self-report scales and open-ended questions is involved. You will be asked to rate the presence or absence of psychopathic traits of the most recent psychopathic individual you have been involved with on one scale. Questions revolve around demographics, your relationship and experiences with the psychopath, including being deceived and its impact on your mental and physical health, your ways of coping, and your support networks.

Duration and location: The entire interview will take approximately an hour. The study is located at:

https://www.surveymonkey.com/s.aspx?sm=tkKgwTr 2fZ4Ehy4i 2b0h6ngQ 3d 3d therefore you can participate at your convenience in an Internet-accessible location. The study is open between November 1st, 2008 and December 31st, 2008.

Potential risk and discomfort: A potential risk is safety, particularly if you are still involved, so please ensure that you are in a safe location before viewing the survey website. Security issues are possible risks associated with any collection of information online. The interview's web source, Survey Monkey, does not have access to your data. Links to websites can be tracked or saved and this may be an issue, particularly if other people have access to your computer. To reduce these risks, Survey Monkey's privacy measures were selected and a link to instructions on Internet security measures will be provided after you exit the interview. You may feel that some questions are too sensitive or personal to discuss. A few questions in this study ask about stressful or traumatic events which have happened to you, so you may experience some distress, including flashbacks. If you feel uncomfortable answering any particular question for any reason, you can leave it blank, and choose to continue or discontinue the interview.

Anonymity and confidentiality: Due to the sensitive nature of this study, no names or easily identifiable information will be requested. The data will be kept confidential, as 
only my supervisor (Dr. Forth) and myself will have access to it. The information collected will be used for a Masters thesis and research publications, but no individually identifiable data will be released in these sources.

Right to withdraw: Your participation is entirely voluntary. You have the right to not disclose information for any question and to end the study any time you wish. If you were referred to this study through a forum for survivors of psychopaths or websites associated with psychopathy research, your anonymity ensures that your participation will not affect your relationships with people involved with the referring sites.

Contact information: Should you require further information regarding this study, you can contact the following individuals, all of whom are affiliated with the Department of Psychology:

(1) Researcher: Melissa, Masters Student in Forensic Psychology, psurvivorstudy@gmail.com

(2) Supervisor: Dr. Adelle Forth, Associate Professor, 1-613-520-2600, ext. 1267, adelle forth@carleton.ca

Should I have any ethical or other concerns regarding this study, I can contact:

(1) Department Chair: Dr. Janet Mantler, 1-613-520-2600, ext. 4173, janet mantler@carleton.ca

(2) Ethics Chair: Dr. Avi Parush, Professor, 1-613-520-2600, ext. 6026, avi parush@carleton.ca

By checking the circle below, I have indicated that $I$ have read the above and agree to participate in this study.

o

Date: 


\section{Appendix B}

\section{SRP III-R12}

Please rate the degree to which you agree with the following statements about the person whom you suspect or know is a psychopath. If there has been more than one psychopath in your life, please choose the most recent one. Only answer items if you are certain about whether you agree or disagree, based on your observations and knowledge. This scale was chosen over other psychopathy scales because it reflects more observable versus unobservable actions. You can be honest because you are given complete anonymity.

$$
\begin{aligned}
& 0=\text { don't } \quad 1=\text { disagree } \quad 2=\text { disagree } \quad 3=\text { neutral } \quad 4=\text { agree } \quad 5=\text { agree } \\
& \text { know strongly }
\end{aligned}
$$

He or she...

1. Is a rebellious person.

2. Is more tough-minded than other people.

3. Thinks he or she could "beat" a lie detector.

4. Has taken illegal drugs (i.e., marijuana, ecstacy)

5. Has never been involved in delinquent gang activity.

6. Has never stolen a truck, car, or motorcycle.

7. Considers most people as wimps.

8. Purposely flatters people to get them on his or her side.

9. Has often done something dangerous just for the thrill of it.

10. Has tricked someone into giving him or her money.

11. Finds it torturing to see an injured animal. $\begin{array}{lllllll}0 & 1 & 2 & 3 & 4 & 5\end{array}$

12. Has assaulted a law enforcement official or $\begin{array}{lllllll}0 & 1 & 2 & 3 & 4 & 5\end{array}$ social worker.

13. Has pretended to be someone else in order $\quad \begin{array}{lllllllll}0 & 1 & 2 & 3 & 4 & 5\end{array}$ to get something.

14. Always plans out his or her weekly activities.

15. Is not tricky or sly.

16. Likes to see fist fights.

17. Would be good at a dangerous job because he or she makes fast decisions.

18. Has never tried to force someone to have $\quad \begin{array}{lllllllll}0 & 1 & 2 & 3 & 4 & 5\end{array}$ sex.

$\begin{array}{llllll}0 & 1 & 2 & 3 & 4 & 5 \\ 0 & 1 & 2 & 3 & 4 & 5 \\ 0 & 1 & 2 & 3 & 4 & 5\end{array}$

$\begin{array}{llllll}0 & 1 & 2 & 3 & 4 & 5\end{array}$

$\begin{array}{lllllll}0 & 1 & 2 & 3 & 4 & 5\end{array}$

$\begin{array}{llllll}0 & 1 & 2 & 3 & 4 & 5\end{array}$

$\begin{array}{llllll}0 & 1 & 2 & 3 & 4 & 5\end{array}$

$\begin{array}{llllll}0 & 1 & 2 & 3 & 4 & 5\end{array}$

$\begin{array}{llllll}0 & 1 & 2 & 3 & 4 & 5\end{array}$

$\begin{array}{llllll}0 & 1 & 2 & 3 & 4 & 5\end{array}$

$\begin{array}{llllll}0 & 1 & 2 & 3 & 4 & 5\end{array}$

$\begin{array}{llllll}0 & 1 & 2 & 3 & 4 & 5\end{array}$

$\begin{array}{llllll}0 & 1 & 2 & 3 & 4 & 5\end{array}$

$\begin{array}{llllll}0 & 1 & 2 & 3 & 4 & 5\end{array}$

$\begin{array}{llllll}0 & 1 & 2 & 3 & 4 & 5\end{array}$


19. Has friends that would say he or she is a warm person.

20. Would get a kick out of 'scamming' $\quad \begin{array}{llllllll}0 & 1 & 2 & 3 & 4 & 5\end{array}$ someone.

21. Has never attacked someone with the idea $\quad \begin{array}{llllllll}0 & 1 & 2 & 3 & 4 & 5\end{array}$ of injuring them.

22. Has never missed appointments.

23. Avoids horror movies.

24. Trusts other people to be honest.

25. Hates high speed driving.

26. Feels so sorry when he or see sees a homeless person.

27. Thinks it's fun to see how far he or she can $\quad \begin{array}{llllllll}0 & 1 & 2 & 3 & 4 & 5\end{array}$ push people before they get upset.

28. Enjoys doing wild things.

29. Has broken into a building or vehicle in order to steal something or vandalize.

30. Doesn't bother to keep in touch with his or $\begin{array}{llllllll}0 & 1 & 2 & 3 & 4 & 5\end{array}$ her family any more.

31. Finds it difficult to manipulate people.

32. Rarely follows the rules.

33. Never cries at movies.

34. Has never been arrested.

35. Thinks he or she should take advantage of other people before they do it to him or her.

36. Doesn't enjoy gambling for real money.

37. Has people who say he or she is coldhearted.

38. Has people who can usually tell if he or she $\quad \begin{array}{llllllll}0 & 1 & 2 & 3 & 4 & 5\end{array}$ is lying.

$\begin{array}{llllllllll}\text { 30. Likes to have sex with people he or she } & & 0 & 1 & 2 & 3 & 4 & 5\end{array}$ barely knows.

40. Loves violent sports and movies.

41. Thinks that sometimes he or she has to pretend that he or she likes people to get something out of them.

42. Is an impulsive person.

43. Has taken hard drugs (e.g., heroin, cocaine)

44. Is a soft-hearted person.

45. Can talk people into anything.

46. Never shoplifted from a store.

47. Doesn't enjoy taking risks.

48. Thinks people are too sensitive when he or she tells them the truth about themselves.

49. Was convicted of a serious crime.

50. Thinks most people tell lies everyday.

$\begin{array}{llllll}0 & 1 & 2 & 3 & 4 & 5 \\ 0 & 1 & 2 & 3 & 4 & 5\end{array}$


51. Keeps getting in trouble for the same things $\begin{array}{llllllll}0 & 1 & 2 & 3 & 4 & 5\end{array}$ over and over.

52. Carries a weapon (knife or gun) for

$\begin{array}{llllll}0 & 1 & 2 & 3 & 4 & 5\end{array}$
protection every now and then.

53. Thinks people cry way too much at funerals.

54. Thinks he or she can get what he or she wants by telling people what they want to hear.

55. Easily gets bored.

56. Never feels guilty over hurting others.

57. Has threatened people into giving him or her money, clothes, or makeup.

58. Thinks a lot of people are "suckers" and $\quad \begin{array}{llllllll}0 & 1 & 2 & 3 & 4 & 5\end{array}$ can easily be fooled.

59. Admits that he or she often "mouths off" $\quad \begin{array}{llllllll}0 & 1 & 2 & 3 & 4 & 5\end{array}$ without thinking.

60. Sometimes dumps friends that he or she $\quad \begin{array}{llllllll}0 & 1 & 2 & 3 & 4 & 5\end{array}$ thinks he or she doesn't need anymore.

61. Would never step on others to get what he $\begin{array}{llllllll}0 & 1 & 2 & 3 & 4 & 5\end{array}$ or she wants.

62. Has close friends who served time in prison.

63. Purposely tried to hit someone with the $\quad \begin{array}{llllllll}0 & 1 & 2 & 3 & 4 & 5\end{array}$ vehicle he or she was driving.

64. Has violated his or her probation from $\quad \begin{array}{lllllllll}0 & 1 & 2 & 3 & 4 & 5\end{array}$ prison. 
Appendix C

\section{Interview Protocol}

\section{A. Survivor Demographics}

This section mostly includes questions about you, and occasionally, the psychopath (just questions \#3 and \#5). If there has been more than one psychopath in your life, please choose the most recent one. Some questions allow you to fill in information, whereas others have several choices of which you can pick one. The "other (please specify):" category can include any answer of your choice that is not applied. If you do not wish to answer a specific question, please leave it blank.

1. Age:

2. Gender (you):

a Male

口 Female

3. Gender (psychopath):

口 Male

๑ Female

4. Race / ethnicity (you):

- Caucasian

- African-American

- Asian

- Hispanic

- Aboriginal

․ Other (please specify):

5. Race / ethnicity (psychopath):

a Caucasian

- African-American

- Asian

a Hispanic

a Aboriginal

a Other (please specify):

6. Location:

a Canada

a United States

a Europe (UK)

a Europe (non-UK)

a Other (please specify): 
7. Employment status:

Not employed (not looking for work)

a Not employed (looking for work)

a Part-time

a Full-time

口 Seasonal or contract

व Retired

8. Occupational background:

口 Information technology / Computing

- Service / Support

Engineering / Science

- Medical / Government

口 Student

口 Other (please specify):

9. Highest level of education completed:

a Elementary school

a Secondary school

- Community college

口 Technical or trade school

口 University

․ Graduate school

10. Which of the following income categories would you consider yourself to be in?

- Low class (i.e., below the poverty line, struggling with basic needs such as food, shelter, and medical care)

- Middle class (i.e., can afford basic needs, have some extra resources)

口 Upper class (i.e., can afford well beyond basic needs, have many extra resources, ability to live luxurious lifestyle if desired)

11. Where did you find out about this study?:

a Love Fraud

口 Psychopath Forum

- Aftermath: Surviving Psychopathy

a Dr. Hare or SSSP site

a Researcher or clinician referral

口 Other (please specify):

12. What is / are your motivation(s) for participation in this study? 


\section{B. Your Relationship and Experience with the Psychopath}

This section asks questions about your relationship and experience with the most recent psychopath in your life. Please note that "involvement" means exposure to or interaction with the psychopath, and not necessarily an intimate partnership. Some questions ask you to fill in information, others have specific items for you to choose or rate. A few questions have a N/A (not applicable) designation. If you do not wish to answer a specific question, please leave it blank.

1. What is/was your relationship to the psychopath?

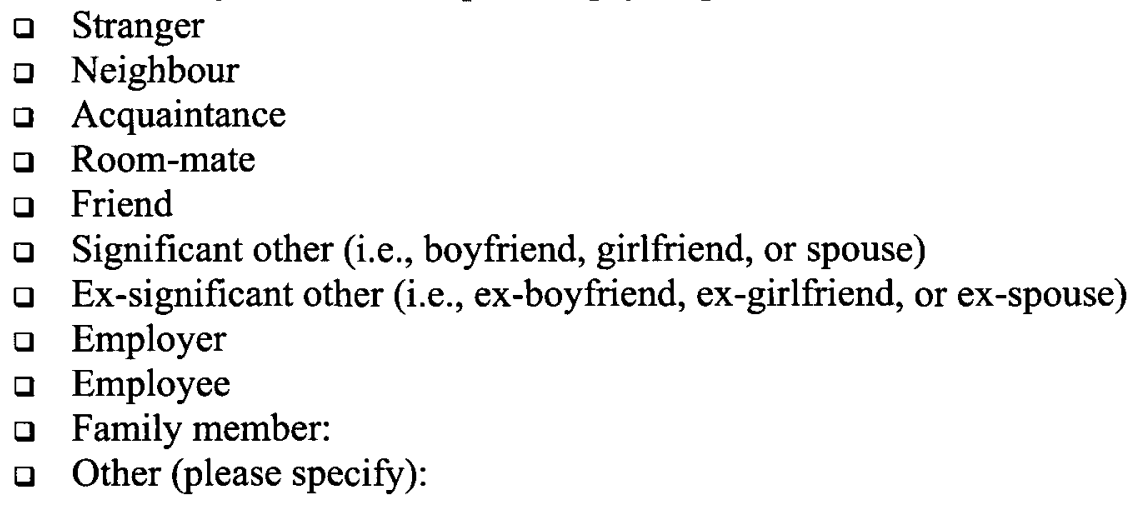

2. Are you currently involved with the psychopath?

a Yes

a No

3. (CURRENT INVOLVEMENT): How long has your relationship lasted to this day?

a Less than 6 months

a 6 months to 12 months

a 1 to 2 years

व 2 to 5 years

a 5 to 10 years

a 10 years to 20 years

a More than 20 years

a $\mathrm{N} / \mathrm{A}$

4. (PAST INVOLVEMENT): How long did the relationship last?

a Less than 6 months

a 6 months to 12 months

a 1 to 2 years

d 2 to 5 years

a 5 to 10 years

a 10 years to 20 years

a More than 20 years

a N/A 
5. (PAST INVOLVEMENT): How long ago did contact with him or her stop?

व Less than 6 months

a 6 months to 12 months

व 1 to 2 years

- 2 to 5 years

․ 5 to 10 years

口 10 years to 20 years

口 More than 20 years

a $\mathrm{N} / \mathrm{A}$

6. How often was your exposure to the psychopath?:

口 Rare (a single incident)

a Mild (a few incidents)

- Moderate (several incidents)

口 Extreme (frequent incidents)

7. What was the most serious degree of physical injury committed against you in adulthood?

a None

․ Mild injury / no medical treatment

a Moderate injury / first aid or outpatient medical treatment

口 Extreme injury / hospitalized

8. What kind(s) of physically violent acts did the psychopath commit against you in adulthood (check all that apply)?

a None

a Physical

a Sexual

9. What kind(s) of nonviolent but harmful acts did the psychopath commit against you in adulthood (check all that apply)?

a None

a Emotional

a Spiritual

口 Financial

口 Substance (i.e., forced intoxication)

- Deceit (i.e., lies, manipulation)

a Property crime (please specify):

10. On the following scale, please rate how you perceive the psychopath to have an impact on these aspects of your health:

physical

Rare Mild

mental

Mild

Moderate

Extreme 


\section{Open-Ended Interview Questions}

This section includes a few questions related to you and your involvement with the most recent psychopath in your life. If you prefer not to answer a specific question, please leave it blank. If the questions are not applicable, please put $\mathrm{N} / \mathrm{A}$. To ensure further anonymity, please use pseudonyms and general statements (i.e., I met the psychopath at an university versus I met the psychopath at the University of [City]).

1. How did you meet him or her?

2. What happened the first time you met him or her?

3. What were your first impressions? What was appealing and / or not appealing about him or her?

4. If you noticed anything worrisome or unusual about him or her when you first met, what were they?

5. If there were any other encounters...

a. Were these worrisome or unusual behaviours common throughout your involvement?

b. How did he or she try to explain away these worrisome or unusual behaviours?

c. What made the explanations believable and / or not believable?

6. If there was any deception involved at any point in your relationship with the psychopath, what were the subjects (i.e., marriage, work, money)?

7. Please summarize one major deception in which you were a victim / survivor of.

a. How did you feel about his or her deceptive behaviour in this circumstance?

b. If you expressed your thoughts, emotions, and feelings about his or her behaviour to him or her, how did he or she respond?

c. How sincere do you feel his or her response(s) was / were to your concerns about his or her behaviour?

d. How did you figure out that deception was being used? 


\section{Appendix D}

\section{Impact of Event Scale-Revised (IES-R)}

The following is a list of difficulties people sometimes have after stressful life events. Please read each item, and then indicate how distressing each difficulty has been for you since the last contact you have had with the most recent psychopath in your life. How much were you distressed or bothered by these difficulties?

\begin{tabular}{|l} 
This has distressed me $\ldots$ \\
$0=$ not at all $\quad 1=$ a little bit $\quad 2=$ moderately $\quad 3=$ quite a bit $\quad 4=$ extremely
\end{tabular}

1. Any reminder brought back feelings about it.

2. I had trouble staying asleep.

3. Other things kept making me think about it.

4. I felt irritable and angry.

5. I avoided letting myself get upset when I thought about it or was reminded of it.

6. I thought about it when I didn't mean to.

7. I felt as if it hadn't happened or wasn't real.

8. I stayed away from reminders about it.

9. Pictures about it popped into my mind.

10. I was jumpy and easily startled.

11. I tried not to think about it.

12. I was aware that I still had a lot of feelings about it, but I didn't deal with them.

13. My feelings about it were kind of numb.

14. I found myself acting or feeling like I was back at that time.

15. I had trouble falling asleep.

16. I had waves of strong feelings about it.

17. I tried to remove it from my memory.

18. I had trouble concentrating.

19. Reminders of it caused me to have physical reactions, such as sweating, trouble breathing, nausea, or a pounding heart.

20. I had dreams about it.

21. I felt watchful and on guard.

22. I tried not to talk about it.

$\begin{array}{lllll}0 & 1 & 2 & 3 & 4 \\ 0 & 1 & 2 & 3 & 4 \\ 0 & 1 & 2 & 3 & 4 \\ 0 & 1 & 2 & 3 & 4 \\ 0 & 1 & 2 & 3 & 4 \\ & & & & \\ 0 & 1 & 2 & 3 & 4 \\ 0 & 1 & 2 & 3 & 4 \\ 0 & 1 & 2 & 3 & 4 \\ 0 & 1 & 2 & 3 & 4 \\ 0 & 1 & 2 & 3 & 4 \\ 0 & 1 & 2 & 3 & 4 \\ 0 & 1 & 2 & 3 & 4\end{array}$

$\begin{array}{lllll}0 & 1 & 2 & 3 & 4 \\ 0 & 1 & 2 & 3 & 4\end{array}$

$\begin{array}{lllll}0 & 1 & 2 & 3 & 4 \\ 0 & 1 & 2 & 3 & 4 \\ 0 & 1 & 2 & 3 & 4 \\ 0 & 1 & 2 & 3 & 4 \\ 0 & 1 & 2 & 3 & 4\end{array}$

$\begin{array}{lllll}0 & 1 & 2 & 3 & 4 \\ 0 & 1 & 2 & 3 & 4 \\ 0 & 1 & 2 & 3 & 4\end{array}$




\section{Appendix E}

\section{Beck Depression Inventory-II (BDI-II)}

Below is a list of common symptoms of depression. Please read each group of statements carefully, and then pick out the one statement in each group that best describes the way you have been feeling since the last contact you have had with the most recent psychopath in your life. Select the number beside the statement you have picked. If several statements in the group seem to apply equally well, select the highest number for that group. Be sure that you do not choose more than one statement for any group.

\begin{tabular}{|c|c|}
\hline $\begin{array}{l}\text { 1. Sadness } \\
0 \text { - I do not feel sad } \\
1 \text { - I feel sad much of the time } \\
2 \text { - I am sad all the time } \\
3 \text { - I am so sad or unhappy that I can't } \\
\text { stand it }\end{array}$ & $\begin{array}{l}\text { 2. Pessimism } \\
0 \text { - I am not discouraged about my future } \\
1 \text { - I feel more discouraged about my future } \\
\text { than I used to be } \\
2 \text { - I do not expect things to work out for } \\
\text { me } \\
3 \text { - I feel my future is hopeless and will } \\
\text { only get worse }\end{array}$ \\
\hline $\begin{array}{l}\text { 3. Past failure } \\
0 \text { - I do not feel like a failure } \\
1 \text { - I have failed more than I should have } \\
2 \text { - As I look back, I see a lot of failures } \\
3 \text { - I feel I am a total failure as a person }\end{array}$ & $\begin{array}{l}\text { 4. Loss of pleasure } \\
0 \text { - I get as much pleasure as I ever did } \\
\text { from the things I enjoy } \\
1 \text { - I don't enjoy things as much as I used to } \\
2 \text { - I get very little pleasure from the things } \\
\text { I used to enjoy } \\
3 \text { - I can't get my pleasure from the things I } \\
\text { used to enjoy }\end{array}$ \\
\hline $\begin{array}{l}\text { 5. Guilty feelings } \\
0 \text { - I don't feel particularly guilty } \\
1 \text { - I feel guilty over many things I have } \\
\text { done or should have done } \\
2 \text { - I feel quite guilty most of the time } \\
3 \text { - I feel guilty all of the time }\end{array}$ & $\begin{array}{l}\text { 6. Punishment feelings } \\
0 \text { - I don't feel I am being punished } \\
1 \text { - I feel I may be punished } \\
2 \text { - I expect to be punished } \\
3 \text { - I feel I am being punished }\end{array}$ \\
\hline $\begin{array}{l}\text { 7. Self-dislike } \\
0 \text { - I feel the same about myself as ever } \\
1 \text { - I have lost confidence in myself } \\
2 \text { - I am disappointed in myself } \\
3 \text { - I dislike myself }\end{array}$ & $\begin{array}{l}\text { 8. Self-criticalness } \\
0 \text { - I don't criticize or blame myself more } \\
\text { than usual } \\
1 \text { - I am more critical of myself than I used } \\
\text { to be } \\
2 \text { - I criticize myself for all my faults } \\
3 \text { - I blame myself for everything bad that } \\
\text { happens }\end{array}$ \\
\hline
\end{tabular}




\begin{tabular}{|c|c|}
\hline $\begin{array}{l}\text { 11. Loss of interest } \\
0 \text { - I have not lost interest in other people or } \\
\text { activities } \\
1 \text { - I am less interested in other people or } \\
\text { things than before } \\
2 \text { - I have lost most of my interest in other } \\
\text { people or things } \\
3 \text { - It's hard to get interested in anything } \\
\text { 13. Worthlessness } \\
\text { - I do not feel I am worthless } \\
1 \text { - I don't consider myself as worthwhile } \\
\text { and useful as I used to } \\
2 \text { - I feel more worthless as compared to } \\
\text { other people } \\
3 \text { - I feel utterly worthless } \\
\text { 15. Changes in sleeping pattern } \\
0 \text { - I have not experienced any change in } \\
\text { my sleeping pattern } \\
\text { la - I sleep somewhat more than usual } \\
\text { lb - I sleep somewhat less than usual } \\
2 \text { a - I sleep a lot more than usual } \\
2 b \text { - I sleep a lot less than usual } \\
\text { 3a - I sleep most of the day } \\
\text { 3b - I wake up 1-2 hours early and can't get } \\
\text { back to sleep }\end{array}$ & $\begin{array}{l}\text { 10. Agitation } \\
0 \text { - I am no more restless or wound up than } \\
\text { usual } \\
1 \text { - I feel more restless or wound up than } \\
\text { usual } \\
2 \text { - I am so restless or agitated that it's hard } \\
\text { to stay still } \\
3 \text { - I am so restless or agitated that I have to } \\
\text { keep moving or doing something } \\
12 \text {. Indecisiveness } \\
0 \text { - I make decisions about as well as ever } \\
1 \text { - I find it more difficult to make decisions } \\
\text { than usual } \\
2 \text { - I have such greater difficulty in making } \\
\text { decisions than I used to } \\
3 \text { - I have trouble making any decisions }\end{array}$ \\
\hline
\end{tabular}




\section{Changes in appetite}

0 - I have not experienced any change in my appetite

la - My appetite is somewhat less than usual

lb - My appetite is somewhat greater than usual

2a - My appetite is much less than before $2 \mathrm{~b}-$ My appetite is much greater than usual $3 \mathrm{a}$ - I have no appetite at all

$3 b$ - I crave food all the time

\section{Tiredness or fatigue}

0 - I am no more tired or fatigued than usual

1 - I get more tired or fatigued more easily than usual

2 - I am too tired or fatigued to do a lot of the things I used to do

3 - I am so tired or fatigued to do most of the things I used to do

\section{Concentration difficulty}

0 - I can concentrate as well as ever

1 - I can't concentrate as well as usual

2 - It's hard to keep my mind on anything for very long

3 - I find I can't concentrate on anything

\section{Loss of interest in sex}

0 - I have not noticed any recent change in my interest in sex

1 - I am less interested in sex than I used to be

2 - I am much less interested in sex now

3 - I have lost interest in sex completely 


\section{Appendix F}

\section{Open-Ended Questions: Mental and Physical Health}

1. If you experienced other physical and / or mental health symptoms not possibly mentioned in either of the two scales (IES-R and BDI-II) you just filled out, what were they?

2. How has your involvement with a psychopath affected your relationships with others? 


\section{Appendix G}

\section{Brief COPE}

Below are some ways you may have been coping with stress in your life since you were involved with a psychopath. According to the scale, please rate the extent to which you have been doing what each item says since the last time you were in contact with the psychopath, not whether it seems to be working or not. Try to rate each item truthfully and separately in your mind from the others.

\section{$1=$ not at all}

I have been doing this...

$2=$ a little bit $\quad 3=$ a medium amount

$4=\mathrm{a} \operatorname{lot}$

1. turning to work or other activities to take my mind off things.

2. concentrating my efforts on doing something about the $\begin{array}{lllll}1 & 2 & 3 & 4\end{array}$ situation I'm in.

3. $\quad$ saying to myself "this isn't real.".

$\begin{array}{llll}1 & 2 & 3 & 4\end{array}$

4. using alcohol or other drugs to make myself feel better.

5. getting emotional support from others.

6. giving up trying to deal with it.

7. taking action to try to make the situation better.

8. refusing to believe that it has happened.

9. saying things to let my unpleasant feelings escape.

10. getting help and advice from other people.

11. using alcohol or other drugs to help me get through it.

12. trying to see it in a different light, to make it seem more positive.

13. criticizing myself.

14. trying to come up with a strategy about what to do.

15. getting comfort and understanding from someone.

16. giving up the attempt to cope.

17. looking for something good in what is happening.

18. making jokes about it.

19. doing something to think about it less (i.e., going to movies, watching TV, reading, daydreaming).

20. accepting the reality of the fact that it has happened.

21. expressing my negative feelings.

22. trying to find comfort in my religion or spiritual beliefs.

23. trying to get advice or help from others about what to do.

24. learning to live with it.

25. thinking hard about what steps to take.

26. blaming myself for things that happened.

27. praying or meditating.

28. making fun of the situation.

$\begin{array}{llll}1 & 2 & 3 & 4\end{array}$

$\begin{array}{llll}1 & 2 & 3 & 4\end{array}$

$\begin{array}{llll}1 & 2 & 3 & 4\end{array}$

$\begin{array}{llll}1 & 2 & 3 & 4\end{array}$

$\begin{array}{llll}1 & 2 & 3 & 4\end{array}$

$\begin{array}{llll}1 & 2 & 3 & 4\end{array}$

$\begin{array}{llll}1 & 2 & 3 & 4\end{array}$

$\begin{array}{llll}1 & 2 & 3 & 4\end{array}$

$\begin{array}{llll}1 & 2 & 3 & 4\end{array}$

$\begin{array}{llll}1 & 2 & 3 & 4\end{array}$

$\begin{array}{llll}1 & 2 & 3 & 4\end{array}$

$\begin{array}{llll}1 & 2 & 3 & 4\end{array}$

$\begin{array}{llll}1 & 2 & 3 & 4\end{array}$

$\begin{array}{llll}1 & 2 & 3 & 4\end{array}$

$\begin{array}{llll}1 & 2 & 3 & 4\end{array}$

$\begin{array}{llll}1 & 2 & 3 & 4\end{array}$

$\begin{array}{lll}2 & 3 & 4\end{array}$

$\begin{array}{llll}1 & 2 & 3 & 4\end{array}$

$\begin{array}{llll}1 & 2 & 3 & 4\end{array}$

$\begin{array}{llll}1 & 2 & 3 & 4\end{array}$

$\begin{array}{llll}1 & 2 & 3 & 4\end{array}$

$\begin{array}{llll}1 & 2 & 3 & 4\end{array}$

$\begin{array}{llll}1 & 2 & 3 & 4\end{array}$

$\begin{array}{llll}1 & 2 & 3 & 4\end{array}$

$\begin{array}{llll}1 & 2 & 3 & 4 \\ & 2 & 3 & 4\end{array}$ 


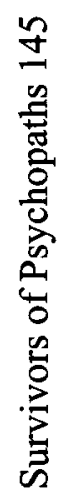

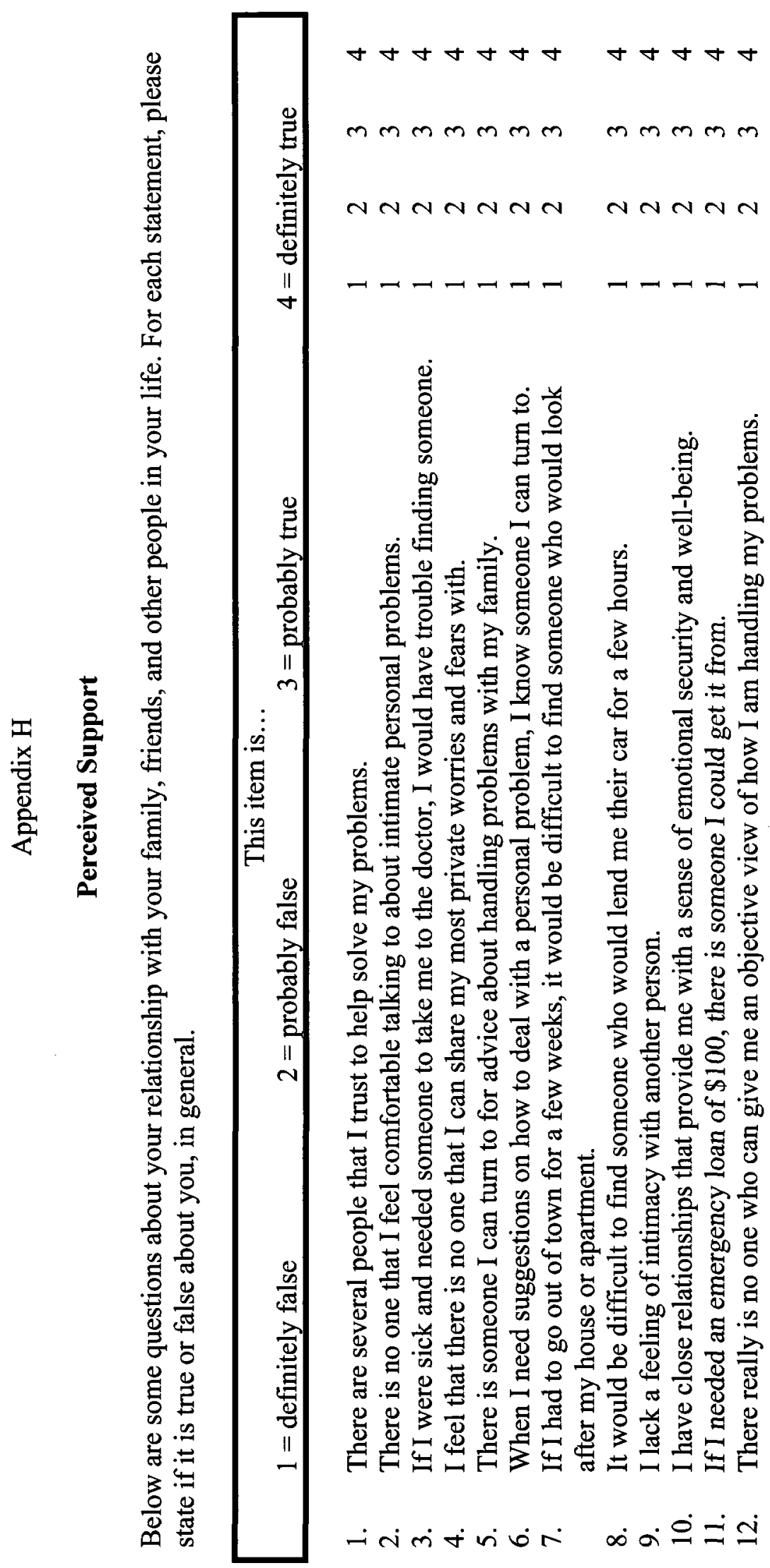


0
0
0
0
0
0
0
0
0
0
0
0
0
0
0
0
0

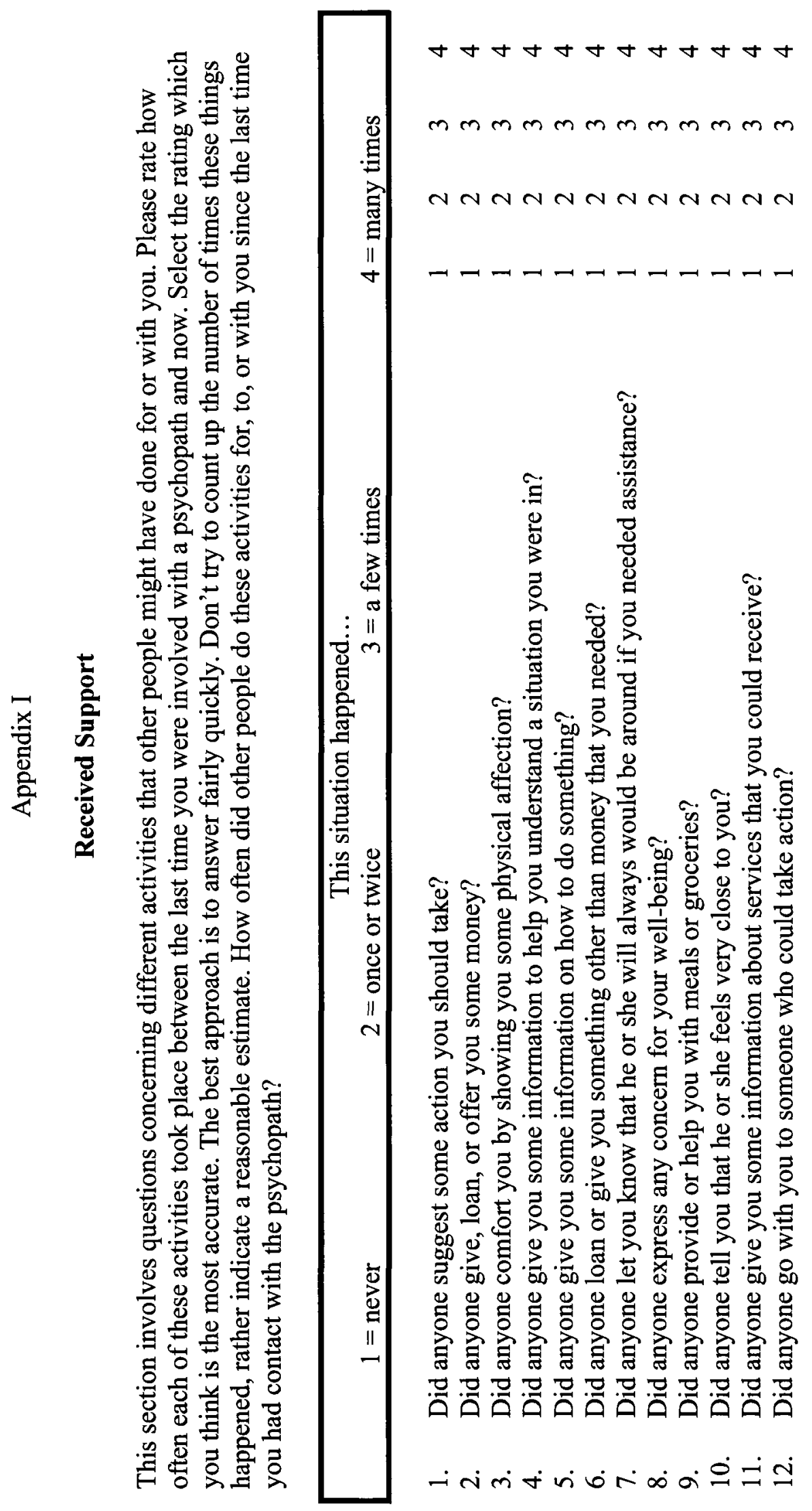




\section{Appendix J}

\section{Debriefing}

What are we trying to learn? We are trying to understand the victimization experiences of survivors of psychopaths, including health consequences and exposure to deception. Secondly, we are looking for characteristics which predict symptoms of distress, such as anxiety and depression. Finally, we are attempting to understand relationships between psychopathy severity, coping strategies, social support, and psychological distress.

Why is this important? Very little is known about survivors of psychopaths, since psychopathy research puts its emphasis on psychopathic individuals. Most of the research focuses on psychopaths in prison, whereas this study may help provide insight about psychopaths in the community. Understanding the victimization, coping, and social support experiences of survivors of psychopaths may allow for better informed and improved therapeutic and legal decisions. Furthermore, recommendations for prediction and subsequently prevention measures in the community may be possible.

What are our hypotheses and predictions? We expect:

(a) Reports of various physical and psychological distress symptoms (i.e., muscle / joint pain, weight loss / gain, anxiety, depression, etc.),

(b) Psychopaths will show different features of psychopathy depending on whether they engaged in immediate or delayed deception,

(c) Close relationships with perpetrators, severity of physical injury, psychopathy severity, and violent crime to be related to greater distress,

(d) Survivors who use problem-focused coping strategies (i.e., getting help or advice from others) are less likely to have PTSD and depression symptoms,

(e) In contrast, emotion-focused coping (i.e., engaging in self-blame) or avoidanceoriented techniques (i.e., turning to work to distract oneself) are assumed to make symptoms worse,

(f) Social support is related to an increase in problem-focused coping, but a decrease in emotion- and avoidance-focused coping techniques, and

(g) Social support reduces distress symptoms.

\section{Where can I learn more?}

Hare, R. D. (1999). Without conscience: The disturbing world of the psychopaths among us. New York: Guilford Press.

Chapter 13 of Without Conscience, "A survival guide" (pp. 207-218), may be of particular importance to survivors of psychopaths.

Kirkman, C. A. (2005). From soap opera to science: Towards gaining access to the psychopaths who live among us. Psychology and Psychotherapy: Theory, Research, and Practice, 78, 379-396. 
What if I have questions later? Should I require further information pertaining to this study, I can contact the following individuals, all of whom are affiliated with the Department of Psychology:

(1) Researcher

(2) Supervisor
Melissa, Masters Student in Forensic Psychology psurvivorstudy@gmail.com

Dr. Adelle Forth, Associate Professor

1-613-520-2600, ext. 1267

adelle forth@carleton.ca

Should I have any ethical or other concerns regarding this study, I can contact:

(1) Department Chair

(2) Ethics Chair
Dr. Janet Mantler

1-613-520-2600, ext. 4173

janet mantler@,carleton.ca

Dr. Avi Parush, Professor

1-613-520-2600, ext. 6026

avi parush@carleton.ca

Is there anything that I can do if I found the research to be emotionally draining? You can contact your local mental health professionals, distress lines, crisis centres, or general physicians. To find one or more of the above, search in Google or the phonebook for your area. Dr. David Kosson, an experienced researcher in psychopathy, developed an online peer support group for survivors of psychopaths, called Aftermath: Surviving Psychopathy. The website is at: http://www.aftermath-surviving-psychopathy.org/ and you may reach Dr. Kosson at: Moving-on-support@,rosalindfranklin.edu

How can I secure my Internet data? There are Internet security steps that can be taken if you wish to prevent others who have access to your computer from seeing that you viewed the study's website. A website which offers support to people who have experienced abuse has simple Internet security instructions at: http://www.brokenspirits.com/security/web security.asp

Can I learn more about the results? If you wish to be informed of the results of this study, of which a summary will be completed by March $1^{\text {st }}, 2009$, please contact Melissa at psurvivorstudy@gmail.com through an anonymous e-mail account (i.e., one that does not contain any identifiers and that only you will have access to) with an empty message and the subject line as "want psurvivorstudy results". A mass e-mail of the report will be sent to everyone who has requested one, but no one will be able to identify any of its recipients.

\section{Thank you very much for your participation!}


Appendix K

\section{E-mail Correspondence Template for Permission to Promote the Current Study}

Dear (website owner or maintainer):

My name is Melissa, and I am a Masters student in the Forensic Psychology program at Carleton University in Ottawa, Ontario, Canada. During my studies, I have found that psychopathy research focuses on the psychopaths instead of survivors. As a result, we lack an understanding of survivors' experiences, and I would like to address this. My research, under the supervision of Dr. Adelle Forth, is on victimization, coping, and social support. It is my hope that my research will raise awareness amongst mental health and criminal justice professionals, and the general public, of issues of involvement with a psychopath.

I have attached the informed consent form to this e-mail to give you an opportunity to learn more about the study, including its purpose, research personnel involved, tasks, duration and location, potential risks and discomfort, anonymity and confidentiality, right to withdraw, and contact information.

I am e-mailing you, as either the owner of a website devoted to psychopathy research or the maintainer of an online support group for survivors of psychopaths, in order to request permission to either (a) have a link to the current study at https://www.surveymonkey.com/s.aspx?sm=tkKgwTr 2fZ4Ehy4i 2b0h6ngQ 3d 3d on your website between November $1^{\text {st }}, 2008$ and December $31^{\text {st }}, 2008$, or (b) promote it in one thread in an appropriate location on your forum.

Please e-mail me at psurvivorstudy@gmail.com if you have any questions or concerns about my study. You may also reach my supervisor at adelle forth@carleton.ca.

Thank you for your consideration and your time, 
Appendix L

\section{E-mails to Psychopathy Researchers Template}

Dear member of the Society for the Scientific Study of Psychopathy (SSSP):

My name is Melissa, and I am a Masters student in the Forensic Psychology program at Carleton University in Ottawa, Ontario, Canada. During my studies, I have found that psychopathy research focuses on the psychopaths instead of survivors. As a result, we lack an understanding of survivors' experiences, and I would like to address this. My research, under the supervision of Dr. Adelle Forth, is on victimization, coping, and social support. It is my hope that my research will raise awareness amongst mental health and criminal justice professionals, and the general public, of issues of involvement with a psychopath.

I have attached the informed consent form to this e-mail to give you an opportunity to learn more about the study, including its purpose, research personnel involved, tasks, duration and location, potential risks and discomfort, anonymity and confidentiality, right to withdraw, and contact information.

I am e-mailing you, as a researcher in the field of psychopathy, to request that if you know of survivors of psychopaths who may be interested in the current study taking place between November $1^{\text {st }}, 2008$ and December $31^{\text {st }}, 2008$, could you please provide them with the following link:

https://www.surveymonkey.com/s.aspx?sm=tkKgwTr 2fZ4Ehy4i 2b0h6ngQ 3d 3d

Please e-mail me at psurvivorstudy@gmail.com if you have any questions or concerns about my study. You may also reach my supervisor at adelle forth@carleton.ca.

Thank you for your consideration and your time, 
Appendix M

\section{LoveFraud's Promotion of the Current Study}

Researchers want to know about your experience with a psychopath

Sunday, 2 November $2008 @$ 11:43am•My Weblog

Plenty of scientific researchers have studied psychopaths. But few have studied the victims of psychopaths, so there is little documentation of what we have all been through.

Perhaps that is beginning to change.

Lovefraud has been contacted by a researcher from Carleton University in Ottawa, Ontario, Canada. She is conducting a study entitled Victimization, coping, and social support of adult survivors of psychopaths. The graduate student is working under the supervision of Dr. Adelle Forth, who is a colleague of Dr. Robert Hare.

The purpose of the study is "to gain an understanding of the victimization experiences of adult $(18+)$ survivors of psychopaths, in an attempt to raise awareness amongst the general public, and mental health and criminal justice professionals."

Everyone at Lovefraud is invited to participate.

The researcher has developed a web-based survey. The survey has both self-report scales and open-ended questions. You will be asked to rate the presence or absence of psychopathic traits of the most recent psychopathic individual you have been involved with on one scale. Questions revolve around demographics, your relationship and experiences with the psychopath, including being deceived and its impact on your mental and physical health, your ways of coping, and your support networks. The survey does not ask for any information that might identify you.

Completing the survey will take approximately one hour, and Lovefraud strongly encourages you to participate. If you are concerned about your safety, please be sure to take appropriate precautions.

Here - finally - is a chance to develop information that may make a difference in how victims of psychopaths are viewed and treated. Let's take advantage of the opportunity.

Go to the survey

Data is being collected from now until Dec. 31, 2008. Be sure to add your voice. 


\section{Appendix $\mathrm{N}$}

\section{Psychopath-Research's Promotion of the Current Study}

[We] have received a request to have our group contribute input from the first professional victim survey that we are aware of. Please be assured that it is a blind study and you will not be identified. You do not have to be registered at the forum to participate.

Survivors of Psychopaths Study: This study is being conducted by Masters student, Melissa, under the supervision of Dr. Adelle Forth from the Department of Psychology at Carleton University in Ottawa, Ontario, Canada.

The purpose of the study is to gain an understanding of the victimization experiences of adult $(18+)$ survivors of psychopaths, in an attempt to raise awareness amongst the general public, and mental health and criminal justice professionals. If you have any questions, please post them at the thread titled Survey Information.

Note: the survey will only be available between November 1st and December 31st, 2008.

Hello, members of Psychopath-Forum. My name is Melissa. I have a Bachelor of Arts, Honours in Psychology from Carleton University in Ottawa, Ontario, Canada. I am currently pursuing a Masters in Forensic Psychology at the aforementioned university and my supervisor is Dr. Adelle Forth, who is a colleague of Dr. Robert Hare. I realized during my studies that the voices of victims are often ignored or neglected in research. In an attempt to change this, my Thesis revolves around victimization, coping, and social support of survivors of psychopaths.

I have created an online survey for adult survivors of psychopaths at https://www.surveymonkey.com/s.aspx?sm=tkKgwTr 2fZ4Ehy4i 2b0h6ngQ 3d 3d which I am inviting you to participate in. I attempted to make my survey accessible to survivors at various stages of contact with the psychopath in their life, from being involved to cutting off all contact, so that I could give voice to a wide variety of victims. Please feel free to provide comments or ask me any questions in this forum or through email at psurvivorstudy@gmail.com. All feedback is welcome, appreciated, and considered.

Sincerely, -Melissa 
Appendix $\mathrm{O}$

\section{Aftermath: Surviving Psychopathy's Promotion of the Current Study}

Aftermath: Surviving Psychopathy has given permission to a researcher to post information about this survey. We believe this study represents a valuable research enterprise. Bear in mind that this survey may not include examples of your experiences, and nothing in the survey should in any way invalidate your experiences.

ADMINISTRATOR

"Dear Aftermath: Surviving Psychopathy Forum Members:

I have received permission from the maintainer of this forum to introduce myself and promote my research, which is under the supervision of Dr. Adelle Forth. I am a Masters student in Forensic Psychology doing research on victimization, coping, and social support of adult survivors of psychopaths for my Thesis. Through your assistance and my research, I hope to raise awareness amongst mental health and criminal justice professionals, and the general public, of issues of involvement with a psychopath.

If you are interested, you can find more information and participate in the study anytime between NOVEMBER 1st, 2008 and DECEMBER 31st, 2008 at the following website: http://www.surveymonkey.com/s.aspx?sm=t ...6ngQ $3 \mathrm{~d} 3 \mathrm{~d}$

Thank you for your consideration and your time.

Melissa" 


\section{Appendix P}

\section{Dr. Hare's Promotion of the Current Study}

Survivors of Psychopaths Study: This study is being conducted by Masters student, Melissa, under the supervision of Dr. Adelle Forth from the Department of Psychology at Carleton University in Ottawa, Ontario, Canada. The purpose of the study is to gain an understanding of the victimization experiences of adult (18+) survivors of psychopaths, in an attempt to raise awareness amongst the general public, and mental health and criminal justice professionals. If you have any questions or comments about the study, please contact Melissa at psurvivorstudy@gmail.com 
Appendix Q

\section{E-mail of Summary of Results}

Dear interested readers,

Thank you for your interest and/or your participation in my study, Victimization, coping, and social support of adult survivors of psychopaths. Since you have requested a summary of the results, I am sending you a report via e-mail. This e-mail is blind carboncopied (BCC'd) in order to protect your identity. I apologize for the lateness of this report. I received over 500 responses, so the data collection, analysis, and write-up was a longer process than expected.

I was able to present my findings at the Society for the Scientific Study of Psychopathy (http://www.psychopathysociety.org/) conference in New Orleans, Louisiana in April 2009. I was one of only two presenters at the conference with a research focus on survivors of psychopaths, but many researchers and professionals acknowledged the need for more knowledge about victims' experiences. I am also enclosing the PowerPoint of my poster, which is rich in psychological and statistical details, with this e-mail.

Here's a recap of my hypotheses and predictions:

(a) Reports of various physical and psychological distress symptoms (i.e., muscle / joint pain, weight loss / gain, anxiety, depression, etc.),

(b) Psychopaths will show different features of psychopathy depending on whether they engaged in immediate or delayed deception,

(c) Close relationships with perpetrators, severity of physical injury, psychopathy severity, and violent crime to be related to greater distress,

(d) Survivors who use problem-focused coping strategies (i.e., getting help or advice from others) are less likely to have PTSD and depression symptoms,

(e) In contrast, emotion-focused coping (i.e., engaging in self-blame) or avoidanceoriented techniques (i.e., turning to work to distract oneself) are assumed to make symptoms worse,

(f) Social support is related to an increase in problem-focused coping, but a decrease in emotion- and avoidance-focused coping techniques, and

(g) Social support reduces distress symptoms. 
The following are the results for the aforementioned hypotheses and predictions:

(a) Survivors of psychopaths experienced cognitive (i.e., intrusion, dissociation, memory problems, concentration issues), biological (i.e., wide range of signs/symptoms, from skin effects to physical injuries), behavioural (i.e., sleeping/eating changes, speech differences, neglect of self-care, limited social activities, work changes), emotional (anger, hate, anxiety, depression, mood swings/bipolar, embarrassment, denial, grief, disappointment) and interpersonal (trust issues, changes in interactions and relationships, sexual interest changes, revictimization) symptoms.

(b) Immediate deception is when the psychopath on first encounter immediately threatens or coerces survivors, resulting in distress. Delayed deception is when the psychopath attempts to impress survivors, then threatens or coerces survivors, resulting in distress, and the cycle continues. No differences were found in different features of psychopathy (manipulation, callous affect, impulsive lifestyle, or antisocial behaviour), between these two types, but there were very few immediate path psychopaths to make good comparisons.

(c) Close relationships with perpetrators, severity of physical injury, psychopathy severity, and violent crime were all related to greater distress.

(d) Survivors who use problem-focused coping strategies (i.e., getting help or advice from others) were actually more likely to have PTSD and depression symptoms. My explanations for this were that i) perhaps many survivors who participated in my study were significant others or ex-significant others of psychopaths, and may have anticipated negative outcomes if they used problem-focused coping strategies, or ii) problem-focused coping strategies may lead to exhaustion, which is a component of depression.

(e) Emotion-focused coping did not increase stress, and this may be because many participants appeared to be well-adjusted or past rather than current victims, having already dealt with many of the stressors caused by psychopaths. Avoidance-oriented coping did however increase distress.

(f) Problem- and avoidance-focused coping lead to decreases in social support. Survivors may be taking action alone or have difficulty working with social support systems because psychopaths may have deceived them.

(g) Social support does reduce distress symptoms.

Please don't hesitate to contact my supervisor (Dr. Adelle Forth, Associate Professor, 1-613-520-2600, ext. 1267, adelle forth@carleton.ca) or myself (psurvivorstudy@gmail.com) should you have any questions or comments. 